Universidade de São Paulo

Faculdade de Saúde Pública

\title{
Vulnerabilidade Social e ocorrência de doenças gastrointestinais associadas com inundações no Município de São Paulo
}

Doris Jimena Roncancio Benítez

Dissertação apresentado ao Programa de Pós-Graduação em Saúde Pública para obtenção do título de Mestre em Ciências

Área de Concentração: Saúde Ambiental Orientadora: Profa. Dra. Adelaide Cássia Nardocci 
Universidade de São Paulo

Faculdade de Saúde Pública

\section{Vulnerabilidade Social e ocorrência de doenças gastrointestinais associadas com inundações no Município de São Paulo}

Doris Jimena Roncancio Benítez

Dissertação apresentada ao Programa de Pós-Graduação em Saúde Pública para obtenção do título de Mestre em Ciências

Área de Concentração: Saúde Ambiental Orientadora: Profa. Dra. Adelaide Cássia Nardocci

Versão original

São Paulo

2015 
É expressamente proibida a comercialização deste documento, tanto na sua forma impressa como eletrônica. Sua reprodução total ou parcial é permitida exclusivamente para fins acadêmicos e científicos, desde que na reprodução figure a identificação do autor, título, instituição e ano da dissertação. 


\section{SUMARIO}

1. INTRODUÇÃO

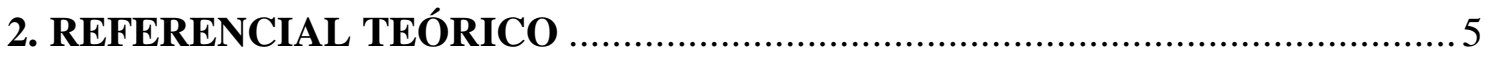

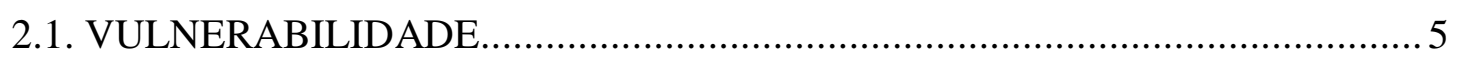

2.2. ESCOLAS E TENDÊNCIAS DE PESQUISA EM VULNERABILIDADE .........8

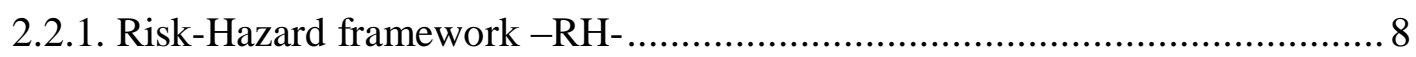

2.2.2. Pressure and release model -PAR........................................................... 10

2.2.3. Modelo de Vulnerabilidade expandida........................................................... 11

2.3. INUNDAÇÕES E EFEITOS NA SAÚDE HUMANA ......................................... 14

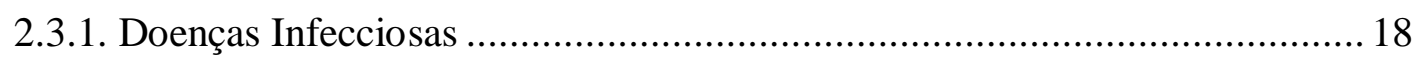

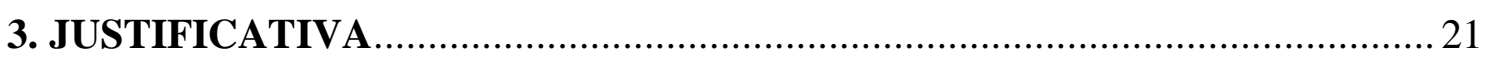

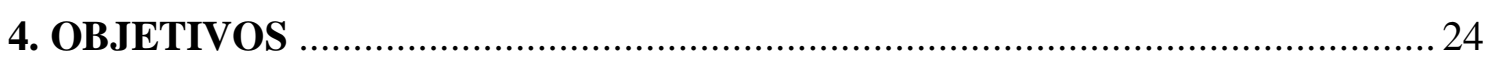

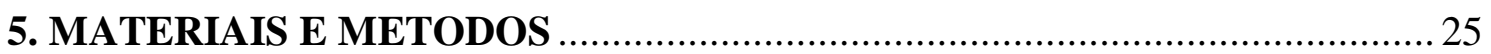

5.1. MATERIAL BIBLIOGRÁFICO E CARTOGRÁFICO …………………......... 25

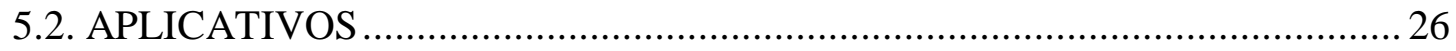

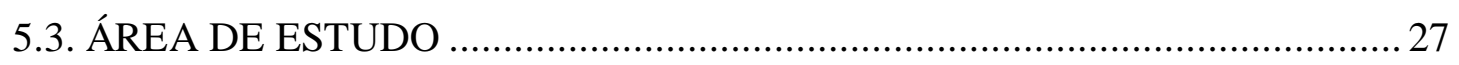

5.4. MODELO DE ASSOCIAÇÃO DE VARIÁVEIS ………................................... 28

5.4.1. Cálculo do índice de vulnerabilidade social SoVI® ..................................... 30

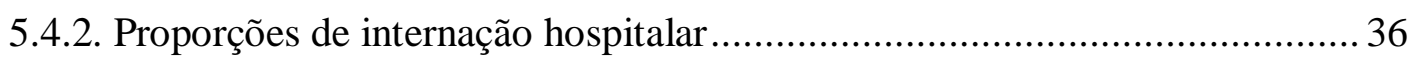

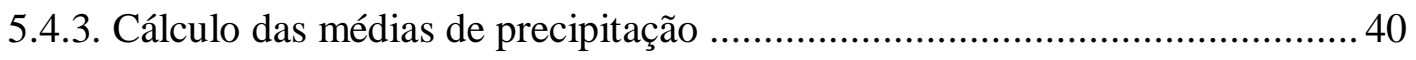

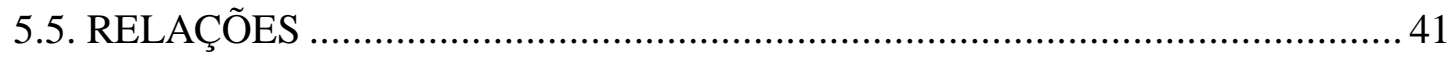

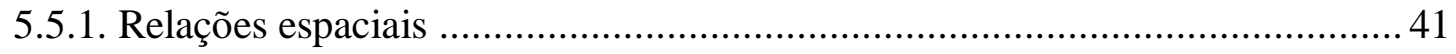

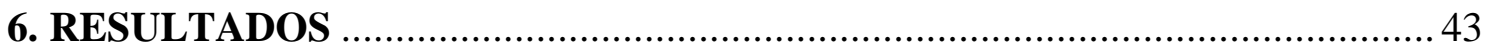

6.1. MODELO DE ASSOCIAÇÃO DE VARIÁVEIS …………………………........ 43

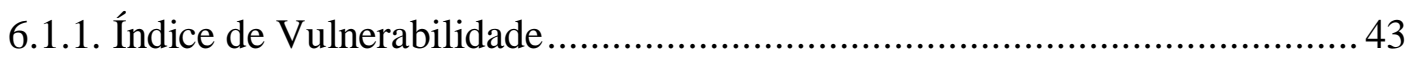

6.1.2. Proporção de Autorizações de Internação Hospitalar .................................... 59

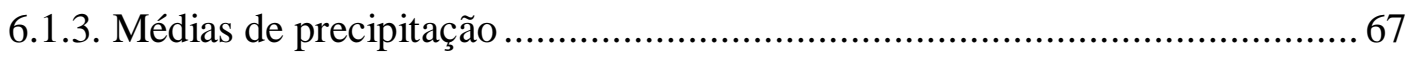

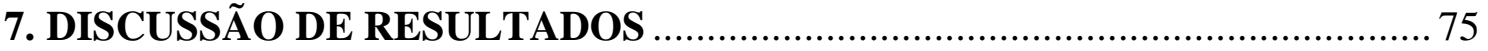

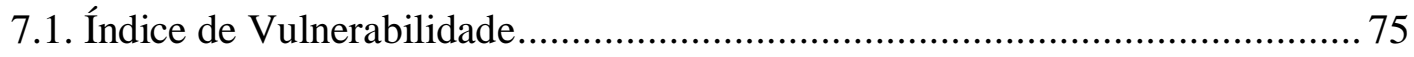

7.2. Proporções de Internação Hospitalar e relações espaciais entre duas variáveis78

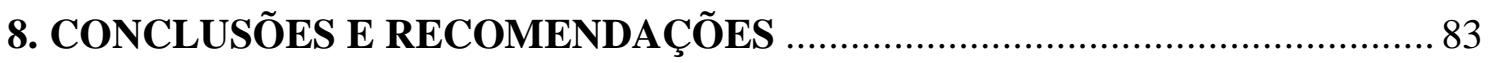

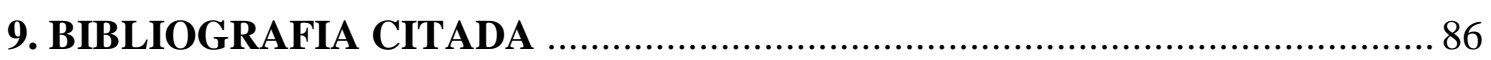

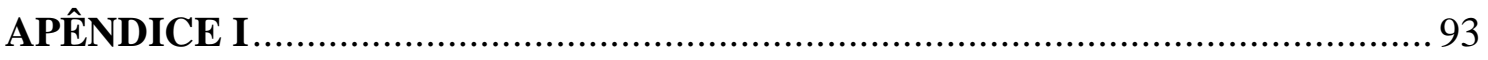


APÊNDICE II

APÊNDICE III

CURRÍCULO LATTES 


\section{RESUMO}

As inundações podem ter um grande impacto na saúde das populações. Doenças produzidas pela exposição direta ou indireta às águas, podem resultar em surtos de doenças gastrointestinais, infecções respiratórias, leptospirose entre outras. Já que os cenários de mudança climática predizem o aumento na frequência e severidade das inundações devido ao aquecimento global, é necessário ter claridade nos impactos gerados sobre a saúde humana como reflexo dos efeitos combinados das mudanças climáticas sobre os ecossistemas, o sistema econômico e o sistema social. A pesquisa visa analisar a vulnerabilidade da população do município de São Paulo às doenças infecciosas relacionadas com inundações. O processo tem como fio condutor o modelo de avaliação da vulnerabilidade conhecido como modelo de vulnerabilidade expandida. Dez variáveis consideradas como representativas para o município de São Paulo, foram escolhidas para a análise da vulnerabilidade social, correlacionadas e analisadas dentro da unidade espacial bacia hidrográfica para o ano 2010, mediante a análise de componentes principais. Bases de dados de precipitação da Rede Telemétrica de Pluviômetros de Superfície do Departamento de Águas e Energia Elétrica (DAAE), foram os dados usados para a avaliação dos níveis de precipitação. Adicionalmente, as estatísticas das bases de dados de Autorização de Internação Hospitalar do Sistema Universal de Saúde (AIH/SUS) foram usadas para a avaliação das variáveis epidemiológicas. Os resultados mostram que a vulnerabilidade social aumenta na direção centro-periferia e que as aglomerações de valores altos, evidentemente mais abundantes do que as aglomerações de valores baixos, aparecem nas bacias de vulnerabilidades sociais significativamente altas. 


\section{SUMMARY}

Floods can have an important impact on people's health. Diseases caused by direct or indirect exposure to flood water can result in outbreaks of gastrointestinal diseases, respiratory infections and leptospirosis among others. Since the climate change scenarios predict an increase in the frequency and severity of floods due to global warming, it is necessary to have clarity of the impacts on human health resulting by the combined effects of climate change on ecosystems and the economic and social systems. The study aims to analyze the vulnerability of the city of São Paulo's population to infectious diseases related to floods. The process has the vulnerability assessment model known as expanded vulnerability model as its conducting wire. Ten variables considered as representative for the city of São Paulo, are the material for the analysis of social vulnerability. Their correlation and variance analysis is measure within the watershed spatial unit for the year 2010, by the principal component analysis methodology. The databases of precipitation made by the Telemetric Rain Gauges network of the Department of Water and Power (DAAE) are the values used to assess precipitation levels. In addition, the databases of Authorization for Hospitalization of the Brazilian Universal Health System (AIH/SUS) are use too for the evaluation of epidemiological variables. The results show that social vulnerability increases in downtown-periphery direction and that the clusters of high values, clearly more abundant than those of low levels, appear in the watersheds classified with significantly high social vulnerability 


\section{LISTA DE FIGURAS}

Figura 1. Modelo de Risco-Ameaça. Cadeia da sequência começa com a ameaça. Conce ito de vulnerabilidade implícito pelas linhas ponteadas. Adaptado de TURNER et. al. (2 $003)$.

Figura 2. Modelo pressão e alivio. Com a ênfase sobre as condições sociais de exposição, conceito de vulnerabilidade usualmente explicito. Tomado de TURNER et. al. (2003). 10

Figura 3. Modelo de vulnerabilidade expandida. Componentes da vulnerabilidade identificado e unidos com fatores além do sistema em estudo e operando em várias escalas. Tomado de TURNER et. al. (2003).

Figura 4. Diagrama esquemático das vias pelas quais as mudanças climáticas afetam a saúde, e influencias modificadoras dos fatores ambientais, sociais e do sistema de saúde. Tomado de CONFALONIERI et al (2007). ........................................................... 16

Figura 5. Localização da área de estudo .......................................................... 28

Figura 6. Mapa das 186 Bacias hidrográficas localizadas no território do município de São Paulo (2012). Sistema de projeção UTM SAD69. Modificado de: Fundação centro tecnológico de Hidráulica (FCTH-USP); Fundação Bacia Hidrográfica do Alto Tietê (FBHAT, 2009). 30

Figura 7. Mapa de Setores Censitários por Distritos (2010). Sistema de projeção LatLong - Spherical. Fonte: Centro de Estudos da Metrópole (CEM)...................................... 32

Figura 8. Processo metodológico para a Análise de Componentes Principais .............. 36

Figura 9. Transformação dos dados de internações hospitalares para o Diagnóstico A09 da estação úmida de 2009, desde casos georreferenciados até contagens por Bacia Hidrográfica.

Figura 10. Cálculo das medias de precipitação para as bacias do município de São Paulo durante a estação chuvosa do ano 2009. 40

Figura 11. Scree plot da análise de componentes principais mostrando os eigenvalores

Figura 12. Mapa de Índice de Vulnerabilidade Social mostrado usando o desvio padrão (A.) e usando a classificação por quantis (B.) …....................................................... 50

Figura 13. Mapas dos componentes principais da vulnerabilidade social no município de São Paulo, SP. (Escores divididos em Quantis) .......................................................... 56

Figura 14. Mapa do índice de Moran Local para o Índice de Vulnerabilidade Social ao nível de bacias Hidrográficas. Município de São Paulo, SP......................................... 58

Figura 15. Mapas de proporções e aglomerados de AIH de Crianças para a estação Úmida de 2009 (A) e 2010 (B). 62

Figura 16. Mapas de proporções e aglomerados de AIH de Idosos para a estação Úmida 
de 2009 (A) e 2010 (B)

Figura 17. Mapas de proporções e aglomerados de AIH de Idosos para a estação Seca de 2010 . 65

Figura 18. Mapas de proporções e aglomerados de AIH de Crianças para a estação Seca de 2009 66

Figura 19. Mapas de precipitação media para as Estação úmida e Seca de 2009 e 2010. 68

Figura 20. Comparação do Índice de Moran local calculado para os dados de proporção de AIH para a faixa etária de crianças na frente do SoVI ${ }^{\circledR}$ para a estação úmida dos anos 2009 e 2010.

Figura 21. Comparação do Índice de Moran local calculado para os dados de proporção de AIH para a faixa etária de idosos na frente do SoVI® para a estação úmida dos anos 2009 e 2010.

Figura 22. Comparação do Índice de Moran local calculado para os dados de proporção de AIH para a faixa etária de idosos e crianças na frente do SoVI® ${ }^{\circledR}$ para a estação seca dos anos 2009 e 2010

Figura 23. Mapa de densidade de domicílios por quilômetro quadrado Segundo o censo de 2010 , SP. 


\section{LISTA DE TABELAS}

Tabela 1. Diagnósticos com maiores números de registros de ocorrência e número de registros encontrados. Autorizações de Internação Hospitalar 2009-2010, São Paulo, SP.

Tabela 2. Componentes principais, variáveis e porcentagens explicadas por eles. 46

Tabela 3. Scores fatoriais e Índice de Vulnerabilidade social das bacias hidrográficas com SoVI classificado como alto e muito alto .51

Tabela 4. Scores fatoriais e Índice de Vulnerabilidade social das bacias hidrográficas com SoVI classificado como baixo e muito baixo. 52

Tabela 5. Scores fatoriais e Índice de Vulnerabilidade social das bacias hidrográficas com SoVI classificado como média-alta. 53

Tabela 6. Scores fatoriais e Índice de Vulnerabilidade social de algumas das bacias hidrográficas com SoVI classificado como média-baixa.

Tabela 7. Scores fatoriais e Índice de Vulnerabilidade social das bacias hidrográficas com SoVI classificado como média.

Tabela 8. Número e proporção de Autorizações de Internação Hospitalar segundo as características demográficas. São Paulo 2009-2010.

Tabela 9. Cálculo do Índice de Moran Global das proporções de AIH de crianças de entre 0 e 5 anos e Idosos com mais de 64 anos para os anos 2009 e 2010.

Tabela 10. Estadísticas de aglomerados espaciais locais, estações chuvosas e secas de 2009-2010 para a faixa etária de crianças.

Tabela 11. Estatísticas de aglomerados espaciais locais, estações chuvosas e secas de 2009-2010 para a faixa etária de idosos.

Tabela 12. Variáveis extraídas da base de dados do censo 2010 ao nível de bacia hidrográfica no município de São Paulo.

Tabela 13 (continuação). Variáveis extraídas da base de dados do censo 2010 ao nível de bacia hidrográfica no município de São Paulo. 


\section{LISTA DE QUADROS}

Quadro 1. Causas de inundações. Adaptado de DU et al (2010)

Quadro 2. Consequências sobre a saúde provocadas pelas inundações. Adaptado e modificado de FREITAS E XIMENES (2012).

Quadro 3. Conceitos e métricas da Vulnerabilidade Social. Adaptado de CUTTER (2003)

Quadro 4. Variáveis usadas para o cálculo do índice de vulnerabilidade social. 


\section{LISTA DE ABREVIATURAS}

AIH

Autorização de Internação Hospitalar

CEBRAP

Centro Brasileiro de Análise e Planejamento

CEM

Centro de Estudos da Metrópole

CID

Classificação Internacional de Doenças

EM-DAT

Emergency Disaster Database

FCTH

Fundação Centro Tecnológico de Hidráulica

$\mathrm{HH}$

High-High

HVRI

Hazards and Vulnerability Research Institute

IBGE

Instituto Brasileiro de Geografia e Estatistica

IPCC

Intergovernmental Panel of Climate Change

LL

Low-Low

OMS

Organização Mundial de Saúde

PIB

Produto Interno Bruto

RMSP

Região Metropolitana de São Paulo

SAS-PMSP

Supervisões de Assistência Social - Prefeitura Municipal de SP

SESC

Serviço Social do Comercio

SoVI®

Social Vulnerability Index

SP

São Paulo

SMVMA

Secretaria Municipal do Verde e do Meio Ambiente

SUS

Sistema Universal de Saúde

VIF

Variance Inflation Factor 


\section{INTRODUÇÃO}

Os cenários de mudanças climáticas predizem o aumento na frequência e severidade das inundações devido ao aquecimento global e suas implicações nas mudanças ambientais do planeta. Segundo AHERN et al. (2005), as inundações podem ter um grande impacto na saúde das populações quando observadas sob a perspectiva da exposição direta ou indireta às águas e os consequentes surtos de doenças gastrointestinais, infecções respiratórias e leptospirose entre outras. Durante as épocas de chuvas torrenciais quando as inundações são mais frequentes, existe um risco maior de infecções seja este devido ao contato direito da população afetada com água contaminada ou pela contaminação das fontes de água potável. Por essa razão os pesquisadores no campo do saber da saúde pública entendem que as doenças infecciosas devem ser uma preocupação importante nas áreas propensas às inundações (THI VIET NGA et al. 2010).

$\mathrm{Na}$ análise de ocorrências de doenças infecciosas no contexto de mudanças ambientais, a saúde humana é o reflexo dos impactos combinados das mudanças climáticas sobre os ecossistemas e o ambiente socioeconômico. Por esta razão e sob as condições atuais de alterações na grande escala, a World Health Organization (WHO, 2000) afirma que é necessário dar prioridade à saúde das populações tanto nos debates políticos quanto nas discussões científicas sobre o aquecimento global. Com esta conjuntura na mente, uma quantidade considerável de pesquisa está sendo realizada para mapear e avaliar o risco, vulnerabilidades e impacto das mudanças climáticas sobre as doenças infecciosas de veiculação hídrica. Segundo CANN et al. (2013) o entendimento dos efeitos que diferentes eventos climáticos extremos têm sobre as doenças infecciosas de veiculação hídrica, é um passo importante na busca de maneiras de mitigar os riscos. Por essa razão, a pesquisa apresentada neste documento visa dar uma aproximação no contexto local, da perspectiva de realizar os estudos de vulnerabilidade às mudanças climáticas e as doenças infecciosas associadas a elas em conjunto com o campo de conhecimento da saúde pública.

Pretende-se analisar e mapear a associação da vulnerabilidade social da população do município de São Paulo às doenças infecciosas relacionadas com inundações. Dessa forma, o suposto inicial da pesquisa consiste na existência de uma relação entre o aumento 
dos níveis de precipitação e o incremento do número de inundações ocorridas. Supõe-se que o incremento na ocorrência de inundações levaria à mudança na dinâmica epidemiológica das doenças infecciosas notificadas no sistema de autorizações de internação hospitalar. Explicitamente, a hipótese descreve uma situação na qual as mudanças nos regimes de precipitação aumentam o número de casos de autorizações de internação hospitalar devidas a diarreia e gastroenterite de origem infecciosa presumível, como resultado da influência mútua entre as condições socioambientais da população e a mudança do regime de precipitação.

Dentro da pesquisa, a identificação da vulnerabilidade da população das áreas urbanas às doenças infecciosas nos períodos de maior ocorrência de inundação, descreve um processo de reconhecimento dos fatores que fazem parte da sensibilidade e susceptibilidade próprias do sistema humano-ambiental do município de São Paulo, e que acompanhadas da exposição apresentada pela ocorrência de inundações, geram uma área urbana com diversos níveis de vulnerabilidade. Assim, o conceito de vulnerabilidade no qual está baseada a pesquisa desenvolvida interpreta a vulnerabilidade não como um fato registrado apenas no contexto da exposição aos perigos, mas também como resultado da sensibilidade e resiliência do sistema que experimenta tais perigos.

Segundo TURNER II et al. (2003) é importante trazer o conceito de sistema do marco conceitual da sustentabilidade para reconhecer como os subsistemas Humano e Ambiente interagem na hora de se enfrentar a um estresse pontual e, partindo dessa ideia, desenvolvem o modelo de avaliação da vulnerabilidade conhecido como análise de vulnerabilidade expandida. O trabalho de pesquisa aqui apresentado, tenta refletir essa visão. Este conceito de sistema Humano-Ambiental expande e redireciona o foco da análise em muitos sentidos.

Para a avaliação da vulnerabilidade social associada às doenças infecciosas relacionadas com inundações no município de São Paulo proposta neste documento, esse conceito de sistema dirigiu a atenção à interpretação das dinâmicas do sistema urbano, como o resultado das sinergias dos subsistemas Humano e Ambiente que são afetadas por processos que operam em diferentes escalas espaciais e temporais dando como resultado um maior ou menor número de casos da doença avaliada. Estas características fazem com que a aplicação do modelo dentro do contexto real seja bastante complexa e precise de 
tempo e elementos bases para o trabalho que não cabem dentro do período do desenvolvimento do mestrado. Por essa razão, dentro da proposta apresentada, são utilizados diferentes elementos trazidos desde outros modelos de avaliação da vulnerabilidade mais facilmente aplicáveis, mas sempre pensando em seguir a visão apresentada desde o modelo de vulnerabilidade expandida.

O subsistema Humano e a sua própria maneira de interagir com a exposição são avaliados com o Índice de vulnerabilidade Social (SoVI $\left.{ }^{\circledR}\right)$ calculado para o ano $2010^{1}$. A base conceitual dele é explicada por CUTTER et al. (2000) dizendo que "O potencial do perigo (ou estresse) ${ }^{2}$ interage com o tecido social subjacente do lugar para criar a vulnerabilidade social". Esse tecido social inclui características sociodemográficas, percepção de e experiência com riscos e ameaças e a capacidade geral de responder aos estresses. Como acontece com o conceito geral de vulnerabilidade, ainda não existe um conjunto único de métricas usadas para avaliar a vulnerabilidade às ameaças naturais. As ameaças apenas têm sido descritas como um conceito de múltiplas dimensões que incorpora questões como os modos de vida, moradia, segurança e gênero (CUTTER et al.2003). Dessa forma, a disponibilidade de dados se transforma num fator de influência importante para a escolha dos indicadores de vulnerabilidade a serem selecionados. Por essa razão a base de dados escolhida para a pesquisa exploratória incluiu os dados do censo mais recentemente realizado no Brasil, fato que permite ter uma melhor informação e entendimento da distribuição espacial da vulnerabilidade social nas bacias hidrográficas do município.

O uso das bacias hidrográficas como unidades mínimas de análise, que descreve o sistema biofísico no qual a população desenvolve as suas atividades diárias, foi escolhido porque o sistema facilita a relação entre as comunidades humanas sem importar se estão agrupadas em comunidades delimitadas por razões políticas e administrativas (GUZMAN HERRADOR et al. 2015). Neste sistema natural se estruturam relações múltiplas entre fatores naturais e humanos num espaço que tem sido historicamente delimitado pela população e o uso que ela faz do espaço. Isto, facilita a associação final

\footnotetext{
${ }^{1} \mathrm{O}$ alcance da pesquisa está limitado na sua escala temporal devido à impossibilidade de encontrar todas as bases de dados utilizadas para o intervalo de tempo de interesse de 2000 e 2010.

${ }^{2} \mathrm{O}$ potencial de perigo está explicado como o resultado dos esforços de mitigação interagindo com o risco (a probabilidade do evento perigoso acontecer)
} 
das variáveis utilizadas para o cálculo da vulnerabilidade social e as proporções de internação Hospitalar com os regimes de precipitação para chegar ao mapeamento da vulnerabilidade considerada.

Há incerteza nos resultados deste tipo de estudos que é um reflexo da qualidade dos dados utilizados nos métodos de avaliação, que são geralmente dados secundários e que não foram coletados com o propósito de avaliar a vulnerabilidade. Não obstante é possível obter conclusões e avaliações da distribuição da vulnerabilidade que sejam uma representação aproximada da realidade. 


\section{REFERENCIAL TEÓRICO}

\subsection{VULNERABILIDADE}

O termo vulnerabilidade tem sido usado durante muito tempo e de maneiras diferentes em diversos campos das ciências. Uma busca simples no dicionário resulta na ideia de que os sistemas são vulneráveis quando têm um ponto pelo qual podem ser atacados (BUARQUE DE HOLANDA FERREIRA, 1999). Esta noção dá a ideia de se referir à capacidade de ser ferido ou o grau no qual um sistema poderia experimentar dano por causa de um perigo (FÜSSEL, 2007). Segundo KELLY e ADGER (2000) a definição simples já traz alguns elementos que são importantes na conceituação do termo da perspectiva dos desastres e das mudanças climáticas.

A palavra perigo, dentro da definição apresentada, implica que a vulnerabilidade não existe isoladamente, só está presente quando estão se considerando os possíveis impactos de uma exposição; mas não só o perigo e a exposição fazem os sistemas vulneráveis, a sua capacidade de ser ferido determina uma outra dimensão da definição porque destaca as condições próprias e atuais dele que acrescentam essa possibilidade de prejuízo, o que no contexto de pesquisa em mudanças climáticas introduz os conceitos de sensibilidade, susceptibilidade e capacidade adaptativa dos sistemas humanos frente às variações das condições climáticas que representam perigo.

Na literatura relacionada com as mudanças climáticas até 2003 a definição de vulnerabilidade tendia a ser separada em duas categorias: A primeira, segundo BROOKS (2003), via a vulnerabilidade segundo os termos da quantidade do dano potencial causado sobre o sistema por um evento climático particular ou um perigo. Isto é, a vulnerabilidade está determinada pela natureza do perigo, a probabilidade e frequência de ocorrência, o tamanho da exposição humana e a sensibilidade do sistema aos impactos do perigo analisado.

A segunda categoria apresentada por BROOKS (2003) enxerga o termo como um estado que existe dentro do sistema antes de se encontrar com um evento que represente perigo. Desde esta perspectiva a vulnerabilidade é mensurada com indicadores que avaliem o desfecho e não aqueles que avaliem o estado do sistema em um tempo anterior à ocorrência do evento. Da discussão que supõe o uso destas duas definições diferentes, 
têm-se derivado os termos vulnerabilidade social e vulnerabilidade biofísica que são, ainda hoje, utilizados por vários autores (ADGER, 1999).

Nos anos mais recentes, o Intergovernmental Panel of Climate Change (IPCC, 2007) propôs uma definição para vulnerabilidade dizendo que o termo se refere à propensão que os sistemas humanos e ecológicos têm de sofrer prejuízo e a sua habilidade de responder aos estresses impostos como resultado dos efeitos das mudanças climáticas. Assim, dentro de uma sociedade, a vulnerabilidade está influenciada pela história de desenvolvimento, pelas exposições físicas, pela distribuição dos recursos antes da ocorrência do estresse e pelas instituições de caráter social e governamental (ADGER et al. 2007). Isto quer dizer que se identifica a vulnerabilidade como o grau de susceptibilidade e a impossibilidade que tem qualquer um dos sistemas (biológicos, socioeconômicos e geográficos) de enfrentar os impactos adversos das mudanças climáticas. Então, define-se a susceptibilidade como o grau no qual o sistema está aberto, passível ou sensível aos estímulos climáticos, a sensibilidade como o grau no qual o sistema é afetado ou responde ao estímulo climático (Note-se que a sensibilidade inclui resposta a ambos os estímulos problemáticos e favoráveis), e a capacidade adaptativa como o potencial dos sistemas de se adaptar (alterar para se ajustar) aos estímulos climáticos ou os efeitos e/ou impactos destes (IPCC, 2007).

Resumindo, não existe uma maneira única e precisa de definir o que é a vulnerabilidade no âmbito da pesquisa de mudanças climáticas. No seu lugar existe, segundo FÜSSEL (2007), um conjunto de conceitos para fazer pesquisa humanaambiental integrada. Isto é, um conjunto de definições integradas como a segurança alimentar, modos de vida, desastres naturais e manejo do risco que, em concordância com a situação na qual são utilizadas e as características da pesquisa desenvolvida, cabem no contexto científico específico que associa as interações humano-ambiente. Assim, dadas as implicações das mudanças climáticas dentro do leque dos setores económicos, humanos, ecológicos e geográficos, há possibilidades de que as pesquisas apontem um amplo intervalo de vulnerabilidades potenciais. Em concordância com isto, existem marcos conceituais para a avaliação de vulnerabilidade dos sistemas às mudanças climáticas para os contextos da saúde humana, as zonas costeiras, o bem-estar humano e modos de vida, a agricultura, a pesca, a silvicultura e os sistemas hídricos, os assentamentos humanos, a saúde pública e os ecossistemas entre outros (PRESTON et al. 
2011).

Contudo, qualquer um dos modelos conceituais específicos nos diferentes contextos, precisa da análise dos fatores que determinam a potencialidade de dano devido às ameaças externas junto com as propriedades intrínsecas dos sistemas. Por isso, como assinalam PRESTON et al. (2011), reconhecem-se duas classes de determinantes da vulnerabilidade: os determinantes biofísicos e os fatores socioeconômicos. Efetivamente, qualquer um dos modelos reconhece que tanto as condições do meio físico, as características bióticas e aquelas de natureza não só económica como também social ou cultural, podem ter uma influência no potencial de dano. Alguns estudos de avaliação e mapeamento da vulnerabilidade, representam os seus alvos de pesquisa dentro de uma categoria de determinantes ou outra, mas uma grande proporção deles, incorporam ambos (PRESTON et al. 2011). Além disso, como assinala FÜSSEL (2007), muitas das construções conceituais que definem a vulnerabilidade coincidem na definição de quatro dimensões fundamentais para descrever uma situação de vulnerabilidade.

- Sistema analisado: São exemplos os sistemas humanos-ambientais, os grupos populacionais, os setores económicos, as regiões geográficas ou os sistemas naturais.

- Atributo de interesse ou preocupação: $O$ atributo ou atributos do sistema vulnerável que são ameaçados pela exposição ao perigo.

- Perigo/Ameaça: Uma influência potencialmente daninha sobre o sistema analisado. Nem sempre o perigo é considerado como uma influência externa, as características internas dos sistemas podem representar eventualmente perigos para ele mesmo.

- Referência temporal: o ponto ou período no tempo de interesse na análise.

Dessa forma, a definição que se acha apropriada para o marco geral da pesquisa a ser desenvolvida reconhece que a vulnerabilidade é intrínseca ao sistema, faz parte dos fatores que afetam as consequências da exposição do sistema sociedade-natureza ao 
perigo e determinam sua severidade e probabilidade de ocorrência, porque modifica a maneira na qual o sistema recebe a influência potencialmente nociva. Esta definição combina as diferentes perspectivas intradisciplinares dentro de um marco conceitual interdisciplinar e serve de base para contextualizar a avaliação da vulnerabilidade.

\subsection{ESCOLAS E TENDÊNCIAS DE PESQUISA EM VULNERABILIDADE}

A pesquisa em mudanças climáticas abriu o caminho para melhorar o conhecimento do funcionamento da biosfera, a estrutura dos sistemas humanos e o rastro que a relação entre ambos tem sobre os sistemas naturais. O surgimento da ciência da sustentabilidade tem contribuído com a construção do entendimento da dinâmica homemnatureza e a vulnerabilidade do sistema dinâmico humano-ambiente. Assim, com o seu objetivo dual de responder às necessidades sociais enquanto se protegem os sistemas essenciais para a vida, esse entendimento é um dos elementos centrais do diálogo da pesquisa na ciência da sustentabilidade (TURNER II et al. 2003). No entanto, para assegurar o desenvolvimento da pesquisa nestes campos é necessário criar marcos conceituais que indiquem o caminho que deve ser seguido, o que tem sido feito por várias comunidades de especialistas no mundo.

Segundo TURNER II et al. (2003), FÜSSEL (2007) e PRESTON et al. (2011) existem dois modelos que são arquétipos no campo de pesquisa já assinalado: o modelo conceitual do risco-ameaça (Risk-Hazard framework - $\mathrm{RH}-$ ) e o modelo de pressão e alívio (Pressure and release model- PAR).

\subsubsection{Risk-Hazard framework-RH-}

O modelo de Risco-Ameaça (Risk-Hazard framework) é característico da literatura técnica sobre risco e manejo de desastres. Como mostra a Figura 1, o modelo conceitua a vulnerabilidade como a relação dose-resposta entre uma ameaça externa sobre o sistema e os seus efeitos adversos ou impactos (FÜSSEL, 2007). Isto é, procura entender o impacto da ameaça como função da exposição ao evento-ameaça e a dose-resposta (sensibilidade) do sistema (TURNER II et al. 2003). Dessa maneira, as pesquisas 
desenvolvidas dentro deste modelo, marcam a exposição e a sensibilidade como aquilo que tem a maior importância e enfatizam os fatores biofísicos que contribuem na sensibilidade do sistema. No entanto, deixam ao lado a capacidade do sistema de influenciar aquela sensibilidade e os aspectos sócio-políticos da vulnerabilidade, como o papel das instituições e a capacidade adaptativa (PRESTON et al.2011).

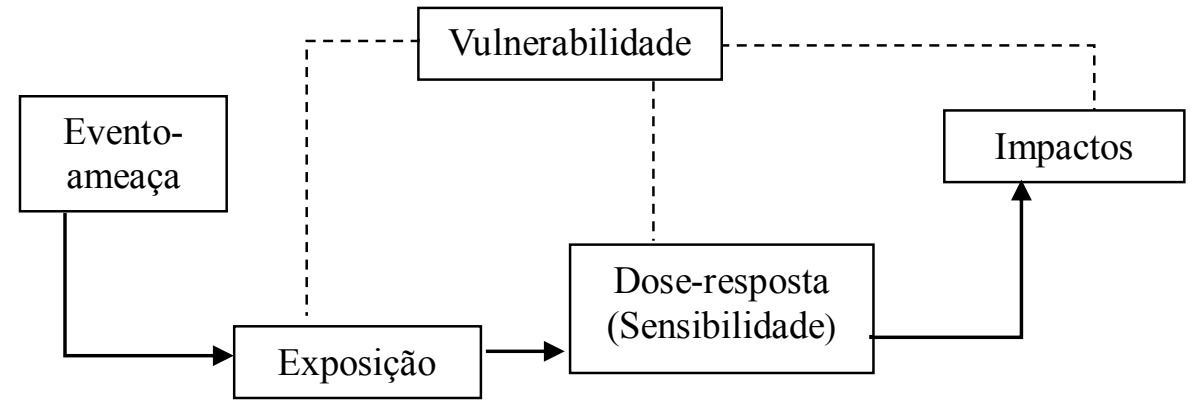

Figura 1. Modelo de Risco-Ameaça. Cadeia da sequência começa com a ameaça. Conce ito de vulnerabilidade implícito pelas linhas ponteadas. Adaptado de TURNER et. al. (2 003).

Esta visão da avaliação da vulnerabilidade corresponde também com o que FÜSSEL (2007) chama de avaliação de impactos, que aparece como um dos três contextos de tomada de decisão que, segundo o autor, são importantes na estimativa da vulnerabilidade porque definem o objetivo final para a avaliação e os critérios de análise levados em conta dentro do marco de avaliação da vulnerabilidade às mudanças climáticas no nível global. Neste contexto de avaliação, os pesquisadores estimam os efeitos potenciais de diversos cenários de mudanças no clima e especificam as áreas alvo que no longo prazo devem mudar para mitigar os efeitos das mudanças climáticas globais.

Os exemplos das aplicações deste tipo de pesquisas, especificamente nos estudos de mapeamento de vulnerabilidade, incluem eventos de ameaça como o aumento dos níveis do oceano, inundações ou eventos de calor extremo. Segundo PRESTON et al. (2011) estes modelos estão melhor representados por um número importante de exercícios de mapeamento da vulnerabilidade nas áreas costeiras. Encontram-se exemplos desenvolvidos na Austrália (SHARPLES et al. 2009), no Bangladesh (KARIM e MIMURA, 2008), Fiji (GRAVELLE e MIMURA, 2008), Turquia (DEMIRKESES et al. 2008) e os Estados Unidos (HAMMAR-CLOSE et al. 2003). Nestes estudos se aplicam medições da vulnerabilidade baseadas nas características geomorfológicas da área de 
estudo ou modelos digitais de terreno e cenários de aumento do nível do oceano e/ou a ocorrência de tormentas para avaliar o terreno em risco de inundação e outros recursos associados que possam ser expostos. No entanto, nenhum deles inclui outro grande grupo de características e processos nas esferas social, econômica, política e cultural que podem modificar tanto a exposição quanto a sensibilidade no espaço e tempo (PRESTON et al. 2011).

\subsubsection{Pressure and release model $-P A R$}

Entretanto o modelo de Pressão e Alivio (TURNER II et al. 2003 e PRESTON et al. 2011) ou o modelo de construtivismo social (FÜSSEL, 2007), definem o risco explicitamente em função das perturbações, fatores de tensão ou estresse e a vulnerabilidade da unidade exposta. Direcionam a atenção às condições que fazem à exposição perigosa, levando à vulnerabilidade e as causas que criam estas condições (TURNER II et al. 2003). Usado geralmente para avaliar grupos sociais que devem encarar desastres, o modelo mostrado na Figura 2, define a vulnerabilidade como uma condição a priori de um lar ou comunidade, que tem sido determinada por fatores socioeconômicos e políticos (FÜSSEL e KLEIN, 2006). Isto quer dizer que não leva em conta a integração dos sistemas humano e natural no sentido de considerar a vulnerabilidade dos subsistemas biofísicos, nem a capacidade adaptativa do sistema social relacionado com as condições do meio no qual habita.

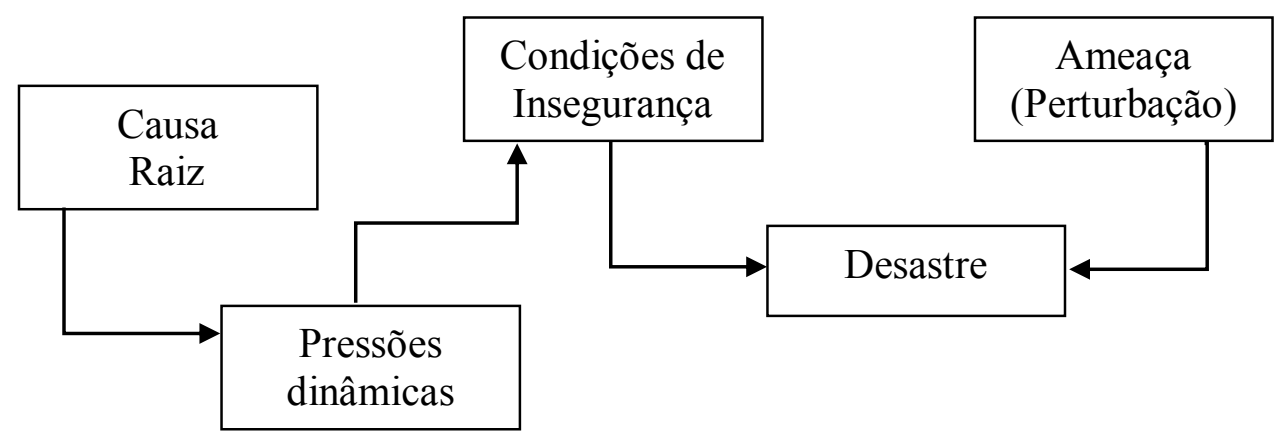

Figura 2. Modelo pressão e alivio. Com a ênfase sobre as condições sociais de exposição, conceito de vulnerabilidade usualmente explicito. Tomado de TURNER et. al. (2003).

Desde a perspectiva das tendências de avaliação que FÜSSEL (2007) apresenta, os modelos PAR correspondem com a primeira e segunda geração de avaliação da 
vulnerabilidade. Assim, a avaliação nesta visão tem como objetivo identificar grupos específicos da população que sejam vulneráveis para dar prioridade na alocação de recursos. Onde as características de maior contribuição são os fatores não-climáticos e a vulnerabilidade. Desta forma, a avaliação da vulnerabilidade está caracterizada principalmente pela ponderação dos impactos nos termos da importância que eles possuem para a sociedade e a consideração de potenciais processos de adaptação.

Segundo PRESTON et al. (2011), durante os 11 anos anteriores à 2009, aproximações mais holísticas para a avaliação da vulnerabilidade tinham sido baseadas no modelo PAR, na busca de um entendimento mais sistemático das interações dos sistemas humano e ambiental. Essas avaliações de caráter mais integral, afirmam, são o reflexo de que as condições de vulnerabilidade social poderiam ter existido a priori e independentemente da ameaça. Porém as implicações dessa vulnerabilidade podem ser ainda mais evidentes e apreciáveis quando a exposição à ameaça acontece. No entanto, e apesar do interagir natural dos sistemas humano e ambiental, a integração das características na vulnerabilidade de ambos sem se definir antes a relação existente entre eles e como ela vai ser integrada dentro da análise, pode levar a conclusões arbitrárias na questão da contribuição que cada um teria na vulnerabilidade do sistema completo.

Portanto, e apesar do desafio que representa, alguns estudos já foram realizados com o alvo de produzir avaliações espaciais integradas da vulnerabilidade às mudanças climáticas baseadas no modelo PAR. É o caso da integração das projeções de mudanças climáticas com estatísticas de educação, riqueza, acesso aos recursos e população para o mapeamento das interações dos aspectos biofísicos e psicossociais da vulnerabilidade na escala global (THROW, 2008) a estimação da vulnerabilidade aos ciclones tropicais em diferentes distritos na Índia (SHARMA, 2008) e o exame da vulnerabilidade às inundações na bacia superior do rio Tâmisa realizado por (HEBB, 2007), onde os mapas de vulnerabilidade se baseiam em indicadores de pobreza, gênero, raça e idade com diferentes cenários de inundação.

\subsubsection{Modelo de Vulnerabilidade expandida}

Existe também uma terceira escola de pensamento, que segundo FÜSSEL e KLEIN, (2006) é mais utilizada nas pesquisas de mudanças globais e mudanças 
climáticas, na qual a vulnerabilidade inclui uma dimensão externa, chamada de exposição, e uma dimensão interna chamada de sensibilidade e capacidade adaptativa, e representa a definição de vulnerabilidade do IPCC. Criado por TURNER II et al. (2003), é o marco conceitual chamado de vulnerabilidade expandida.

Neste marco conceitual se dá atenção direta aos sistemas humano-ambiente integrados, cuja vulnerabilidade e sustentabilidade são preditas sinergicamente nos subsistemas sociais e ambientais enquanto estão sendo afetadas pelos processos que acontecem em diferentes escalas espaço temporais e funcionais (PRESTON et al.2011). Isso quer dizer que o modelo de análise leva em conta:

i) As múltiplas ameaças/perturbações ou estresses que possam interagir e a sequência na qual eles podem acontecer;

ii) A exposição além da presença de uma ameaça; isto é, incluindo a maneira na qual o sistema integrado humano-natureza experimenta a ameaça;

iii) A sensibilidade do sistema integrado à exposição;

iv) A capacidade do sistema de enfrentar a ameaça e responder diante dela (resiliência), incluindo as consequências e os riscos da recuperação lenta após o evento.

v) A restruturação do sistema depois das respostas adotadas.

vi) Escalas envolvidas e dinâmicas escalares das ameaças, do sistema humanonatureza e das suas respostas.

Desta forma, o que o modelo propõe é levar em conta não só as características biofísicas e sociopolíticas do sistema humano-ambiental analisado que fazem dele um sistema vulnerável na sua escala própria, como também características ambientais, políticas, sociais e económicas dentro de outras escalas maiores que podem influenciar a vulnerabilidade do sistema na escala local, como pode ser observado na Figura 3 
O emprego deste tipo de modelo dentro da pesquisa em mudanças ambientais tem a dificuldade de precisar da representação de determinantes espaciais da vulnerabilidade e as suas interações complexas. $\mathrm{Na}$ maioria das pesquisas que pretendem integrar diferentes esferas do sistema humano-ambiente, a avaliação é realizada dentro de um espaço geográfico fixo com uma resolução fixa e levando em conta um número limitado de pressões externas que determinam a escala da avaliação. Em poucas palavras, segundo TURNER II et al. (2003), existe uma limitante na representação da natureza dinâmica da vulnerabilidade e a capacidade adaptativa que se espalham dentro de múltiplas escalas espaciais e temporais, não só no aspecto geográfico e físico como também na integração do papel das instituições, os direitos cidadãos e a gestão pública.

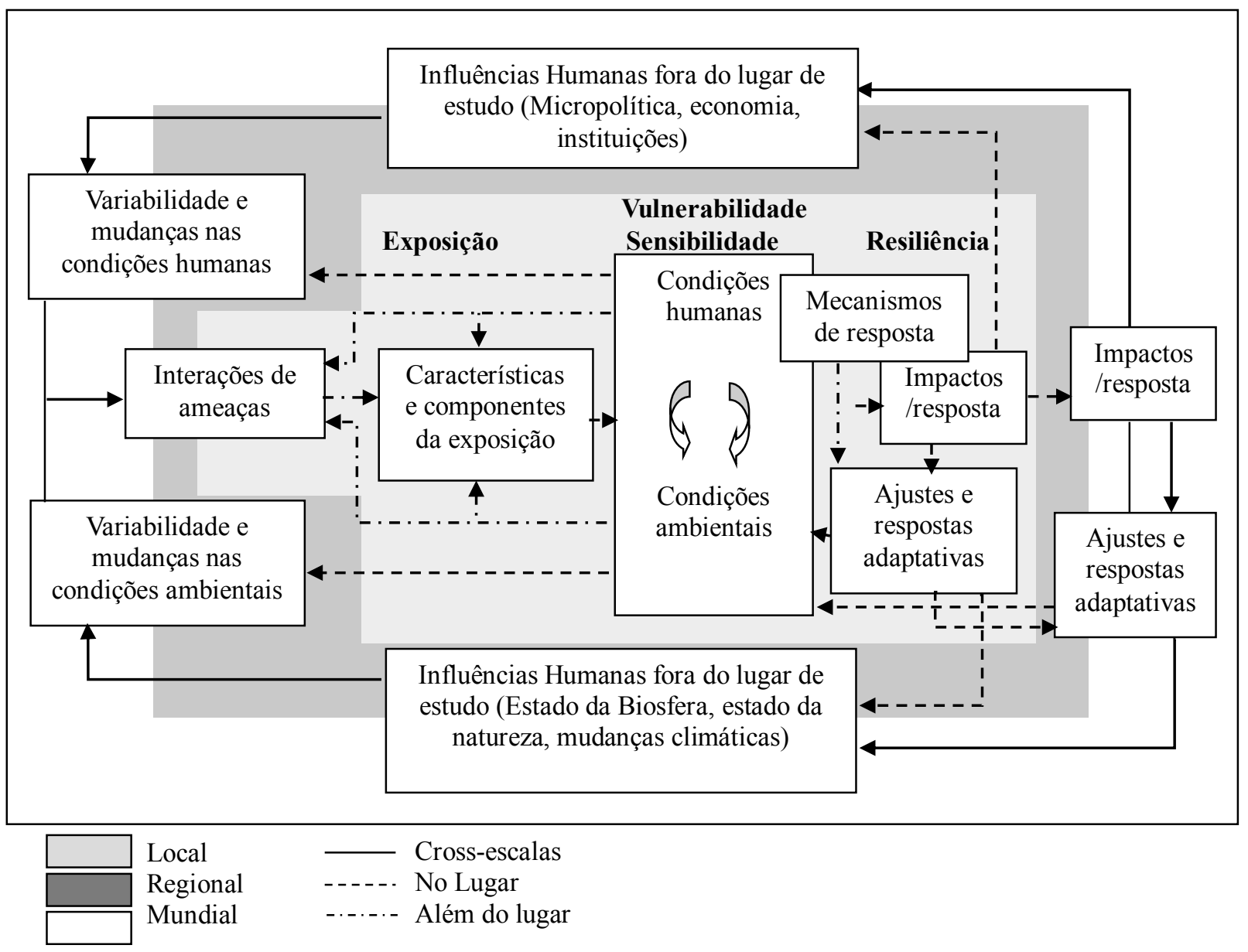

Figura 3. Modelo de vulnerabilidade expandida. Componentes da vulnerabilidade identificado e unidos com fatores além do sistema em estudo e operando em várias escalas. Tomado de TURNER et. al. (2003).

Embora seja um modelo conceitual complexo, existem esforços para avaliar a vulnerabilidade desde esta perspectiva, por exemplo O'BRIEN et al. (2004) examinam os 
fatores de estresse climático junto com as pressões da globalização, fazendo uma avaliação de vulnerabilidade dentro de múltiplas escalas. LUERS et al. (2003) mapearam a vulnerabilidade agrária na escala local, baseada tanto nas condições biofísicas e comportamentos locais, quanto nos mercados nacionais e a globalização no vale Yaqui, México.

\subsection{INUNDAÇÕES E EFEITOS NA SAÚDE HUMANA}

Os maiores impactos das mudanças climáticas na saúde humana são mais prováveis de acontecer por causa das mudanças na magnitude e frequência de eventos climáticos extremos que desencadeiam desastres naturais ou emergências (MCMICHAEL et al. 2001). Os eventos climáticos extremos incluem as precipitações extremas, tormentas severas, as ondas de calor e as inundações. “Têm sido definidas na literatura científica como a condição que acontece quando a água transborda o espaço natural ou artificial que ocupa numa corrente, rio, ou qualquer outro corpo d'água; ou quando se acumula por causa de escorregamento sobre áreas de baixa elevação* (DU et al. 2010). Sendo resultado do interagir das precipitações, o escoamento superficial, evaporação, vento, nível do oceano e a topografia local e algumas outras causas, os seus regimes podem variar dependendo do tamanho da bacia hidrográfica e o clima (CONFALONIERI et al. 2007).

São classificáveis segundo a suas causas (Quadro 1) e a sua natureza (Frequência, velocidade de início, velocidade e profundeza da água, escala espacial e temporal). A causa mais comum de inundação é a chuva (HASIZUME, 2013). Quando a precipitação acontece por um período longo de tempo pode causar o aumento progressivo dos níveis dos rios que por sua vez resulta no transbordamento, se pelo contrário a chuva é de grande intensidade, pode causar escoamento rápido e transbordamento súbito do corpo d'água.

Relatórios indicam que precipitações vão se intensificar e que essa tendência pode continuar no futuro (GREENOUGH et al. 2001; CONFALONIERI et al., 2007; DU

\footnotetext{
* [The condition that occurs when water overflows the natural or artificial confines of stream, river, or other body of water, or accumulates by drainage over low-lying areas]
} 
et al., 2010; BINDOFF et al., 2013). Mudanças nas características regionais das precipitações têm sido sugeridas como causas do incremento da frequência e intensidade das enchentes. Segundo a EM-DAT (GUHA-SAPIR, BELOW e HOYOLIS, 2014), as inundações são o desastre natural de maior ocorrência no mundo, correspondem a 40\% dos desastres naturais acontecidos na última década e são responsáveis por o $6,2 \%$ dos óbitos e $43 \%$ da população afetada por desastres no mesmo intervalo de tempo.

As inundações proveem um vínculo importante entre as mudanças climáticas e o desenvolvimento humano porque trazem como consequência um conjunto de impactos que afetam, desde variadas perspectivas, às populações expostas (MARCHEGGIANI et al. 2010).

Quadro 1. Causas de inundações. Adaptado de DU et al (2010)

\begin{tabular}{|c|c|c|}
\hline Causas & Subcategoria & Comentário/exemplos \\
\hline \multirow[t]{2}{*}{ Precipitação } & Chuva & $\begin{array}{l}\text { Impacto vai depender do } \\
\text { tamanho e velocidade da } \\
\text { chuva }\end{array}$ \\
\hline & Neve & $\begin{array}{l}\text { Impacto imediato devido a } \\
\text { força da queda. Após queda, } \\
\text { impacto pelo derretimento } \\
\text { da neve ou o gelo formado. }\end{array}$ \\
\hline \multirow[t]{4}{*}{ Aumento no nível da água } & \multirow[t]{2}{*}{ Água do oceano } & $\begin{array}{l}\text { Aumento súbito nos níveis } \\
\text { associado com ondas de } \\
\text { maré alta, tsunamis e } \\
\text { tormentas; }\end{array}$ \\
\hline & & $\begin{array}{l}\text { Aumentos ao longo prazo } \\
\text { caudados pelo aquecimento } \\
\text { global }\end{array}$ \\
\hline & \multirow[t]{2}{*}{ Água doce } & $\begin{array}{l}\text { Aumento dos níveis por } \\
\text { represamento, planejado ou } \\
\text { não, dos cursos da água }\end{array}$ \\
\hline & & $\begin{array}{l}\text { Aumento dos níveis da água } \\
\text { subterrânea. }\end{array}$ \\
\hline \multirow[t]{3}{*}{ Falha estrutural } & Falha na represa & $\begin{array}{l}\text { Colapso de estruturas de } \\
\text { retenção da água }\end{array}$ \\
\hline & $\begin{array}{lll}\text { Deslocação } & \text { da } & \text { água } \\
\text { armazenada } & & \end{array}$ & $\begin{array}{l}\text { Quedas de solo em massa } \\
\text { dentro dos reservatórios, } \\
\text { deslocando grandes } \\
\text { quantidades de água. }\end{array}$ \\
\hline & $\begin{array}{l}\text { Deterioração das defensas } \\
\text { contra o oceano }\end{array}$ & $\begin{array}{l}\text { Quebra dos diques na Nova } \\
\text { Orleans (2005) }\end{array}$ \\
\hline
\end{tabular}




\begin{tabular}{|l|lll|l|}
\hline $\begin{array}{l}\text { Redução do escoamento } \\
\text { natural }\end{array}$ & $\begin{array}{l}\text { Prevenção da absorção } \\
\text { natural }\end{array}$ & $\begin{array}{l}\text { Desenvolvimento de zonas } \\
\text { húmidas, o que reduz a } \\
\text { absorção da chuva }\end{array}$ \\
\hline $\begin{array}{l}\text { Bloqueio das redes de } \\
\text { esgoto }\end{array}$ & $\begin{array}{l}\text { O planejamento pobre das } \\
\text { redes de esgoto ou bloqueio } \\
\text { das redes causado por } \\
\text { entulhos ou lixo. }\end{array}$ \\
\hline
\end{tabular}

As revisões sistemáticas de diversos estudos proveem a maior evidencia da relação que existe entre a saúde e os fatores climáticos. A Figura 4 mostra como essa relação pode ser causada por exposições diretas ou por outros caminhos e as influências modificadoras simultâneas dos fatores ambientais, sociais e do sistema de saúde. Como é apontado por diversos autores (AHERN, 2005; IVERS e RYAN, 2006; ALDERMAN et al. 2012; FREITAS e XIMENES, 2012), os impactos das inundações sobre a saúde variam entre as populações afetadas em decorrência das características socioeconômicas da população, da vulnerabilidade dos espaços geográficos que elas habitam e das particularidades do evento de inundação que as atinja. Por essa razão a vulnerabilidade diferenciada entre as populações expostas às inundações nos países desenvolvidos e aqueles em desenvolvimento e os impactos negativos associados com ela, são um assunto importante para se levar em conta na hora de discutir os impactos das inundações sobre a saúde humana (ALDERMAN et al. 2012).

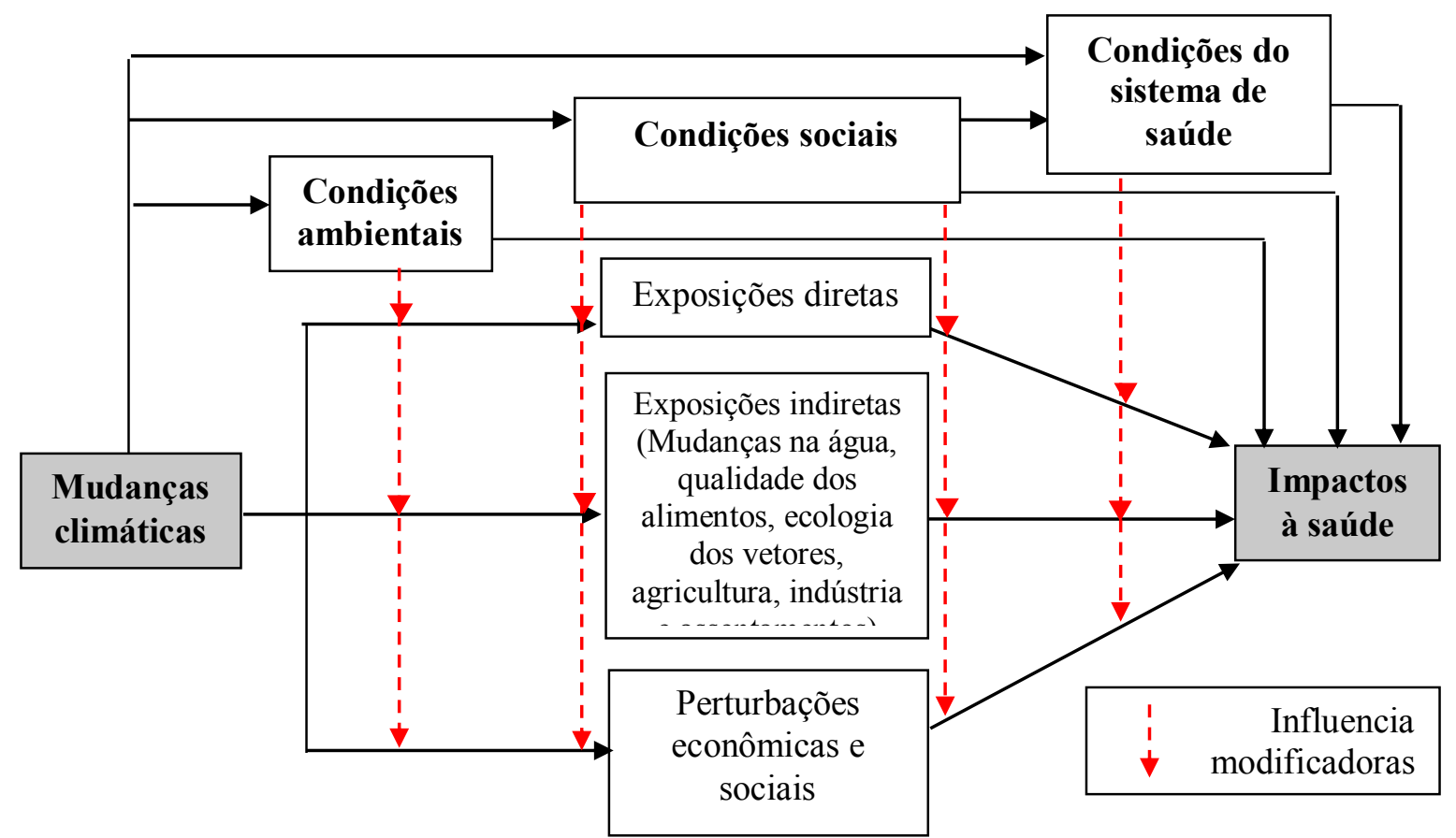

Figura 4. Diagrama esquemático das vias pelas quais as mudanças climáticas afetam a saúde, e influencias modificadoras dos fatores ambientais, sociais e do sistema de saúde. Tomado de CONFALONIERI et al (2007). 
Nas diferentes revisões consultadas, se resumem e avaliam criticamente as publicações realizadas em revistas científicas sobre o tema, categorizando os efeitos das inundações sobre a saúde em decorrência do tipo de exposição apresentada no momento do evento, como efeitos de imediato, médio e de longo prazo (AHERN et al. 2005; DU et al. 2010; ALDERMAN et al. 2012;), e qualificando as doenças usando a décima classificação internacional de doenças da Organização Mundial de Saúde (OMS), CID10 (FREITAS e XIMENES, 2012).

É comum encontrar que os agravos mais frequentemente listados nas estatísticas de mortalidade são os traumas físicos graves, os afogamentos, a hipotermia e as diarreias. Um outro efeito importante é a interrupção dos serviços de saúde, que pode ser devida a falhas nos sistemas de transporte ou falhas estruturais e de logística (ALDERMAN et al. 2012; DU et al. 2010; FREITAS e XIMENES, 2012). Nas estatísticas de morbidade os efeitos no curto ou médio prazo mais frequentemente listados, são as doenças de origem infecciosa e parasitária e os efeitos da contaminação química por acidentes tecnológicos; resultado de exposições indiretas ou efeitos secundários e que tem sido alvo da pesquisa científica mais persistente, uma vez que são as consequências à saúde mais facilmente identificáveis (AHERN et al. 2005).

Das consequências no longo prazo, fala-se das sequelas que as perturbações econômicas e sociais têm e cujos efeitos são evidentes em diferentes momentos após o evento sucedido (DU et al. 2010). A invalidez como efeito de traumas sofridos durante a inundação ou causada pela intensificação das doenças crónicas, encontram-se dentro desta lista. As doenças de natureza mental, a perturbação social e os seus problemas relacionados (como os comportamentos violentos/antissociais), o aumento das doenças não transmissíveis e/ou previsíveis com vacinação devido à falha nos serviços médicos e a mal nutrição como efeito de problemas socioeconômicos decorrentes e de quedas na produção agrícola entre outros, são as mais frequentemente descritas (AHERN et al. 2005; ALDERMAN et al. 2012; DU et al. 2010).

Em geral se conclui que nos termos de respostas da saúde pública, requer-se alguma precaução ao sacar conclusões gerais da literatura global, porque as inundações variam grandemente nas suas características e no tamanho e vulnerabilidade da população que atingem (AHERN et al. 2005). Assim, nos países em desenvolvimento, devem-se 
encarar pressões como a baixa qualidade em serviços de saúde e infraestrutura, que fazem com que os desastres possam ter características devastadoras porque eles exacerbam, no longo prazo, as condições de pobreza e vulnerabilidade da população. Por essa razão, como é assinalado por ALDERMAN et al. (2012) as medidas preventivas e o planejamento para a adaptação na prevenção da mortalidade e morbidade após os eventos de inundação, devem ser específicas do contexto avaliado.

\subsubsection{Doenças Infecciosas}

Segundo a World Health Organization - WHO (2014), as inundações estão relacionadas com incrementos no risco de doenças infecciosas de veiculação hídrica e aquelas transmitidas por vetores. No entanto, esse risco aumenta quando existe um grande deslocamento da população acompanhado ou não de dano nas fontes de água e/ou prejuízos que possam levar à poluição dos sistemas de distribuição. Existem variados estudos que tentam relacionar agravos à saúde com episódios de inundação e pretendem gerar evidencia epidemiológica contundente da relação existente entre ambos (IVERS e RYAN, 2006; MARCHEGGIANI et al. 2010; BICH et al. 2011).

Segundo AHERN et al. (2005), nas condições de inundação, existe o potencial para o incremento da transmissão via fecal-oral de doenças, especialmente nas áreas onde a população não tem acesso à água potável e saneamento. Isto acontece devido às condições de danos potenciais na infraestrutura dos sistemas de distribuição de água potável e à possível contaminação das fontes de água. Os micróbios mais comuns encontrados na água são as bactérias, protozoários, vírus e helmintos. Os protozoários em particular, teriam a capacidade de entrar nas águas subterrâneas se acontecesse uma conexão entre os aquíferos e as águas superficiais, devida ao prejuízo de poços ou nascentes (FANG e CHHETRI, 2013).

Como mostra o Quadro 2, a evidencia epidemiológica encontrada para a relação inundação-doença infecciosa de transmissão pela via oral-fecal, cita doenças como cólera (SUR et al. 2000), criptosporidiose (KATSUMA, D., et al., 1998), diarreia de origem não específica (WOODRUFF et al. 1988; SIDDIQUE et al. 1991), poliomielite, doenças causadas por rotavirus y febre tifoide e paratifoide (AHERN et al. 2005; FREITAS e 
XIMENES, 2012) entre outras. Existe evidencia de risco de diarreia relacionada com inundações nos países com alto PIB parece ser baixo e dadas as condições socioeconômicas e de infraestrutura raramente são documentados casos de surtos de doenças infecciosas após desastres naturais (GREENOUGH et al. 2001). No entanto é difícil fazer afirmações devido à dificuldade que representa realizar estudos epidemiológicos em condições de emergência que possam mostrar evidencia contundente.

Quadro 2. Consequências sobre a saúde provocadas pelas inundações. Adaptado e modificado de FREITAS E XIMENES (2012).

\begin{tabular}{|c|c|}
\hline $\begin{array}{c}\text { Agravos e Doenças, Incluindo alguns } \\
\text { sinais e sintomas }\end{array}$ & $\begin{array}{c}\text { Capítulos da Classificação } \\
\text { Internacional de Doenças } 10\end{array}$ \\
\hline $\begin{array}{l}\text { Diarreias e Gastroenterites } \\
\text { Cólera } \\
\text { Febre Tifoide } \\
\text { Varíola } \\
\text { Hepatites A } \\
\text { Hepatites E } \\
\text { Poliomielite } \\
\text { Malária } \\
\text { Febre Amarela } \\
\text { Dengue } \\
\text { Encefalite de St. Louis } \\
\text { Filariose linfática } \\
\text { Leptospirose } \\
\text { Esquistossomose } \\
\text { Shiguelose } \\
\text { Escherichia coli (E. coli) } \\
\text { Giardíase }\end{array}$ & $\begin{array}{l}\text { Capitulo I. } \\
\text { Doenças Infecciosas e parasitárias }\end{array}$ \\
\hline $\begin{array}{l}\text { Rinite alérgica } \\
\text { Infecções respiratórias agudas } \\
\text { Sinusites severas } \\
\text { Asmas } \\
\text { Infecções pulmonares } \\
\text { Síndrome tóxica da poeira orgânica } \\
\text { Laringite }\end{array}$ & $\begin{array}{c}\text { Capítulo X } \\
\text { Doenças do aparelho respiratório }\end{array}$ \\
\hline
\end{tabular}

Segundo FANG e CHHETRI, (2013), a relação entre inundações e doenças transmitidas por vetores abrange três componentes principais: o hóspede vertebrado, o vetor invertebrado, e o parasito (baterias, vírus, etc.). Todos eles respondem às mudanças climáticas de diferentes maneiras. O aumento da temperatura acelera o desenvolvimento 
de vetores e patógenos, no entanto o aumento extremo delas pode levar a taxas de mortalidade mais elevadas. No caso da ocorrência de enchentes, pode acontecer que com água estancada ou de muito lento escorregamento exista uma maior oferta de criadouros. No entanto, se uma inundação acontecesse e o fluxo das águas é forte, deveria dar conta de lavar os lugares de reprodução.

A coleta de água doce nos abrigos temporários para a população deslocada, ou mesmo dentro dos domicílios afetados especialmente nos centros urbanos, é também um efeito secundário que pode ser relacionado com incrementos na transmissão em condições de emergência (AHERN et al. 2005).

No caso do Brasil, os exemplos dos impactos produzidos pela variabilidade climática estão principalmente representados por doenças como malária, leptospirose e leishmaniose especialmente em áreas urbanas (CONFALONIERI, 2003). A leptospirose, acompanhada das chuvas de verão no Rio de Janeiro, resultou em episódios epidémicos nos anos 1988 e 1996 nas áreas de coleta de lixo precária e com abundante número de roedores. Segundo CONFALONIERI (2003) no período entre 1975 e 1996 ocorreram 3947 casos da doença no mesmo município. Estudos sobre epidemiologia e surtos da doença já foram realizados em Belo Horizonte (FIGUEREIDO et al. 2001) e São Paulo (PEREIRA, 1998). 


\section{JUSTIFICATIVA}

Segundo as informações encontradas na EM-DAT (GUHA-SAPIR et al. 2014), nos 100 últimos anos, 7 dos 10 maiores desastres naturais no Brasil foram inundações. Neste período de tempo a base de dados registra mais de 39 milhões de pessoas ${ }^{3}$ afetadas pelas enchentes em todo o país. Se a frequência dos eventos de inundação tem tendência a aumentar, a avaliação da vulnerabilidade no contexto de exposição das áreas urbanas é significativa para a gestão de atenção aos desastres e se converte numa ferramenta importante para a avaliação de planos de manejo dos riscos à saúde das populações mais vulneráveis às inundações nas épocas de chuvas torrenciais.

Os riscos à saúde associados com redes de esgoto combinadas $^{4}$ que se transbordaram, têm sido pesquisados por DONOVAN et al., (2008). Os autores encontraram que a probabilidade de contrair doenças gastrointestinais pela ingestão incidental de água em áreas próximas das redes de esgoto transbordadas, estava entre 0,14 e 0,70 durante o curso de um ano para os visitantes que usavam as águas do rio Passaic (Nova Jersey) para efeitos recreativos respectivamente. SCHETS et al. (2008) investigaram a qualidade microbiológica das águas superficiais canalizadas e a de lagoas recreativas em Amsterdam que recebem água poluída de redes de esgoto, esgotos crus dos lares e fezes de cães e aves.

O risco aproximado de infecção com Crytosporidium e Giardia por cada evento de exposição esteve entre $0,00002 \%$ e $0,007 \%$ e de $0,03 \%$ até $0,2 \%$ respectivamente para mergulhadores profissionais expostos de maneira ocupacional às águas do canal. CURRIERO et al. (2001) analisaram a relação geral entre as precipitações e os surtos de doenças produzidas pelos patógenos presentes na água para 548 surtos reportados nos Estados Unidos desde 1948 até 1994. Eles acharam uma associação estatisticamente significativa entre os eventos climáticos e as doenças. Transbordos de águas das redes de esgoto combinadas são mencionados pelos pesquisadores como uma das fontes potenciais de contaminação neste caso.

\footnotetext{
${ }^{3}$ Deve-se levar em conta que para que o desastre seja registrado na base de dados citada deve cumprir com pelo menos um dos seguintes critérios: 10 ou mais óbitos reportados, 100 pessoas reportadas como afetadas, chamado por ajuda internacional e/ou a declaração do estado de emergência.

${ }^{4}$ Redes que transportam uma combinação de águas efluentes dos esgotos da cidade e água das chuvas.
} 
VELDHUIS et al., (2010) conduziram um estudo de avaliação quantitativa do risco microbiológico, para avaliar o risco associado com a exposição dos cidadãos a patógenos nas águas resultantes das inundações, provocadas pelas redes de esgoto transbordadas. Neste caso, dois cenários de exposição foram usados para estimar o risco de infecção com Cryptosporidium, Giardia e Campylobacter: Ingestão acidental devida aos salpicos produto do tráfego e ingestão acidental da água por parte das crianças nos momentos de jogo. Os valores do cálculo anual de risco variaram entre $5 \times 10^{-6}$ para Cryptoporidium assumindo cenários de exposição baixos, até 0,03 para Giardia assumindo cenários de exposição altos.

Recentemente, THI VIET NGA et al. (2010) e seus colaboradores quantificaram o risco à saúde das inundações na região metropolitana de Manila (Filipinas), utilizando a metodologia da avaliação quantitativa do risco microbiológico, combinada com os sistemas de informação geográfica para mapear o risco associado com a ingestão incidental da água de inundação poluída com Escherichia coli. Vários cenários de exposição foram utilizados de acordo com a profundidade da inundação e para diferentes faixas etárias. A pesquisa concluiu que o nível de risco está entre 1\% e 20\% nos cenários de inundação entre 50 centímetros e maiores a dois metros, nas idades de entre cinco e quatorze anos. Esclarecendo que se as inundações fossem maiores de dois metros e se elas ocorressem com frequências mais altas, a linha base de vulnerabilidade trocaria consequentemente.

Outras pesquisas similares têm sido feitas no Reino Unido por FEWTRELL et al. (2011) para conhecer a quantidade potencial de casos de doença gastrointestinal resultado do contato com água de inundação. O mapeamento da vulnerabilidade no contexto das mudanças climáticas é uma aproximação que permite a representação dos contextos locais dentro da avaliação da vulnerabilidade através da representação da heterogeneidade espacial dos determinantes e as suas interações (PRESTON et al. 2011). Para estes autores os benefícios deste tipo de avaliações são sempre duplos. Primeiro ajudam na construção do planejamento do espaço, porque reconhecem que diferentes atividades no uso do solo, podem ser percebidas como mais ou menos apropriadas dadas as diferenças nas necessidades de serviços, oportunidades e riscos que têm as populações; e segundo expressam a importância que tem o manejo do componente de risco no 
planejamento espacial dentro das novas perspectivas que as mudanças climáticas colocam com as alterações na distribuição espacial das ameaças climáticas. Desta maneira, o plano do projeto de pesquisa encontra-se imerso numa realidade latente e jovem dentro do âmbito da pesquisa em saúde e traz consigo uma conotação relevante no campo da saúde ambiental atual. 


\section{OBJETIVOS}

\subsection{Objetivo Geral}

Analisar a associação entre a vulnerabilidade social e as internações hospitalares por doenças gastrointestinais, no município de São Paulo

\subsection{Objetivos Específicos}

Construir um modelo de vulnerabilidade social por microbacias hidrográficas no município de São Paulo.

Analisar as relações espaciais dos componentes do modelo dentro dos limites geográficos do município de São Paulo.

Realizar uma análise espacial exploratória da vulnerabilidade social e as internações por doenças gastrointestinais nas condições e períodos de maior e menor ocorrência de precipitação. 


\section{MATERIAIS E METODOS}

Nos estudos de revisão de literatura científica sobre doenças infecciosas relacionadas com inundações é comum a afirmação de que embora a relação entre estas duas ocorrências exista devido aos efeitos diretos e indiretos da exposição ao evento de inundação, a tendência de realizar a quantificação dos danos dos desastres naturais desde a óptica dos danos materiais e econômicos ocasionados (VELDHUIS et al. 2010), faz com que esta relação não tenha sido estudada com profundidade (AHERN et al., 2005; ALDERMAN et al. 2012 e DU et al. 2010).

Neste estudo, foram utilizados os métodos de análise concordantes com a pesquisa científica do tipo exploratório. Em conformidade com os objetivos propostos a pesquisa foi realizada em duas etapas. A primeira consistiu na identificação do método de análise que permitisse associar os componentes referidos dentro do referencial teórico no modelo de vulnerabilidade expandida, e a segunda etapa, com a realização de um estudo de caso no município de São Paulo primeiro avaliando as informações disponibilizadas utilizando o método de análise escolhido e, em seguida, realizando o relacionamento espacial das variáveis selecionadas, para analisar a vulnerabilidade às doenças gastrointestinais relacionadas com inundações.

\subsection{MATERIAL BIBLIOGRÁFICO E CARTOGRÁFICO}

A pesquisa realizada teve como principais fontes bibliográficas artigos científicos internacionais encontrados sob as palavras chaves environmental change, infectious disease, floods e mapping vulnerability na base de dados Science direct (www.sciencedirect.com), plosone (http://www.plosone.org/) e pubmed (http://www.ncbi.nlm.nih.gov/pubmed/) e as palavras chaves correspondentes em português e espanhol: mudança climática, doenças infecciosas, inundações $e$ mapeamento da vulnerabilidade e cámbio climático, enfermedades infecciosas, inundaciones e mapeamento de la vulnerabilidad.

Alguns outros materiais bibliográficos consultados foram encontrados através de 
consultas no sistema integrado de bibliotecas da Universidade de São Paulo (http://www.sibi.usp.br/).

$\mathrm{Na}$ análise da informação geográfica, foram utilizados os materiais cartográficos a seguir:

- Mapa de setores censitários do ano 2010 obtido da base de dados de setores censitários do Centro de Estudos da Metrópole (CEM), no formato shapefile e sistema de projeção LatLong - Spherical.

- Bases de dados do censo 2010 do Instituto Brasileiro de Geografia e Estatística (IBGE), encontrada no banco de dados do Núcleo de Pesquisas em Avaliação de Riscos Ambientais da Faculdade de Saúde Pública.

- Mapa de bacias hidrográficas do ano 2012, obtido da Fundação Centro Tecnológico de Hidráulica (FCTH-USP), no formato shapefile e sistema de projeção UTM SAD69.

- Bases de dados sobre autorização de Internação Hospitalar (AIH-SUS), georreferenciadas no Centro de Estudos da Metrópole (CEM) pelo CEP de residência do paciente, dos anos 2009 e 2010.

- Acumulados de semanais de precipitação para os anos 2009 e 2010, calculados pelo método de Krigagem referenciado por (NYCHKA, WIKLE e ROYLE, 1999), obtido pela colaboração do meteorologista Msc. Kleber Lopes da Rocha Filho, do Sistema de Alerta a Inundações de São Paulo (SAISP).

O datum Horizontal utilizado para a visualização final dos resultados, é SIRGAS 2000 .

\subsection{APLICATIVOS}

Para a construção do mapa de vulnerabilidade do município de São Paulo na segunda 
etapa desenvolvida, foram utilizados softwares de análise estatística e de Análise de informação geográfica. O software de análise estatística R versão 3.1 .1 (2013) permitiu a identificação das variáveis a serem introduzidas no modelo de associação, o cálculo das associações estatísticas dessas variáveis para cada uma das bacias do município e as relações subsequentes com os dados de precipitação e taxas de internação hospitalar para a Diarreia e gastroenterite de origem infecciosa presumível (CID 2010: A09). Entretanto, os softwares de análise de informação geográfica ArcGIS nas suas versões 9.3 e 10.1 e OpenGeoDa 0.9.8.14, foram utilizados na criação de bancos de dados, a análise espacial dos dados geográficos e o desenho dos mapas resultantes.

\section{3. ÁREA DE ESTUDO}

O estudo de caso foi desenvolvido com dados do município de São Paulo, localizado a 2332'51" de latitude Sul e 46³7'10" de longitude Oeste, servindo como núcleo central da região metropolitana de São Paulo na região sudeste do Brasil (Ver Figura 5), um dos cinco maiores aglomerados urbanos do mundo (SILVA, 2010). São Paulo é a capital administrativa do estado homônimo e ocupa uma área de $1.521,110 \mathrm{Km}^{2}$ (PREFEITURA DE SP, 2014). Está dividido em 31 subprefeituras e 96 distritos que constituem a menor unidade administrativa municipal (PREFEITURA DE SP-SMVMA, 2004). Dados oficiais do ano 2010 mostram que a população é de 11,253,503 habitantes e uma população estimada para 2014 de 11'895.893 (IBGE, 2014). Nas suas características climatológicas, a região é classificada como tropical sub-úmida, com regimes pluviométricos bem definidos: a estação chuvosa de outubro a março (com um índice médio de $1000 \mathrm{~mm}$ ) e a estação seca de abril a setembro (com um índice de cerca de $300 \mathrm{~mm}$ ). Possui uma precipitação média anual (1991-2013) 1557,1 mm (NOBRE et al., 2011).

A escolha desta área de estudo está baseada tanto na história importante de ocorrências de inundações quanto na facilidade de acesso às bases de dados geográficos e socioeconómicos necessários para desenvolver a pesquisa. No entanto, a principal justificativa para a escolha da área de estudo está na riqueza científica que pode ter a análise das vulnerabilidades sociais e ambientais de uma cidade que apresenta marcados e simultâneos desafios nas suas estruturas sociais, econômicas e ambientais, dentro do 
contexto dos cenários de mudanças climáticas e as implicações na saúde que essas mudanças podem ter.

Segundo NOBRE et al., 2011, a análise das tendências de comportamento da temperatura na região metropolitana de São Paulo (RMSP) dá possibilidades de ocorrências cada vez mais frequentes e intensas de eventos meteorológicos extremos, numa área urbana que já sofre todo verão com enchentes e inundações. $\mathrm{O}$ risco de enchentes e deslizamentos de terra causados pelas chuvas intensas está acompanhado de outro fator de risco, associado a um número elevado de doenças infecciosas de veiculação hídrica causadas pelo contato com a água contaminada por agentes infecciosos que pode aumentar nas áreas com péssimas condições de saneamento básico. A associação de todas estas caraterísticas numa área urbana como o município de São Paulo, apresenta um cenário significante de pesquisa desenvolvida na linha de vulnerabilidade e saúde ambiental.

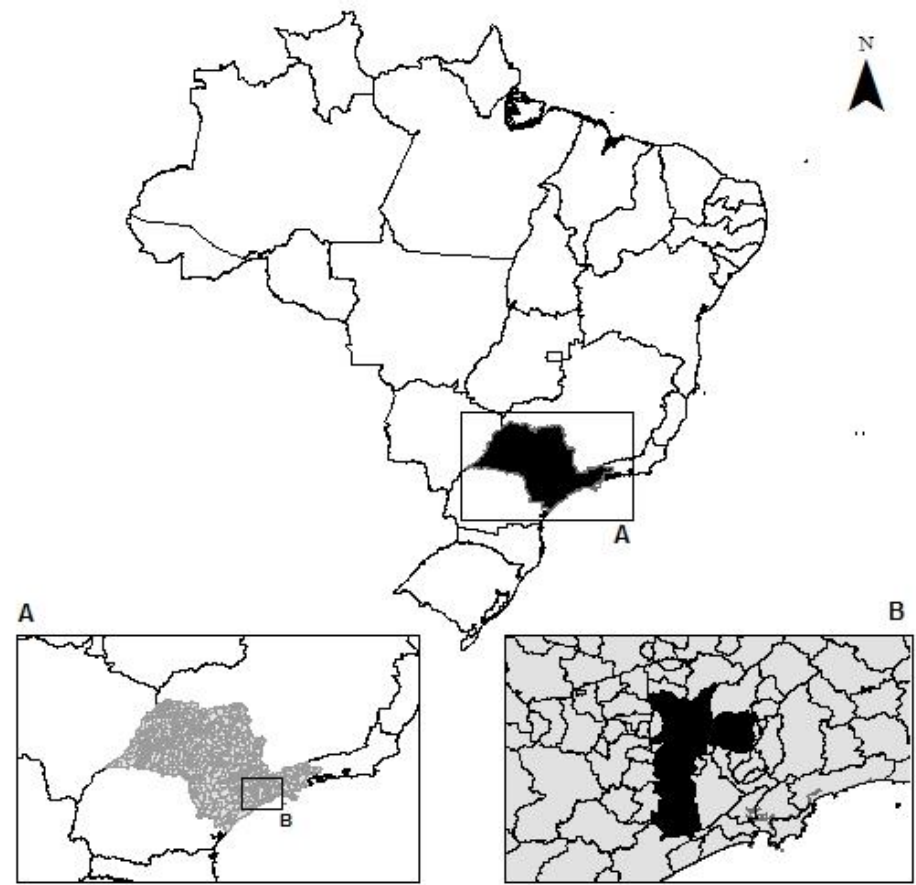

Figura 5. Localização da área de estudo

\subsection{MODELO DE ASSOCIAÇÃO DE VARIÁVEIS}

Para definir a vulnerabilidade de um lugar às possíveis consequências de eventos climáticos, requer-se da identificação de aquelas características do sistema de interesse que o põem dentro de um contexto vulnerável na frente de uma ameaça específica. Desde 
esta perspectiva, determinar a vulnerabilidade de um sistema ambiental complexo como as áreas urbanas, implica a análise dos subsistemas que constituem o sistema complexo e interagem entre eles em resposta de fatores externos que constituem ameaças. Assim, podem se definir as variáveis que serão as representações operacionais das características do sistema capazes de prover informação da susceptibilidade, a sensibilidade, a capacidade adaptativa e a resiliência do sistema impactado por o evento relacionado com a ameaça de origem natural (BIRKMANN, 2006). Levando em conta o anterior no desenvolvimento da metodologia de pesquisa, reconheceu-se a importância de demarcar a análise dentro da definição dos indicadores que compõem o estado vulnerável no sistema estudado e as interações existentes entre eles. Com este objetivo em mente, múltiplas sugestões de metodologias de análise têm sido desenvolvidas (Ver seção 2.2.). No entanto, o processo de pesquisa registrado neste documento está baseado na aproximação ao marco conceitual do modelo de vulnerabilidade expandida, já assinalado na página 11.

Assim, decidiu-se analisar a sensibilidade e capacidade adaptativa do sistema, utilizando a metodologia de CUTTER (2003) para o cálculo do Índice de vulnerabilidade social ou Social Vulnerability Index (SoVI®), cuja base conceitual abrange o cálculo de um índice que faz tangível quanto as características socioeconômicas influenciam os mecanismos de resposta das comunidades humanas na frente de ameaças naturais. Simultaneamente, foram calculadas as variáveis proporções de internação hospitalar causadas pelo diagnóstico de diarreia e gastroenterite de origem infecciosa presumível (CID A09), que representam o desfecho à possível exposição às aguas de inundação, e a variável médias de precipitação como indicador da influência externa que representa ameaça ao sistema urbano. O indicador precipitação média foi escolhido devido à impossibilidade de encontrar dados pontuais de eventos de inundação acontecidos no município de São Paulo que não estivessem ligados de maneira exclusiva com falhas no tráfego. Todas as variáveis foram calculadas dentro dos limites da bacia hidrográfica como unidade natural de planejamento que reúne condições ambientais próprias e representa o subsistema biofísico que interage com o subsistema humano, e pode ser analisado per se e numa escala conceitual maior como parte de a unidade política município. 
Inicialmente desenvolvido para ser calculado nos Estados Unidos de América para obter informação sobre a vulnerabilidade das comunidades às ameaças ambientais e/ou desencadeadas pelas consequências das mudanças climáticas, o índice já foi calculado para a Noruega, a área central de Portugal, Tóquio e mais recentemente para a China (ZHOU et al. 2014) entre outros lugares (HVRI 2013). A seguir se apresentam os mapas e bases de dados construídas como matérias-primas para o cálculo do SoVIß-São Paulo.

a. Bacias Hidrográficas

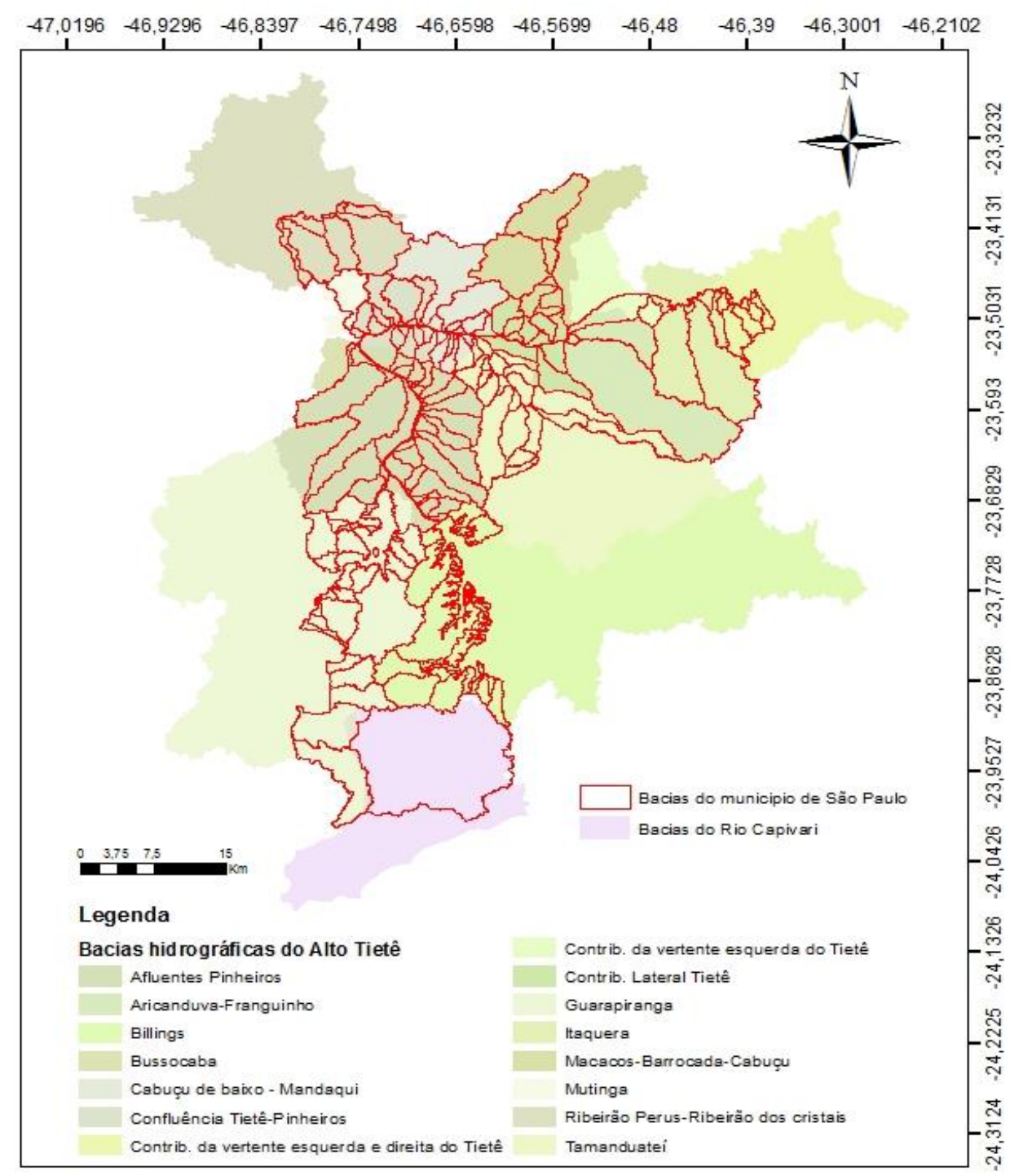

Figura 6. Mapa das 186 Bacias hidrográficas localizadas no território do município de São Paulo (2012). Sistema de projeção UTM SAD69. Modificado de: Fundação centro tecnológico de Hidráulica (FCTH-USP); Fundação Bacia Hidrográfica do Alto Tietê (FBHAT, 2009). 
A bacia hidrográfica é definida como uma unidade geográfica onde o ciclo hidrológico pode ser avaliado com o uso da equação de balance hídrico com o objetivo de estabelecer as características hidrológicas da região. Usualmente é determinada, desde a topografia, como a área que parece contribuir com toda a água que passa através de um corte transversal em um ponto dado do curso de água (VICAIRE, [s.d]). Para representação mais detalhada das bacias hidrográficas avaliadas, apresenta-se um mapa em escala menor no apêndice III.

As características fisiográficas da bacia influenciam em grande medida, as respostas hidrográficas e os regimes de fluxo e períodos de seca (ILLGEN, 2014). Por isso, quando falamos de bacias dentro de um ambiente urbano, as mudanças sobre as características fisiográficas geradas pelo interagir natural do homem e o médio físico no qual desenvolve as suas atividades, influenciam as respostas hidrográficas e cada área do território do município delimitada como bacia hidrográfica terá umas características próprias que definiram uns regimes de fluxo específicos e a ocorrência ou não de inundações nesse território.

Por isso e devido ao interesse central de observar as tendências das doenças gastrointestinais associadas com inundações, considerou-se conveniente realizar a análise tomando como unidade geográfica mínima a bacia hidrográfica. Levando em conta que foi adotada como unidade territorial de planejamento no estado de São Paulo pela Lei Estadual $n^{\circ} 7.663 / 91$ e que desde esse momento ficou estabelecida como a unidade referencial para a gestão dos recursos hídricos do estado (ROMÉRO, J.A. e GILDA, 2004), pensou-se que a análise de vulnerabilidade e a associação das doenças gastrointestinais com os eventos de inundação, seria enriquecida se a visão do sistema biofísico fosse recolhida num sistema natural cujas características próprias constituem um sistema ambiental definido no qual os processos hidrológicos podem ser analisados, não unicamente desde a visão ecológica como também desde a perspectiva da hidrologia dos ambientes urbanos.

Como apresentado na Figura 6 na área do município de São Paulo os principais cursos de água que percorrem o território são os Rios Tietê, Pinheiros, Tamanduateí, Aricanduva e Embu-Guaçu. Além deles estão os córregos Pirajuçara, Ipiranga, Cabuçu de cima, Cabuçu de baixo e Mandaqui, entre outros. (PREFEITURA SP-SMVMA, 2004). Conforme ressalta a Secretaria Municipal do Verde e Meio Ambiente-SMVMA- (2004), 
a maior parte dos terrenos do Município se situa na bacia Hidrográfica do Alto Tietê, da qual fazem parte outros 35 municípios da região metropolitana. Dentro dos limites do município estão presentes três (3) das suas sub-bacias: a sub-bacias Cotia-Guarapiranga, a Pinheiros-Pirapora e a Billings-Tamanduateí. Uma porção menor do território do município está inserida no contexto dos cursos de água que drenam para o litoral, dentro do território da Bacia Hidrográfica da Baixada Santista.

b. Construção da base de dados

Para a construção da base de dados, usaram-se as variáveis do censo da população brasileira de 2010 coletados pelo IBGE para os 18953 setores censitários do município de São Paulo. Mostrados na Figura 7 como as divisões de cor cinza do território, encontram-se inseridos dentro dos distritos da cidade (de cor vermelha) e representam unidades territoriais criadas para fins de controle cadastral de coleta de dados (IBGE, 2000).

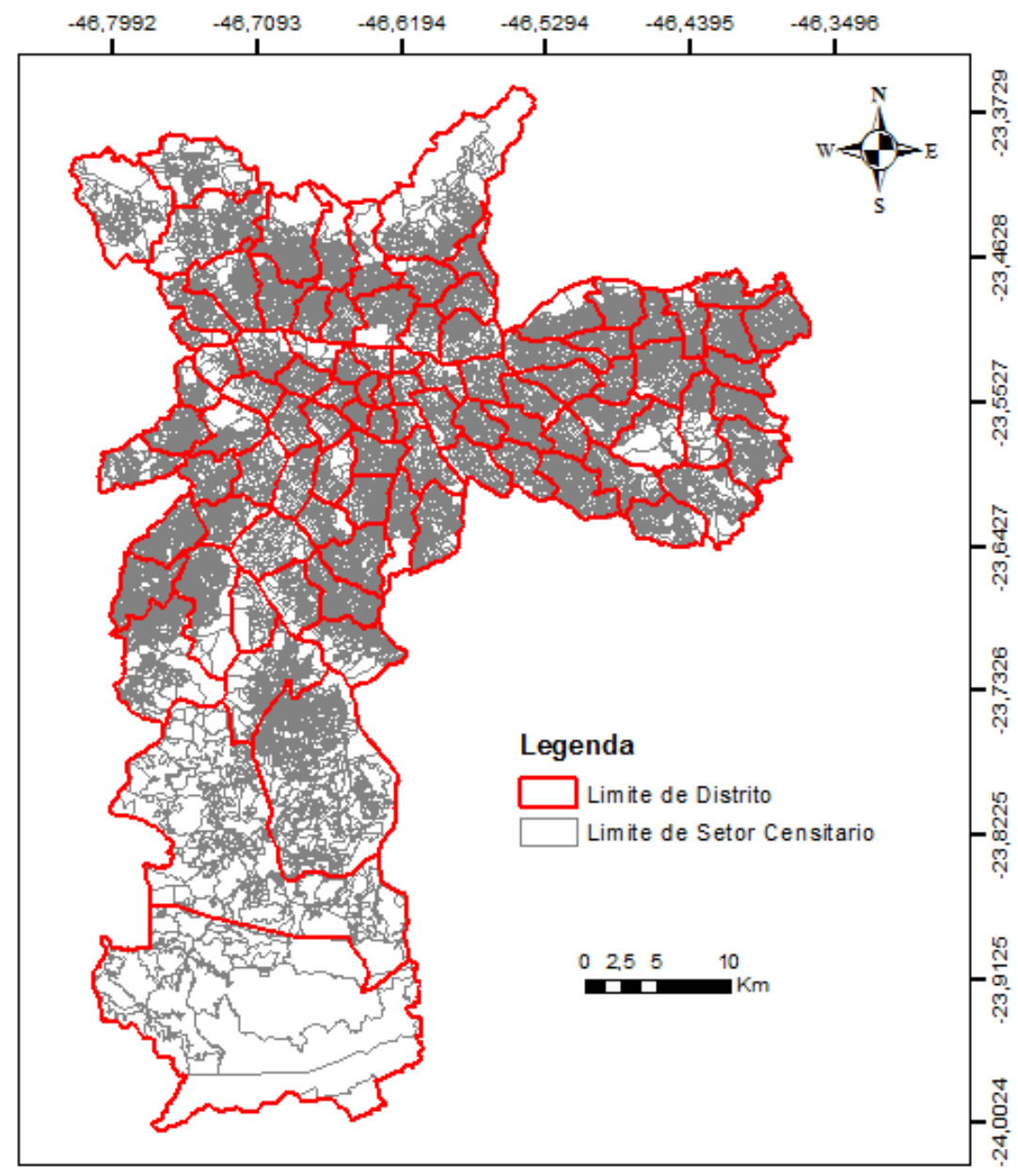

Figura 7. Mapa de Setores Censitários por Distritos (2010). Sistema de projeção LatLong - Spherical. Fonte: Centro de Estudos da Metrópole (CEM). 
Dos dados disponibilizados, escolheram-se inicialmente 42 variáveis que caracterizaram as maiores dimensões da vulnerabilidade segundo os conceitos e métricas da vulnerabilidade social, agrupadas segundo CUTTER et al. (2003) e descritas no Quadro 3, adicionando as variáveis representativas das características de saneamento básico consideradas como fatores que contribuem na transmissão de doenças infecciosas.

Cada uma destas variáveis é apresentada na base de dados do IBGE como uma função dos setores censitários e com o objetivo do presente projeto de pesquisa de realizar a análise final na escala de bacia hidrográfica, foi necessário construir uma "malha de bacias hidrográficas" do município de São Paulo. Para isso, efetuou-se a intersecção (intersect) do mapa de setores censitários do município com as variáveis de interesse tomadas do censo 2010 como os seus atributos e o mapa de bacias hidrográficas. A malha final continha cento e oitenta e cinco (185) bacias hidrográficas das 186 bacias originais ${ }^{5}$. Três (3) das bacias finais não foram levadas em conta para o próximo passo metodológico devido a que o número de moradores totais e o número de domicílios particulares permanentes registrados na base de dados era zero ${ }^{6}$.

A ferramenta Dissolve foi utilizada para realizar os cálculos de médias e somas necessários para a composição das variáveis nas 182 bacias hidrográficas do município. A tabela de atributos resultante desta operação, foi a base de dados usada para realizar as operações estatísticas para o cálculo final do Índice de Vulnerabilidade Social.

Quadro 3. Conceitos e métricas da Vulnerabilidade Social. Adaptado de CUTTER (2003)

\begin{tabular}{|l|l|c|}
\hline \multicolumn{1}{|c|}{ Conceito } & \multicolumn{1}{|c|}{ Descrição } & $\begin{array}{c}\text { Aumenta ou diminui } \\
\text { a Vulnerabilidade }\end{array}$ \\
\hline Nível & $\begin{array}{l}\text { A habilidade de absorber perdas e aumentar a } \\
\text { capacidade de resiliência aos impactos. Um } \\
\text { socioeconômico }\end{array}$ & $\begin{array}{l}\text { Nível alto }(+/-) \\
\text { comunidades de absorber e se recuperar das } \\
\text { perdas de maneiras mais rápida. }\end{array}$ \\
\hline Gênero & $\begin{array}{l}\text { As mulheres podem ter mais dificuldade durante } \\
\text { o momento da recuperação do que os homens, a }\end{array}$ & Gênero $(+)$ \\
\hline
\end{tabular}

\footnotetext{
${ }^{5}$ A bacia Intermedia Engordador/Barrocada (número 13 no mapa do apêndice 3) localizada no nordeste, resultou ser parte da área total de uma bacia não pertencente aos setores censitários do município de São Paulo, razão pela qual e ficou fora do intersect realizado

${ }^{6}$ As bacias hidrográficas Intermedia Pinheiros-Perus, Montante Ribeirão São Miguel e Intermedia Santa fé/Itaim localizadas no limite noroeste do município.
} 


\begin{tabular}{|c|c|c|}
\hline & $\begin{array}{l}\text { maior parte das vezes devido ao setor da } \\
\text { economia onde desenvolvem as suas atividades } \\
\text { e as responsabilidades de cuidado familiar. }\end{array}$ & \\
\hline Raça e etnia & $\begin{array}{l}\text { Impõe barreiras de língua e cultura que afetam o } \\
\text { acesso aos dinheiros utilizados para a } \\
\text { recuperação pós-desastre, assim como lugares } \\
\text { de residência localizados em áreas em risco de } \\
\text { desastre. }\end{array}$ & Não Brancos (+) \\
\hline Idade & $\begin{array}{l}\text { Os extremos no espectro de idade afetam as } \\
\text { possibilidades de sair das áreas perigosas. }\end{array}$ & $\begin{array}{c}\text { Idosos }(+) \\
\text { Crianças }(+) \\
\end{array}$ \\
\hline Rural/Urbano & $\begin{array}{l}\text { Os residentes das áreas rurais podem ser mais } \\
\text { vulneráveis devido às rendas menores e à } \\
\text { dependência a empregos locais baseados na } \\
\text { economia extrativa. As áreas com densidades } \\
\text { populacionais altas (urbanas) complicam a } \\
\text { evacuação no caso de eventos perigosos. }\end{array}$ & $\begin{array}{c}\text { Rural }(+) \\
\text { Urbano }(+)\end{array}$ \\
\hline $\begin{array}{l}\text { Saneamento } \\
\text { básico }\end{array}$ & $\begin{array}{l}\text { A perda de redes de esgoto, água, comunicações } \\
\text { e infraestrutura em geral compõem perdas } \\
\text { potenciais na hora de a ocorrência de desastres. }\end{array}$ & $\begin{array}{c}\text { Infraestrutura de } \\
\text { Saneamento básico } \\
(+)\end{array}$ \\
\hline $\begin{array}{l}\text { Estrutura } \\
\text { familiar }\end{array}$ & $\begin{array}{l}\text { As famílias com um grande número de } \\
\text { dependentes ou famílias com um responsável } \\
\text { único, tem dificuldades financeiras para pagar } \\
\text { pelo cuidado dos seus dependentes. Isto leva a } \\
\text { ter que balançar as responsabilidades do } \\
\text { trabalho e cuidado pelos membros da família. }\end{array}$ & $\begin{array}{l}\text { Famílias com um } \\
\text { responsável único }(+)\end{array}$ \\
\hline Educação & $\begin{array}{l}\text { A educação está ligada com o nível } \\
\text { socioeconômico, com a possibilidade de ter } \\
\text { melhores e maiores níveis de educação que } \\
\text { resultem em maiores rendas no longo prazo. }\end{array}$ & $\begin{array}{l}\text { Pouca educação }(+) \\
\text { Alto nível de } \\
\text { educação }(+)\end{array}$ \\
\hline
\end{tabular}

c. Análise estatística

O procedimento estatístico utilizado foi a análise de fatores realizada utilizando os pacotes car e psych da biblioteca do software R versão 3.1.1, especificamente a análise de componentes principais $\left(\mathrm{PCA}^{7}\right)$. $\mathrm{O}$ processo de construção da análise foi realizado seguindo a metodologia descrita por CUTTER et al. (2003) e CHEN et al. (2013). Esta metodologia de análise estatística permite a análise multidimensional do fenómeno estudado transformando uma base de dados complexa num novo grupo de variáveis independentes (componentes principais). Cada um dos componentes encontrados explica uma porção da variância total do conjunto de dados iniciais. Quanto maior seja a variância que o componente é capaz de explicar, maior quantidade de informação ele contém.

\footnotetext{
${ }^{7}$ Principal Components Analysis.
} 
Antes de realizar análise de componentes principais, vários testes de correlação foram realizados à base de dados obtida no passo metodológico anterior para ter certeza que a multicolinearidade das variáveis escolhidas não representasse um problema no momento de realizar a análise. A presença de multicolinearidade foi detectada primeiro realizando o cálculo da matriz de correlação das variáveis padronizadas para ter uma ideia geral de quanto elas estavam relacionadas entre elas e assim usar as variáveis que aportassem maior quantidade de informação à análise. Por tanto, as variáveis que mostraram uma alta correlação com outras não foram levadas em conta para o seguinte passo metodológico. O grupo de variáveis restante foi testado usado o Fator de Inflação da Variância (função $\operatorname{VIF}^{8}($ ) do pacote car no R), retirando uma a uma as variáveis com VIFs que excedessem o critério de seleção utilizado ${ }^{9}$, neste caso valores de VIF menores do que 10 .

Seguindo a abordagem metodológica de CUTTER et.al. (2003), para determinar se as variáveis escolhidas são adequadas para a análise de componentes principais, foram utilizados os testes de esfericidade de Bartlett (função cortest.bartlett() do pacote psych no R) que determina se as variáveis são suficientemente correlacionadas para que o resultado da análise de componentes seja útil, e o fator de adequação de Kaiser-MeyerOlkim (função $K M O($ ) no pacote psych o R) que tem o mesmo objetivo que o teste anterior, mas usa um princípio diferente para avaliar a correlação entre as variáveis e o seu cálculo não é afetado pelo número de variáveis na base de dados. O estatístico KMO varia entre 0 e 1 sendo que à maior proximidade de 1 o cálculo do PCA usando essa variável ou grupo de variáveis, será mais eficiente.

O cálculo do PCA foi realizado utilizando a função principal O no pacote psych no R. Esta função utiliza a matriz de correlação para normalizar as variáveis introduzidas. Foi escolhida a rotação varimax que minimiza o número de componentes resultantes e maximiza a suma das variâncias que eles representam, e o critério dos eigenvalores

\footnotetext{
${ }^{8}$ Variance Inflation Factor: "uma medida do grau em que cada variável independente é explicada pelas demais variáveis independentes" (MILOCA, S.D.)

${ }^{9}$ Como o razoamento da análise de componentes principais é reduzir o número de variáveis analisadas sem perder informação, procuram-se variáveis "altamente correlacionadas com um grupo de outras variáveis mas que estão muito pouco correlacionadas com variáveis fora desse grupo" (FIELD, 2000). Essas variáveis com alta correlação entre elas podem então ser 'medidas' sob uma variável única que chama-se de fator ou componente principal no caso estudado. Assim, se alguma das variáveis resulta altamente correlacionada com variáveis pouco correlacionadas entre elas, fará com que a análise de componentes principais resulte em um componente único, que diminui a utilidade do resultado.
} 
maiores ou iguais do que 1 como método para fazer a escolhia dos fatores a serem utilizados no PCA. Uma vez calculados, os componentes principais foram observados para decidir se cada um deles contribui para aumentar (+) ou diminuir (-) a vulnerabilidade e o sinal matemático correspondente foi assignado para cada um deles sobre essa base. O índice foi logo computado, somando todos os escores fatoriais dos componentes para cada bacia. Seguindo novamente o procedimento de CUTTER et al. (2003), deu-se pesos iguais para cada um dos componentes, devido a que não se tem uma justificativa teórica para assumir que um componente contribui à vulnerabilidade mais do que qualquer outro componente achado.

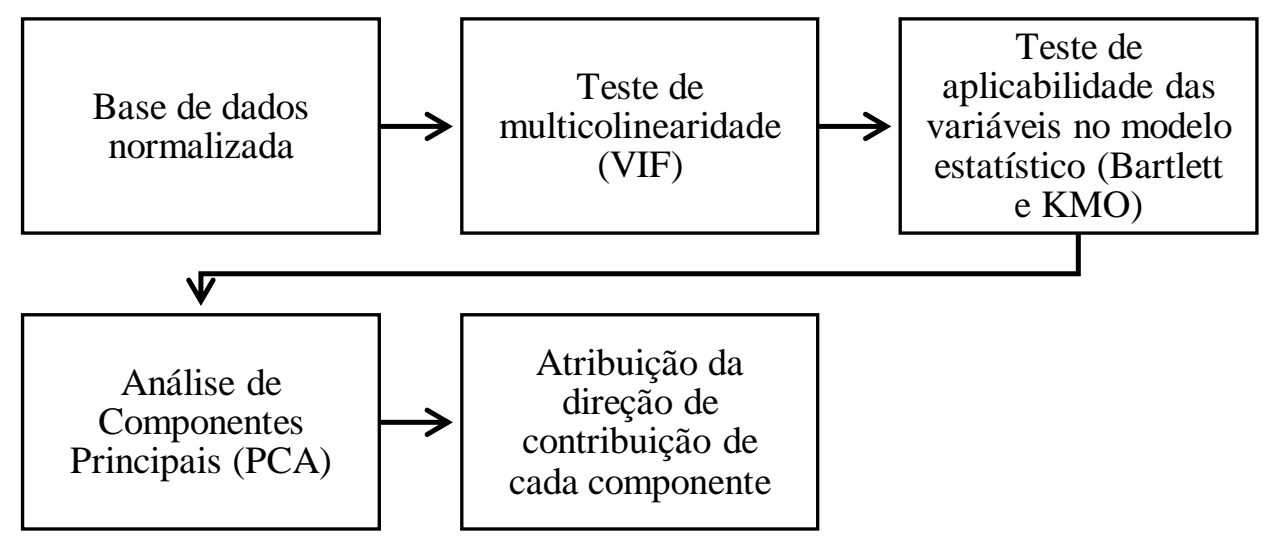

Figura 8. Processo metodológico para a Análise de Componentes Principais

\subsubsection{Proporções de internação hospitalar}

No cálculo das proporções de internação hospitalar foram utilizadas as bases de dados de autorização de Internação Hospitalar (AIH-SUS) dos anos 2009 e 2010, georreferenciadas no CEM pelo CEP de residência do paciente. O uso desta base de dados representa uma limitação para a análise realizada, devido a que nela se registram unicamente os atendimentos hospitalares realizados pela rede de atendimento pública e não correspondem à totalidade dos casos de Internação Hospitalar que podem ter-se registrado no período de tempo estudado.

Inicialmente a escolha dos diagnósticos principais a serem utilizados na pesquisa foram definidos como as doenças infecciosas e parasitarias presentes no capítulo I da Classificação Internacional de Doenças (OMS, 1997) que constitui os diagnósticos A00 até B99. No entanto, após a estudo da base de dados, decidiu-se utilizar o diagnóstico 
principal com a maior proporção de casos registrados para os dois anos em estudo, isto é o diagnóstico A09: Diarreia e gastroenterite de origem infecciosa presumível.

a. Exploração da base de dados de Autorização de Internação Hospitalar.

$\mathrm{Na}$ base de dados de Autorizações de Internação Hospitalar utilizada (anos 2009 e 2010), estão registrados dez milhões cento e setenta e nove mil novecentas e nove (10’179.909) autorizações de internação hospitalar para o município de São Paulo. Desse total, somente 41.059 eram diagnósticos classificados entre o A00 e o B99.

No total foram encontrados 415 diagnósticos classificados como doenças infecciosas e parasitarias, trezentos e sessenta e dois (362) dos quais tinham cem (100) registros de ocorrência ou menos, quarenta e quatro (44) tinham menos de mil (1000) registros de ocorrência e só seis (6) tinham mais de mil ocorrências. A Tabela 1 apresenta os diagnósticos encontrados que registravam o maior número de ocorrências.

Tabela 1. Diagnósticos com maiores números de registros de ocorrência e número de registros encontrados. Autorizações de Internação Hospitalar 2009-2010, São Paulo, SP.

\begin{tabular}{llc}
\hline Diagnóstico & \multicolumn{1}{c}{ Descrição } & Número de AIH registradas \\
\hline A48.0 & Gangrena gasosa & 1032 \\
& $\begin{array}{l}\text { Doença pelo HIV resultando em infecções } \\
\text { Bicobacterianas }\end{array}$ & 1182 \\
A49.9 & Infecção bacteriana não especificada & 1901 \\
A46 & Erisipela & 2844 \\
& Diarreia e gastroenterite de origem & 5410 \\
A09 & infecciosa presumível & 7830 \\
A41.9 & Septicemias não especificadas & \\
\hline
\end{tabular}

Os diagnósticos com maior número de ocorrências registradas foram o A41.9 que descreve as septicemias não especificadas, com sete mil oitocentos e trinta (7830) registros e o diagnóstico A09 que descreve a diarreia e gastroenterite de origem infecciosa presumível com cinco mil quatrocentos e dez (5410) autorizações de internação hospitalar registradas. Sendo o objetivo da pesquisa à análise e associação de doenças infecciosas com os eventos de inundação, decidiu-se que o diagnóstico A09 diarreia e gastroenterite de origem infecciosa presumível era o mais adequado para a realização da análise. Isto, 
devido a que a diarreia e gastroenterite são doenças infecciosas que cabem na classificação das doenças de veiculação hídrica.

Segundo (PREFEITURA DE SÂO PAULO, [s.d]), os casos de A09 (Diarreia e gastroenterite de origem infecciosa presumível) estão definidos pelo "aumento do volume das fezes com diminuição de sua consistência e aumento do número de evacuações, que se instala de modo agudo". São critérios de exclusão a Diarreia persistente (definida como estado diarreico que se inicia como diarreia aguda e que se prolonga além de duas semanas) e a diarreia crônica (definida como o estado diarreico com duração maior de 30 dias). O diagnóstico é realizado mediante o exame físico e raramente há necessidade de solicitação de exames clínicos.

Os critérios de admissão hospitalar estão descritos como: Vômitos persistentes, Incapacidade de ingerir líquidos, persistência de distúrbios hidroeletrolíticos e acidobásicos após abordagem inicial e suspeita de infecção com sistêmica.

b. Cálculo de Proporções de internação hospitalar

Os registros de A09 foram filtrados pela data de ingresso e a idade do paciente e finalmente organizados em quatro (4) subgrupos:

- Crianças de cinco (5) anos ou menos ingressadas na estação úmida ( $1^{\circ}$ de Outubro a 31 de Março) e na estação seca ( $1^{\circ}$ de Abril a 30 de Setembro).

- Idosos de 64 anos ou mais ingressados na estação úmida ( $1^{\circ}$ de Outubro a 31 de Março) e na estação seca ( $1^{\circ}$ de Abril a 30 de Setembro).

Para conhecer o número de internações ocorridas para os residentes da bacia hidrográfica, foi necessário realizar a união espacial (spatial join) dos dados georreferenciados e separados em grupos, com a camada de bacias hidrográficas disponibilizada pela FCTH-USP. A união espacial resultou num mapa de bacias hidrográficas cuja tabela de atributos apresentava o novo atributo conta (count): A contagem dos pontos da camada internações hospitalares que, pela sua localização 
espacial, estavam dentro de uma bacia hidrográfica

$$
\frac{\text { Número de internações por faixa etária }}{\text { População da faixa etária na bacia }} \times 10000
$$
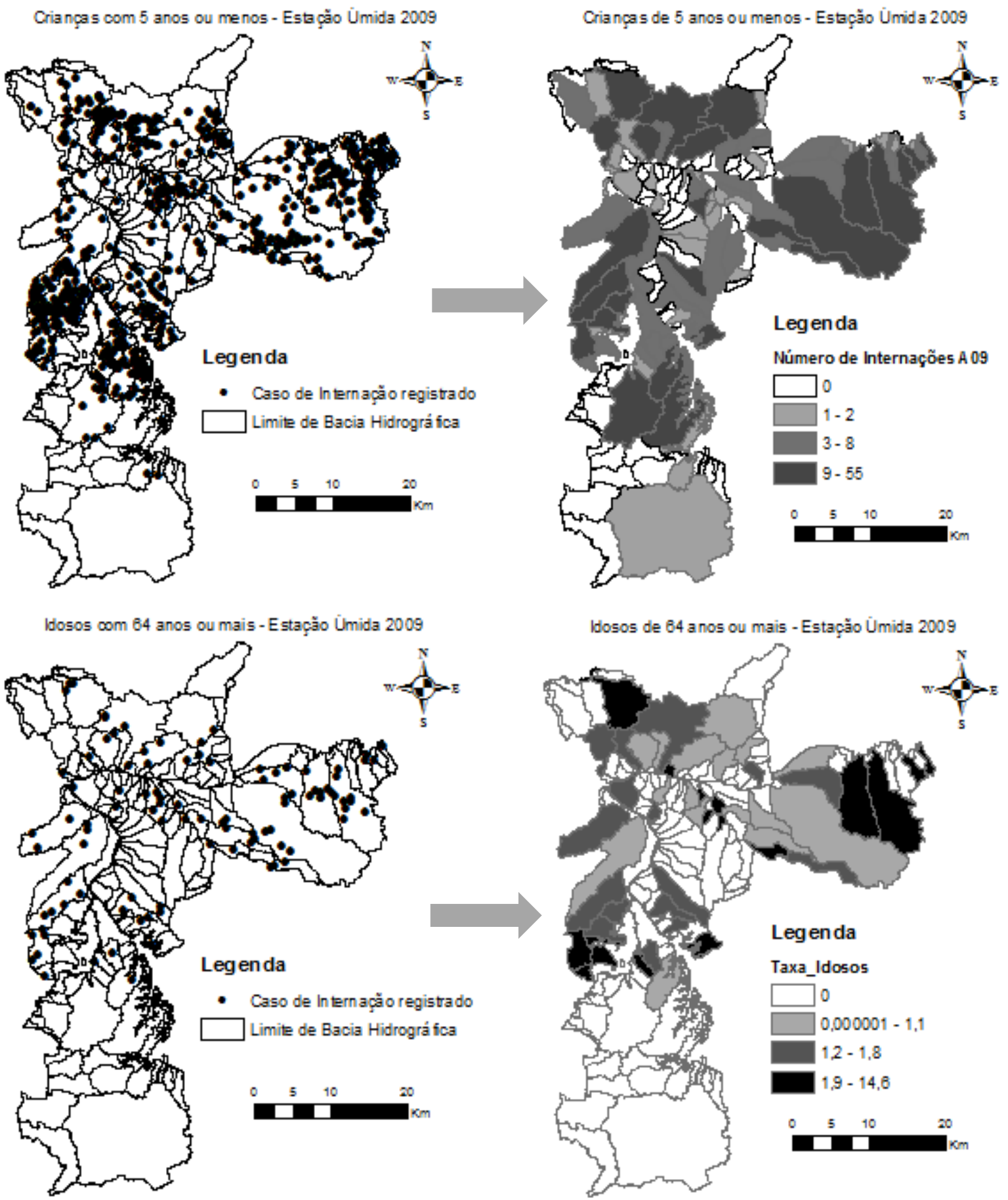

Figura 9. Transformação dos dados de internações hospitalares para o Diagnóstico A09 da estação úmida de 2009, desde casos georreferenciados até contagens por Bacia Hidrográfica. 


\subsubsection{Cálculo das médias de precipitação}

Para o cálculo das médias de precipitação para os períodos seco e úmido dos anos em estudo, foram utilizados os acumulados semanais de precipitação calculados no Sistema de Alerta a Inundações de São Paulo (SAISP). As medições de precipitação semanais para quarenta e nove (49) estações meteorológicas localizadas dentro dos limites do território do município de São Paulo e nas áreas próximas aos limites com outros municípios da área metropolitana, foram utilizadas como base para os cálculos realizados pelo método de Krigagem, sob a metodologia descrita por (NYCHKA et al. 1999). Os resultados foram armazenados como arquivos do tipo raster.

Os acumulados foram convertidos em arquivos vector de pontos e posteriormente foram armazenados em quatro (4) datasets correspondentes com as estações seca e chuvosa para cada ano, segundo as datas ${ }^{10}$ já descritas no item 5.1.2.

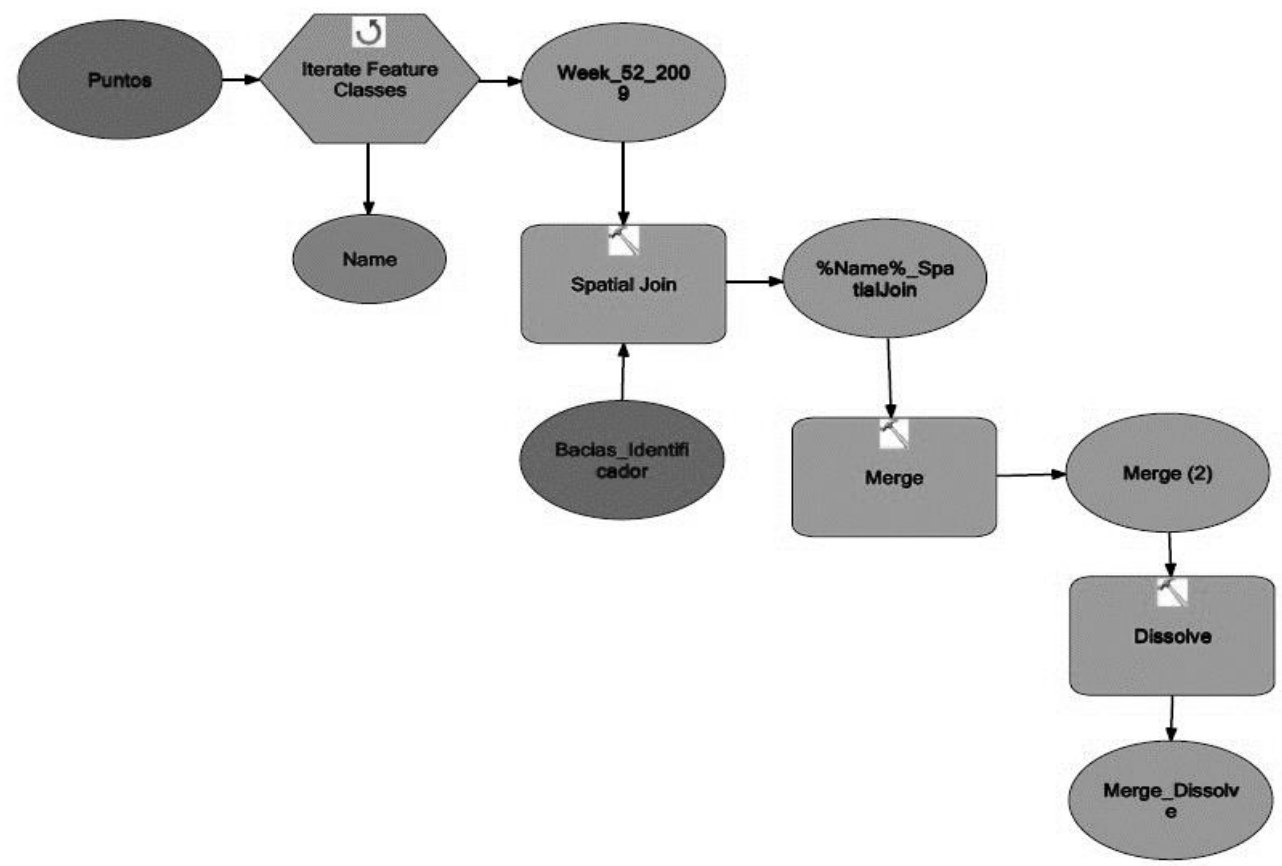

Figura 10. Cálculo das medias de precipitação para as bacias do município de São Paulo durante a estação chuvosa do ano 2009.

\footnotetext{
${ }^{10}$ As divisões temporais utilizadas, segundo as divisões temporais dos acumulados de precipitação disponibilizados foram realizadas por semanas. Assim as semanas da estação seca para ambos os anos em estudo foram da semana 13 até a 39 e para a estação úmida da semana 00 até a 12 somadas às semanas da 40 até a 52.
} 


\subsection{RELAÇÕES}

\subsubsection{Relações espaciais}

a. Autocorrelação espacial.

As relações espaciais das variáveis finais a serem avaliadas (Índice de Vulnerabilidade social, precipitação e proporção de internações hospitalares) foram estudadas primeiro analisando a autocorrelação espacial das variáveis não climáticas no espaço para identificar padrões de distribuição de cada uma nas bacias do território do município. Assim, as variáveis índice de Vulnerabilidade Social e proporção de Autorizações de Internação Hospitalar, foram analisadas no software ArcGIS 10.1 para calcular o índice de Moran Global e conhecer quais delas apresentam autocorrelações espaciais.

Para quantificar e mapear a intensidade dos aglomerados encontrados, foram utilizados Indicadores de Associação Espacial Local (LISA), especificamente o índice de Moran Local. O teste foi realizado com significância de 5\% e 999 permutações no software OpenGeoDa 0.9.8.14, para as variáveis com índice I (Moran Global) significativo. Em ambos os cálculos, as matrizes de vizinhança foram calculadas utilizando o conceito de vizinhança de lados e vértices ${ }^{11}$ também chamado de matriz de vizinhança tipo Queen.

b. Relações espaciais entre duas variáveis

Os mapas resultantes do cálculo do Índice de Moran Local obtido para a variável Proporção de Internações Hospitalares nas faixas etárias estudadas, foram posteriormente comparados com o mapa do Índice de Vulnerabilidade Social resultante do método descrito no item $c$ da seção 5.4.1. A comparação foi realizada de maneira descritiva, buscando observar os pontos em comum e os diferenciais do comportamento das variáveis no espaço e assim concluir sobre a vulnerabilidade da população no seu contexto comum com o desfecho Internações hospitalares causadas pelo diagnóstico Diarreia e gastroenterite de origem infecciosa presumível, e os regímenes de precipitação no

\footnotetext{
${ }^{11}$ Polígonos que compartilham um limite e/ou ponto são vizinhos (ESRI, 2013)
} 
município de São Paulo.

Embora a análise da sobreposição dos mapas de Proporção de Internações Hospitalares e as médias de precipitação sejam consideradas importantes para a obtenção de conclusões relacionadas com o objetivo geral da pesquisa, considerou-se que os valores de precipitação calculados a partir de poucas medições reais no terreno (isto é, poucas estações pluviométricas para a área avaliada), não são suficientemente fiáveis e não representam um valor agregado significativo que possa dar uma perspectiva diferente à análise de resultados. No entanto, estes valores são apresentados no item seis (6) de resultados. 


\section{RESULTADOS}

Os resultados se apresentam em concordância com as subseções descritas na seção 5 materiais e métodos. No entanto, os resultados da análise de relações espaciais são apresentados junto com os mapas resultantes das análises do índice de vulnerabilidade e proporção de Internações hospitalares respectivamente.

\subsection{MODELO DE ASSOCIAÇÃO DE VARIÁVEIS}

\subsection{1. Índice de Vulnerabilidade}

\section{a. Base de Dados}

Das quarenta e duas (42) variáveis extraídas da base de dados do censo de 2010 do IBGE que foram avaliadas como adequadas para o cálculo do Índice de Vulnerabilidade Social, as trinta e nove (39) variáveis registradas no Quadro 4 são as variáveis finais resultado da normalização e computação das variáveis cruas em proporções e funções de densidade.

Quadro 4. Variáveis usadas para o cálculo do índice de vulnerabilidade social.

\begin{tabular}{|c|c|}
\hline Conceito & Descrição da variável \\
\hline \multirow{2}{*}{ Urbano/Rural } & Proporção de setores censitários urbanos \\
\hline & Densidade de domicílios particulares permanentes (\# domicílios/ $\mathrm{Km}^{2}$ ) \\
\hline \multirow[b]{2}{*}{$\begin{array}{l}\text { Status sócio-e } \\
\text { conômico }\end{array}$} & Proporção de aglomerados subnormais \\
\hline & $\begin{array}{l}\text { Média do número de salários mínimos mensais das pessoas responsáveis } \mathrm{p} \\
\text { or domicílios particulares permanentes }\end{array}$ \\
\hline \multirow{4}{*}{$\begin{array}{l}\text { Estrutura fami } \\
\text { liar }\end{array}$} & Número de domicílios particulares permanentes \\
\hline & Moradores em domicílios particulares permanentes \\
\hline & Média do número de moradores por domicílio \\
\hline & $\begin{array}{l}\text { Média do número de responsáveis de domicílios particulares permanentes } \\
\text { alfabetizados }\end{array}$ \\
\hline \multirow{4}{*}{$\begin{array}{l}\text { Saneamento } \\
\text { básico }\end{array}$} & $\begin{array}{l}\text { Proporção média de domicílios particulares permanentes com abastecime } \\
\text { nto de água da rede geral. }\end{array}$ \\
\hline & $\begin{array}{l}\text { Proporção média de domicílios particulares permanentes com abastecime } \\
\text { nto de água da chuva armazenada em cisterna }\end{array}$ \\
\hline & $\begin{array}{l}\text { Proporção média de domicílios particulares permanentes com outra forma } \\
\text { de abastecimento de água }\end{array}$ \\
\hline & $\begin{array}{l}\text { Proporção média de domicílios particulares permanentes com banheiro ou } \\
\text { sanitário e esgotamento sanitário via rede de esgoto ou pluvial }\end{array}$ \\
\hline
\end{tabular}




\begin{tabular}{|c|c|}
\hline & $\begin{array}{l}\text { Proporção média de domicílios particulares permanentes com banheiro ou } \\
\text { sanitário e esgotamento sanitário via fossa séptica }\end{array}$ \\
\hline & $\begin{array}{l}\text { Proporção média de domicílios particulares permanentes com banheiro ou } \\
\text { sanitário e esgotamento sanitário via fossa rudimentar }\end{array}$ \\
\hline & $\begin{array}{l}\text { Proporção média de domicílios particulares permanentes com banheiro ou } \\
\text { sanitário e esgotamento sanitário via vala }\end{array}$ \\
\hline & $\begin{array}{l}\text { Proporção média de domicílios particulares permanentes com banheiro ou } \\
\text { sanitário e esgotamento sanitário via rio, lago ou mar }\end{array}$ \\
\hline & $\begin{array}{l}\text { Proporção média de domicílios particulares permanentes com banheiro ou } \\
\text { sanitário e esgotamento sanitário via outro escoadouro }\end{array}$ \\
\hline & $\begin{array}{l}\text { Proporção média de domicílios particulares permanentes com lixo coleta } \\
\text { do }\end{array}$ \\
\hline & $\begin{array}{l}\text { Proporção média de domicílios particulares permanentes com lixo coletad } \\
\text { o } \\
\text { por serviço de limpeza }\end{array}$ \\
\hline & $\begin{array}{l}\text { Proporção média de domicílios particulares permanentes com lixo coletad } \\
\text { o } \\
\text { em caçamba de serviço de limpeza }\end{array}$ \\
\hline & $\begin{array}{l}\text { Proporção média de domicílios particulares permanentes com lixo queima } \\
\text { do na propriedade }\end{array}$ \\
\hline & $\begin{array}{l}\text { Proporção média de domicílios particulares permanentes com lixo enterra } \\
\text { do na propriedade }\end{array}$ \\
\hline & $\begin{array}{l}\text { Proporção média de domicílios particulares permanentes com lixo jogado } \\
\text { em terreno baldio ou logradouro }\end{array}$ \\
\hline & $\begin{array}{l}\text { Proporção média de domicílios particulares permanentes com lixo jogado } \\
\text { em rio, lago ou mar }\end{array}$ \\
\hline & $\begin{array}{l}\text { Proporção média de domicílios particulares permanentes com outro destin } \\
\text { o } \\
\text { de lixo }\end{array}$ \\
\hline & $\begin{array}{l}\text { Proporção média de domicílios particulares permanentes com energia } \\
\text { Elétrica }\end{array}$ \\
\hline & $\begin{array}{l}\text { Proporção média de domicílios particulares permanentes com energia } \\
\text { elétrica de companhia distribuidora }\end{array}$ \\
\hline & $\begin{array}{l}\text { Proporção média de domicílios particulares permanentes com energia } \\
\text { elétrica de outras fontes }\end{array}$ \\
\hline & Proporção de domicílios particulares permanentes sem energia elétrica \\
\hline Educação & $\begin{array}{l}\text { Média do número de responsáveis de domicílios particulares permanentes } \\
\text { não-alfabetizados }\end{array}$ \\
\hline & Pessoas alfabetizadas com 5 ou mais anos de idade \\
\hline$P_{a}$ & Proporção de residentes com cor ou raça branca \\
\hline Raça & Proporção de residentes com cor ou raça diferente de branca \\
\hline & Proporção de crianças com menos de 5 anos \\
\hline & Proporção de Homens \\
\hline Idade/Gênero & Proporção de Idosos com mais de 64 anos \\
\hline & Proporção de Mulheres entre 5 y 15 anos \\
\hline & Proporção de Mulheres \\
\hline
\end{tabular}

O grupo de variáveis no conjunto chamado de saneamento básico, não 
representam de maneira direta a base teórica descrita por CUTTER (2003) e a sua descrição dos fatores que influenciam a vulnerabilidade social aos desastres naturais. No entanto, são fatores considerados importantes na avaliação e controle da vulnerabilidade da população às doenças infecciosas, e em consequência são importantes para o contexto avaliado neste projeto.

\section{b. Análise estatística}

Após a normalização das variáveis e as provas de multicolinearidade, foram excluídas entre as variáveis consideradas potencialmente importantes para o estudo (por exemplo o número de mulheres residentes e a proporção de domicílios conectados à rede de esgoto), as que apresentavam problemas de multicolinearidade. Outras variáveis não foram levadas em conta porque no momento de ser testadas com os estatísticos de KMO e Bartlett, não resultaram consideradas como aplicáveis para o cálculo da análise de componentes principais do modelo avaliado. Todas as variáveis não consideradas são apresentadas no Apêndice I. No final, dez (10) variáveis foram avaliadas para 182 das 186 bacias do município.

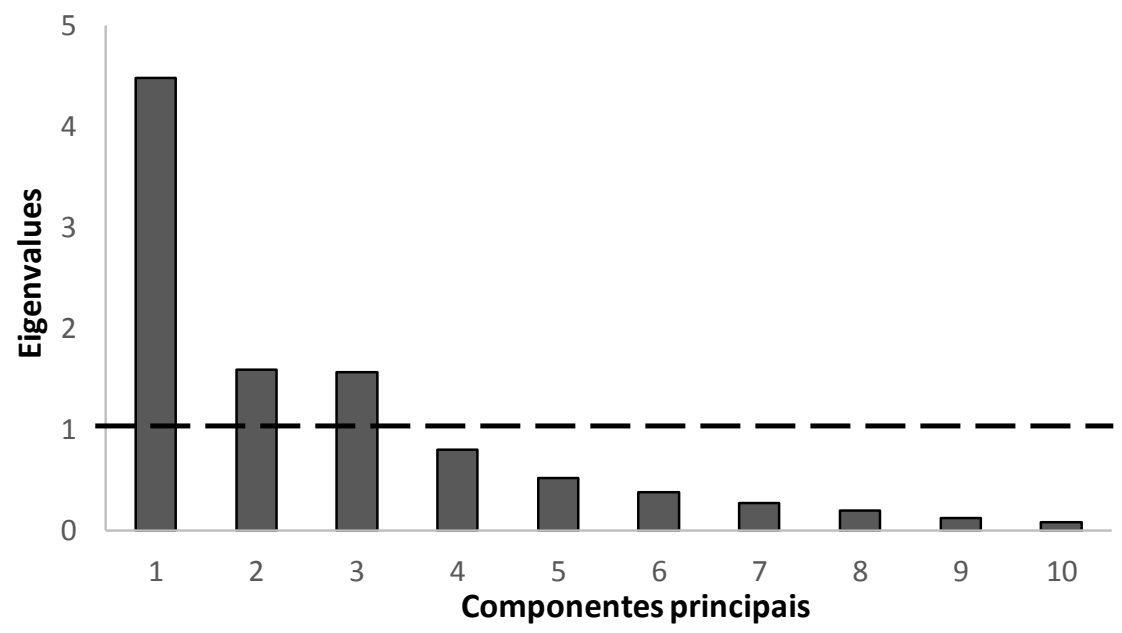

Figura 11. Scree plot da análise de componentes principais mostrando os eigenvalores

No estudo de caso realizado para a cidade de São Paulo, os valores de KMO da matriz de variáveis final é maior do que $0.7^{12}$, e os resultados do teste de esfericidade de

\footnotetext{
${ }^{12}$ Valor próximo de um (1)
} 
Bartlett são significativos $(d f=78, p<0.05)^{13}$. De acordo com o critério de Kaiser (eigenvalores maiores do que 1; mostrados na Figura 11) para o modelo avaliado, da análise com as dez (10) variáveis escolhidas, resultaram três (3) componentes principais.

Tabela 2. Componentes principais, variáveis e porcentagens explicadas por eles.

\begin{tabular}{|c|c|c|c|c|c|}
\hline $\begin{array}{l}\text { Componente } \\
\text { (CP) }\end{array}$ & Signo & Métrica & Variável & Cargas & $\begin{array}{c}\text { \% da } \\
\text { variância } \\
\text { Explicada }\end{array}$ \\
\hline \multirow{6}{*}{$\begin{array}{c}\text { Componente } \\
\text { Principal } \\
1\end{array}$} & \multirow[t]{6}{*}{ Abs* } & Raça ou etnia & Proporção de brancos & $-0,53$ & \multirow{6}{*}{$43 \%$} \\
\hline & & \multirow{2}{*}{ Idade } & Proporção de crianças & 0,90 & \\
\hline & & & Proporção de Idosos & $-0,88$ & \\
\hline & & \multirow[t]{2}{*}{ Gênero } & Proporção de mulheres 5 e 15 & 0,93 & \\
\hline & & & $\begin{array}{l}\text { Proporção de mulheres } \\
\text { responsáveis }\end{array}$ & $-0,82$ & \\
\hline & & $\begin{array}{l}\text { Estrutura } \\
\text { familiar }\end{array}$ & Moradores por Domicilio & 0,89 & \\
\hline \multirow{3}{*}{$\begin{array}{c}\text { Componente } \\
\text { Principal } \\
2\end{array}$} & \multirow[t]{3}{*}{-} & Status & Renda em salários mínimos & 0,85 & \multirow{3}{*}{$17 \%$} \\
\hline & & $\begin{array}{l}\text { socioeconômi } \\
\text { co }\end{array}$ & & & \\
\hline & & Urbano/Rural & Densidade de domicílios & 0,93 & \\
\hline \multirow{2}{*}{$\begin{array}{c}\text { Componente } \\
\text { Principal } \\
\mathbf{3}\end{array}$} & \multirow[t]{2}{*}{ Abs* } & \multirow[t]{2}{*}{$\begin{array}{l}\text { Saneamento } \\
\text { básico }\end{array}$} & $\begin{array}{l}\text { Proporção domicílios na Rede } \\
\text { Geral }\end{array}$ & 0,89 & \multirow{2}{*}{$16 \%$} \\
\hline & & & $\begin{array}{l}\text { Proporção domicílios com } \\
\text { eletricidade }\end{array}$ & 0,88 & \\
\hline \multicolumn{3}{|c|}{$\begin{array}{l}\text { Cálculo dos escores fatoriais totais } \\
{ }^{*} \text { Abs }\left(\text { Absoluto }^{14}\right)\end{array}$} & $\mathrm{CP} 1-\mathrm{CP} 2+\mathrm{CP} 3$ & & \\
\hline
\end{tabular}

Como pode ser observado na Tabela 2, os três (3) componentes principais encontrados incluem a idade, o gênero, a raça ou etnia, a estrutura familiar, a renda média e as necessidades básicas satisfeitas ou variáveis de saneamento básico. No total, estas variáveis representam o $76 \%$ da variabilidade social do município.

Quando comparados, encontra-se que a maior força entre os componentes se encontra no componente 1 que está constituído pela estrutura etária (Proporção de

\footnotetext{
${ }^{13}$ Que faz com que rejeitemos a hipótese nula do teste de que a matriz de correlação é diferente da matriz de identidade e concluir que existem correlações no conjunto de variáveis apropriadas para a análise de componentes principais. Quer dizer, que as variáveis não são completamente ortogonais (RAKOTOMALALA, 2013).

${ }^{14}$ Foi dado o nome de absoluto, no entanto não representa o valor absoluto do número mas a não designação de um signo único para os escores obtidos para esse componente.
} 
crianças e idosos), o gênero (a proporção de mulheres responsáveis e a proporção de mulheres de entre 5 e 15 anos), a estrutura familiar (representada por a média de moradores por domicilio) e a raça ou etnia (proporção de brancos) que juntos explicam o $43 \%$ da variação da vulnerabilidade entre as bacias hidrográficas estudadas. A renda (renda média mensal em número de salários mínimos) e a densidade de domicílios (Número de domicílios por quilômetro quadrado), constituem o segundo componente principal e explicam o $17 \%$ da variabilidade. A proporção de domicílios conectados à rede geral de abastecimento de água e à rede elétrica conformam o terceiro dos componentes, explicando $16 \%$ da variabilidade.

O componente um (1), está dominado ${ }^{15}$ pelos indicadores idade e gênero, seguidos da estrutura familiar e finalmente pelo indicador raça ou etnia. Os dois primeiros indicadores possuem cargas ou pesos positivos e negativos, que indicam como as variáveis analisadas se comportam dentro do componente. Assim, no indicador idades por exemplo, a proporção de crianças varia de maneira inversa à proporção de idosos. O que isto significa na análise prática é que uma bacia hidrográfica com uma proporção grande de crianças terá uma proporção pequena de idosos. Mesma coisa acontece com as proporções de mulheres entre cinco (5) e quinze (15) anos e a proporção de mulheres responsáveis.

No caso do indicador raça ou etnia, o peso ou carga negativa indica que quando o componente principal 1 tenha um valor alto, a bacia hidrográfica terá uma proporção de pessoas de raça branca menor. No entanto, o peso que tem este indicador dentro do componente é pequeno comparado com os valores dos outros indicadores e por tanto tem um efeito pequeno. Dessa forma, pode-se esperar que nos casos onde os scores do componente 1 sejam grandes, não exista uma diferença representativa no número de pessoas brancas e pessoas de outras raças. Por tanto, o componente 1 pode representar bacias com grandes proporções de mulheres entre cinco (5) e quinze (15) anos, grandes proporções de crianças e domicílios de famílias numerosas ou bacias com grandes proporções de idosos, grandes proporções de mulheres responsáveis e domicílios onde residem famílias pouco numerosas. Devido à grande quantidade de informação que fornece este componente, decidiu-se que para o cálculo do Índice de Vulnerabilidade

\footnotetext{
${ }^{15}$ Aquelas variáveis descritas como dominantes foram aquelas com cargas maiores ou iguais a 0.6 , um limite arbitrário somente criado para a descrição dos componentes encontrados.
} 
Social, os scores conservaram o sinal que for atribuído na análise estatista pelo programa $\mathrm{R}$.

O segundo componente encontrado, identifica um grupo de unidades de estudo com altas densidades de domicílios por quilómetro quadrado e altas médias do número de salários mínimos mensais recebidos pelas pessoas responsáveis pelos domicílios. Isto é, um grupo de bacias nas que as características socioeconômicas da população permitem acesso a melhores condições de moradia e indiretamente, indicam melhor acesso a serviços de educação e saúde. Uma alta renda somada a densidades altas de domicílios por quilômetro quadrado que caracterizam estas bacias, reduzem a vulnerabilidade social, razão pela qual para o cálculo final do Índice de Vulnerabilidade Social, o sinal negativo foi atribuído ao componente.

Segundo os resultados obtidos da análise de componentes principais observado na Tabela 2, o terceiro componente descreve bacias hidrográficas com uma grande proporção de domicílios conectados à rede geral de abastecimento de água e uma grande proporção de domicílios conectados à rede elétrica. Isto sugere indiretamente, que existe acesso a melhores condições de saneamento básico (por exemplo conexão à rede de esgoto e coleta de lixo). No entanto, sendo este último componente um indicador das condições sanitárias e de qualidade de vida da população, considera-se que o score fatorial que tenha resultado do cálculo do PCA para cada bacia, representa condições únicas dentro desse território e nessa ordem de ideias, contribuirá com o aumento ou diminuição da vulnerabilidade dentro de cada unidade de estudo de maneira particular. Dessa forma, decidiu-se que cada score fatorial deveria conservar o sinal particular atribuído pelo programa $\mathrm{R}$ para cada bacia.

Uma vez computado o índice de vulnerabilidade social, isto é, uma vez aplicada a formula resultante da análise anteriormente descrita para cada componente e anotada na Tabela 2, foi construído um mapa mostrando os valores resultantes do índice. Usaram-se duas formas de visualização dos resultados:

A. Usando o desvio padrão dos valores para mostrar a variabilidade do Índice de Vulnerabilidade calculado ao longo da área estudada (Figura 12A). 
B. Como os valores do Índice de Vulnerabilidade Social desviam muito pouco da média na maioria das bacias avaliadas, um segundo mapa foi feito mostrando os resultados do índice de vulnerabilidade divididos em 5 quantis (Figura 12B).

Observa-se que a série dos valores do índice, varia entre menos doze virgula quarenta $(-12,40)$ e quatorze virgula um $(14,1)$. A média dos valores é de menos zero virgula vinte e dois $(-0,22)$ e o desvio padrão de um virgula setenta e dois $(1,72)$. As bacias hidrográficas com valores do índice maiores do que 1,5 desvios padrão, são consideradas como as mais vulneráveis (Vulnerabilidade Alta e Muito alta). A Figura 13 mostra os mapas construídos. 


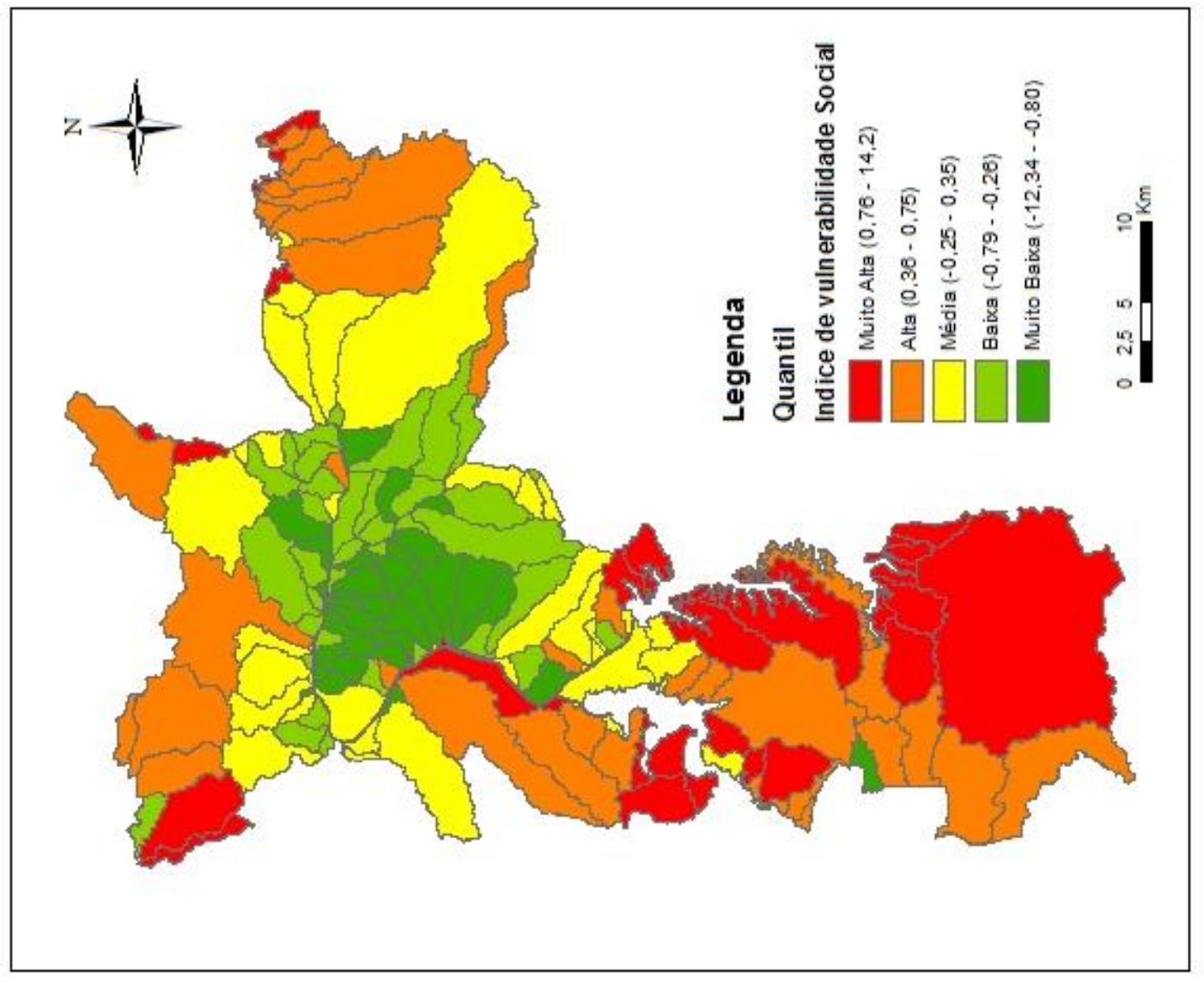

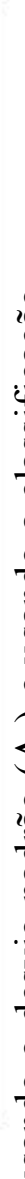

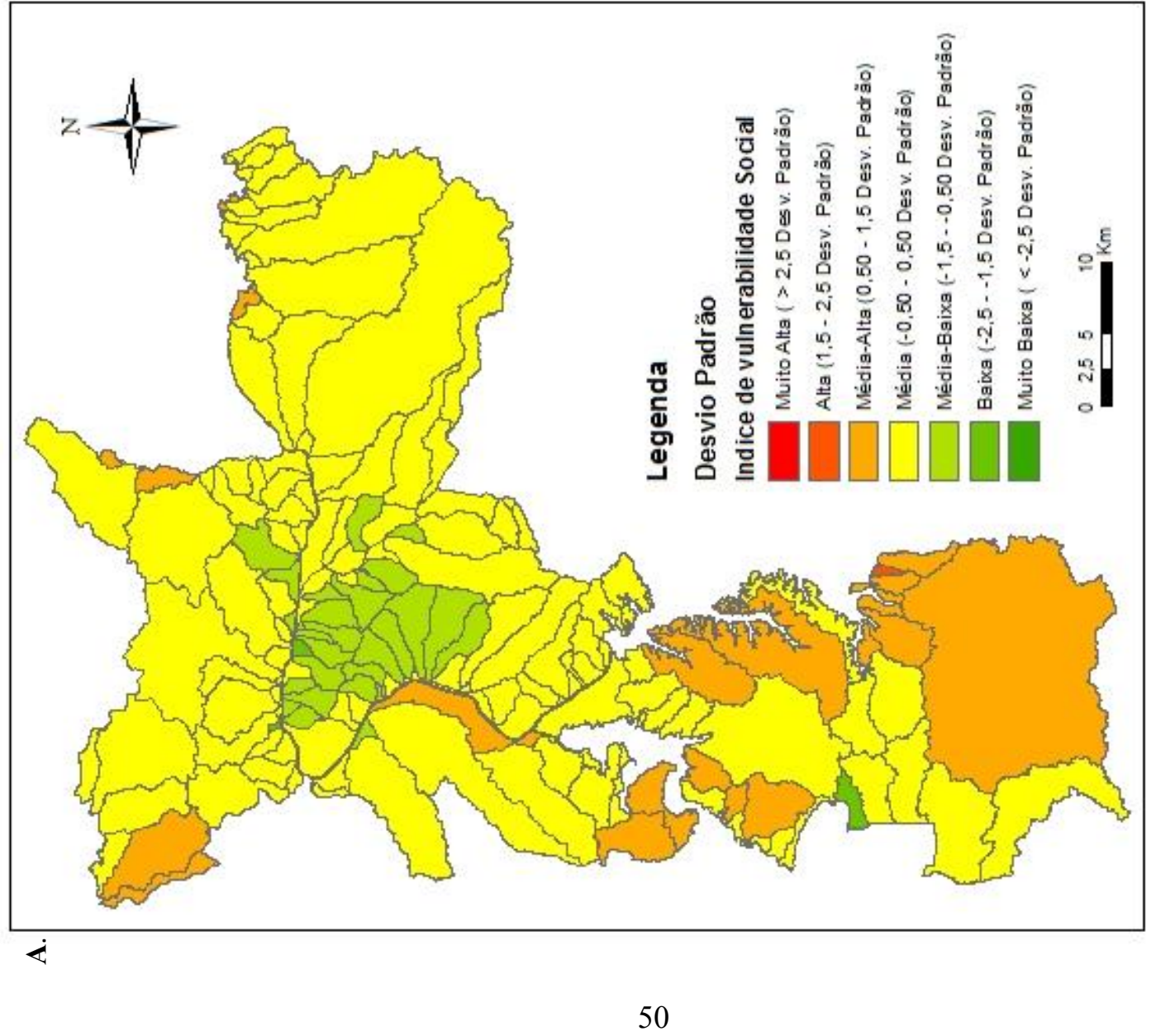

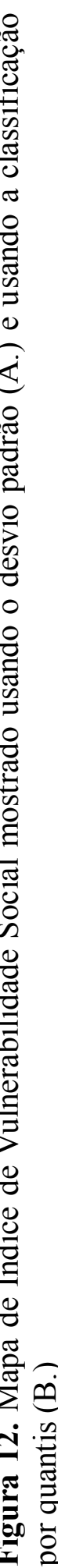


No caso do mapa hierarquizado pelo desvio padrão só uma (1) bacia aparece classificada dentro da vulnerabilidade muito alta (apenas $0,5 \%$ do total de bacias estudadas), esta é a chamada "bacia. do Dreno de Brooklin/Uberaba" (bacia número 72, apêndice III), localizada na zona sul do município, no distrito de Itaim Bibi. A vulnerabilidade alta aparece em duas (2) bacias que representam um virgula um por cento $(1,1 \%)$ do total de unidades estudadas. Elas são a "bacia Uberaba/Sapateiro" (número 71, apêndice III), localizada na zona sul do município no distrito Itaim Bibi, seguida da "bacia de contribuição direta Billings" (número 1, apêndice III), localizada também na zona sul do município no distrito Parelheiros.

A alta vulnerabilidade social é acionada por forças diferentes em cada bacia. Dessa maneira, scores fatoriais altos no componente 3 (CP3) saneamento básico, levam a uma vulnerabilidade muito alta no caso da bacia do Dreno de Brooklin/Uberaba e a uma vulnerabilidade alta na bacia Uberaba/Sapateiro. Entretanto, para a bacia de contribuição direta Billings, o Índice de Vulnerabilidade Social alto deve-se ao score fatorial significativamente alto para o Componente 1 (CP1), Indicadores demográficos. A Tabela 3 mostra os scores fatoriais de cada uma das bacias referidas e uma representação da contribuição descrita que cada um desses scores faz no Índice de Vulnerabilidade social resultante.

Tabela 3. Scores fatoriais e Índice de Vulnerabilidade social das bacias hidrográficas com SoVI classificado como alto e muito alto.

\begin{tabular}{lrrrr}
\hline \multicolumn{1}{c}{ Bacia } & CP1 & CP2 & CP3 & SoVI \\
\hline 1. Contr. Direta Billings & 3,844102 & $-0,194944$ & $-0,002827$ & 4,0362193 \\
71. Bacia Uberaba/ Sapateiro & 0,5480383 & $-0,113002$ & 2,3238923 & 2,9849325 \\
72. Bacia Dreno do Brooklin/ Uberaba & 1,6288554 & $-0,032672$ & 12,544392 & 14,205919 \\
\hline
\end{tabular}

Continuando com a análise, observa-se que uma (1) bacia hidrográfica foi classificada como a menos vulnerável (vulnerabilidade muito baixa), a bacia chamada de “Aclimação/Moringuinho" cuja área faz parte dos distritos Cambuci, Sé e Liberdade, na zona central do município (Número 23 do apêndice III). O baixo Índice de vulnerabilidade resultante pode ser explicado observando o score fatorial alto do componente 2 que descreve bacias com populações de rendas médias mensais altas e uma densidade urbana importante o que no cálculo final diminuiu consideravelmente o índice. 
Três (3) bacias foram classificadas dentro do índice de vulnerabilidade Baixa, que representam $2 \%$ do total de bacias avaliadas. Elas são a bacia "Pirituba/Fiat Lux" localizado na zona oeste do município no distrito Pirituba (Número 32 do apêndice III), a bacia “ Sumaré/Água preta” localizada na zona central no distrito Barra Funda (Número 49 do apêndice III) e a bacia "Ribeirão Grande" localizada na zona sul do município no distrito Parelheiros (Número 174 do apêndice III). As maiores contribuições na diminuição da vulnerabilidade nestas três bacias são o componente 2 (densidade de urbanização rendas, CP2) para as bacias Pirituba/Fiat Lux e Ribeirão Grande e o componente 1 (indicadores demográficos) para a bacia Intermedia Sumaré/Água preta, que neste caso descreve uma bacia com uma grande proporção de idosos e baixas médias do número de moradores por domicilio.

Na Tabela 4 estão anotados os scores fatoriais resultantes da análise de componentes principais para as bacias classificadas com vulnerabilidades sociais baixas e muito baixas. Note-se como a maior parte dos scores possuem sinal negativo para os componentes 1 e 3 e valores positivos altos para o componente 2 que, como já tem-se apontado, são tomados como negativos na hora de realizar o cálculo do Índice de Vulnerabilidade.

Tabela 4. Scores fatoriais e Índice de Vulnerabilidade social das bacias hidrográficas com SoVI classificado como baixo e muito baixo.

\begin{tabular}{lrrrr}
\hline \multicolumn{1}{c}{ Bacia } & \multicolumn{1}{c}{ CP1 } & \multicolumn{1}{c}{ CP2 } & \multicolumn{1}{c}{ CP3 } & \multicolumn{1}{c}{ SoVI } \\
\hline 23. Bacia Aclimação/ Moringuinho & $-0,320867$ & 11,915225 & $-0,100652$ & $-12,33674$ \\
32. Bacia Interm. Pirituba/ Fiat Lux & 0,2000387 & 4,3590664 & 0,36706 & $-3,791968$ \\
49. Bacia Interm. Sumaré/ Água Preta & $-2,27564$ & $-0,115922$ & $-0,580276$ & 1,8112862 \\
174. Rib. Grande & 0,6875871 & 4,1675714 & $-0,254396$ & $-3,73438$ \\
\hline
\end{tabular}

Perto de $15 \%$ das bacias caíram dentro da classificação de vulnerabilidade médiaalta. A maior parte delas apresenta scores altos do componente 1 assim como scores baixos do componente 2. Isto é, bacias caracterizadas por altas proporções de crianças, altas proporções de meninas entre cinco (5) e quinze (15) anos, domicílios albergando famílias numerosas, proporções de renda média mensal baixas e/ou níveis de urbanização baixos que podem representar, indiretamente, menores condições de saneamento e acesso a serviços de educação e saúde. 
Muitas das unidades de estudo presentes dentro de esta classificação, se encontram nos limites do município com outras cidades da região metropolitana em distritos como Anhanguera, Jardim Ângela, Parelheiros, Marsilac, Grajaú, Vila Jacuí, Tremembé, Jaçanã e Jardim Helena. São a exceção a bacia Morro do "S”/Pirajussara localizada próximo a zona central do município (número 83 no mapa do apêndice III), e a bacia Ponte baixa/Morro do "S" vizinha da bacia anteriormente descrita (número 81 no mapa do apêndice III). A Tabela 5 mostra os scores fatoriais das bacias descritas. Os números que precedem os nomes das bacias são as etiquetas utilizadas no mapa do apêndice III.

Tabela 5. Scores fatoriais e Índice de Vulnerabilidade social das bacias hidrográficas com SoVI classificado como média-alta.

\begin{tabular}{|c|c|c|c|c|}
\hline Bacia & CP1 & CP2 & CP3 & SoVI \\
\hline 2. Bacia Capivari/ Taquacetuba & 2,32440 & $-0,12070$ & $-0,12560$ & 2,31950 \\
\hline 3. Bacia Taquacetuba/ Vermelho & 1,10160 & $-0,05430$ & $-0,21920$ & 0,93670 \\
\hline 4.Bacia Varginha/ Cacaia & 1,36950 & $-0,07730$ & $-0,07130$ & 1,37550 \\
\hline 8. Bacia Embu Mirim/ Guarapiranga & 1,32510 & $-0,07820$ & $-0,19620$ & 1,20710 \\
\hline 9. Bacia Embu Mirim/ Itupu & 0,94180 & $-0,07230$ & $-0,19870$ & 0,81540 \\
\hline 11. Bacia Engordador/ Tremembé & 1,22870 & $-0,11640$ & $-0,16360$ & 1,18150 \\
\hline 14. Bacia Engordador/ Barrocada & 1,69040 & $-0,38510$ & $-0,44880$ & 1,62670 \\
\hline 58. Bacia Jacu/ Mongaguá & 1,05750 & $-0,10440$ & $-0,11750$ & 1,04440 \\
\hline 61. Bacia São Martinho/ Água Vermelha & 1,41170 & $-0,05490$ & $-0,18380$ & 1,28280 \\
\hline 62. Bacia Lageado/ São Martinho & 1,48130 & $-0,07250$ & $-0,13320$ & 1,42060 \\
\hline 63. Bacia Itaim/ Lageado & 1,34180 & $-0,10930$ & $-0,00120$ & 1,44990 \\
\hline 81. Bacia Ponte Baixa/ Morro do '"'S'"' & 0,98410 & $-0,09920$ & $-0,10380$ & 0,97950 \\
\hline 83. Bacia Morro do '"'S'"'/ Pirajussara & 0,39960 & $-0,14040$ & 1,17940 & 1,71940 \\
\hline 142. Córr. Embu Mirim & 1,24850 & $-0,06490$ & $-0,12880$ & 1,18460 \\
\hline 143. Rio Curucutu & 1,65340 & $-0,11450$ & $-0,23780$ & 1,53010 \\
\hline 145. Rio Cocaia & 0,98000 & $-0,10490$ & $-0,18430$ & 0,90060 \\
\hline 150. Rib. Varginha & 1,13910 & $-0,09850$ & $-0,29540$ & 0,94220 \\
\hline 155. Córr. do Itaim & 1,45210 & $-0,08780$ & $-0,11620$ & 1,42370 \\
\hline 156. Córr. Santa Fé & 1,02510 & $-0,09610$ & $-0,16100$ & 0,96020 \\
\hline 160. Bacia Jusante Córr. Golfe Clube & 1,30710 & $-0,11280$ & $-0,00260$ & 1,41730 \\
\hline 161. Rib. Vermelho & 1,08850 & $-0,07420$ & $-0,36820$ & 0,79450 \\
\hline 163. Rib. Taquacetuba & 1,59480 & $-0,10820$ & $-0,21640$ & 1,48660 \\
\hline 173. Bacia Capivari / Curucutu & 1,59390 & $-0,08020$ & $-0,09880$ & 1,57530 \\
\hline 176. Córr. Golfe Clube & 1,18320 & $-0,14520$ & $-0,35650$ & 0,97190 \\
\hline 177. Contr. Montante Rib. Parelheiros & 0,80900 & $-0,10680$ & $-0,05140$ & 0,86440 \\
\hline 184. Rio Capivari & 1,10990 & $-0,12350$ & $-0,31780$ & 0,91560 \\
\hline
\end{tabular}

Observa-se também que trinta e uma (31) bacias das 182 avaliadas, isto é 
dezessete por cento $17 \%$ do total, foram classificadas com uma vulnerabilidade social média-baixa. Todas elas caracterizadas por scores fatoriais abaixo de zero para o componente 1, o que indica bacias caracterizadas por grandes proporções de idosos e com médias de moradores por domicilio pequenas. Os scores igualmente negativos mas visivelmente pequenos para o componente 2 (Ver. Tabela 6), aumentam o índice de vulnerabilidade calculado para estas unidades de estudo porém não em quantidades que comprometam o efeito positivo que tem o componente 3 (saneamento básico). Todas as bacias hidrográficas antes descritas estão localizadas na região central do município em distritos como Moema, Jardim Paulista, Bela Vista, Perdizes, Pinheiros, Itaim Bibi, Consolação, Liberdade, República, Santa Cecilia, Vila Mariana, Lapa e Barra Funda.

Tabela 6. Scores fatoriais e Índice de Vulnerabilidade social de algumas das bacias hidrográficas com SoVI classificado como média-baixa.

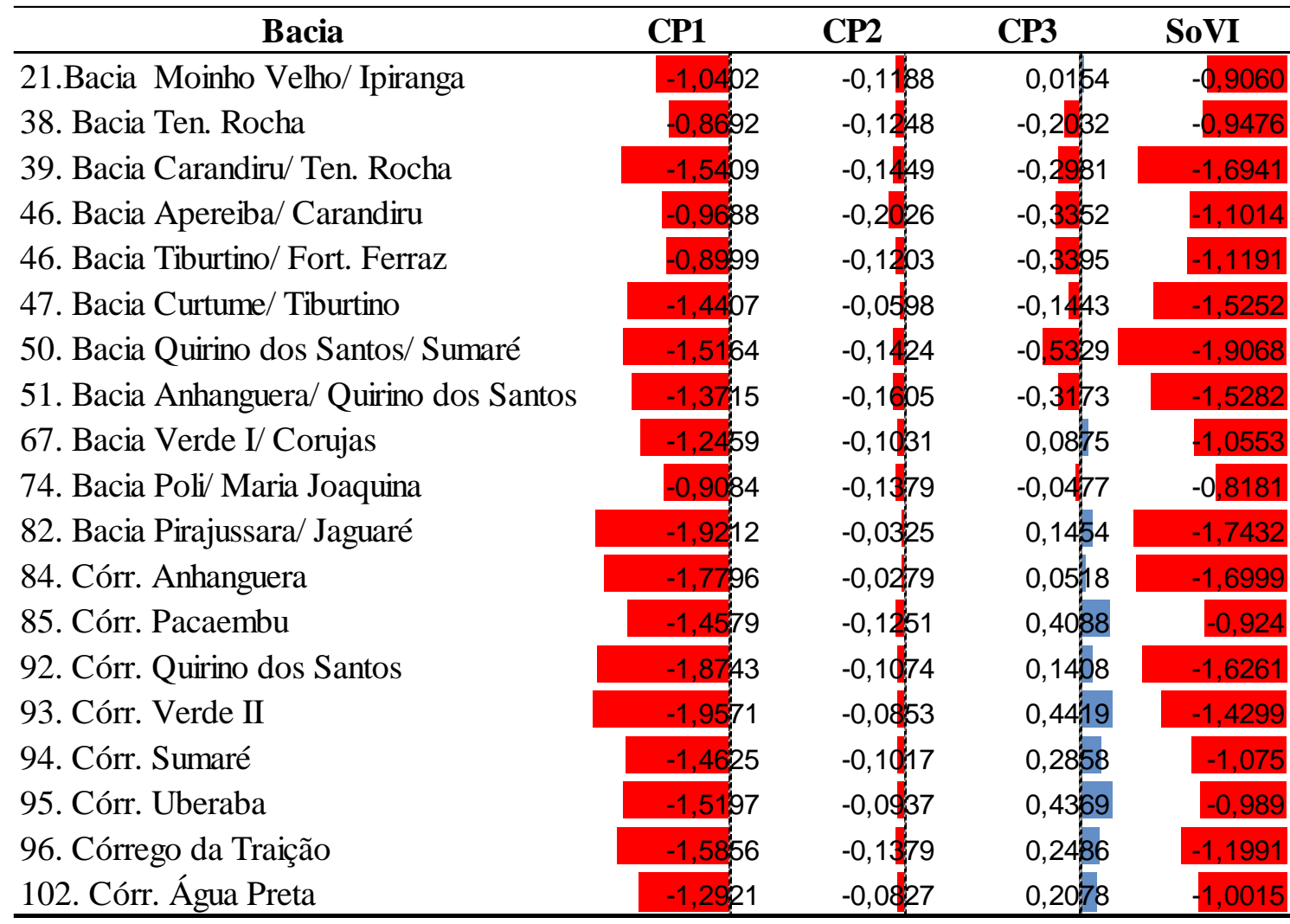

Concluindo com a descrição do achado para o Índice de Vulnerabilidade Social hierarquizado pelo desvio padrão, cento e dezessete (117) bacias, que representam $65 \%$ do total de bacias do município, foram classificadas com uma vulnerabilidade média. A maior parte delas estão localizadas nas áreas intermédias entre os limites do município 
com outros municípios da área metropolitana e o centro da cidade, em distritos como Saúde, Campo Grande, Santo Amaro, Butantã, Vila Leopoldina, Pirituba, Casa Verde e Santana entre outros.

Todas as bacias neste grupo apresentam scores negativos para o componente 2, no entanto os valores nunca ultrapassam a unidade (1) sendo a média do conjunto de escores de - 0,117. Mesma coisa acontece com o componente 3 (saneamento básico) que apresenta uma variabilidade pequena (valor máximo de 1,64 e mínimo de -0,55) e uma média de -0,110. Para o componente 1 , o valor médio para este grupo de bacias é 0,041 com um máximo de 1,14 e mínimo de -1,38, que descreve um conjunto de bacias cujo tamanho da população de crianças e idosos não apresentam uma tendência marcada. A Tabela 7 apresenta 30 das 117 bacias classificadas com Vulnerabilidade Social Média e mostra as contribuições para o cálculo de Índice de Vulnerabilidade Social antes descritas.

Tabela 7. Scores fatoriais e Índice de Vulnerabilidade social das bacias hidrográficas com SoVI classificado como média.

\begin{tabular}{|c|c|c|c|c|}
\hline Bacia & CP1 & CP2 & CP3 & SoVI \\
\hline 6. Golfe Clube & 0,7065641 & $-0,137$ & $-0,450$ & 0,3936036 \\
\hline 7. Contr. Direta Guarapiranga & 0,1744524 & $-0,11$ & $-0,21$ & 0,0717918 \\
\hline 10. Contr. Direta Sul Rio Cabuçu de Cima & 0,0098449 & $-0,1$ & $-0,22$ & $-0,099497$ \\
\hline 12. Tremembé/ Paciência & 0,1979428 & -0 , & $-0,2 \underline{3}$ & 0,0938567 \\
\hline 17. São MigueV/ Santa Fé & $-0,583507$ & $-0,097^{\prime}$ & $-0,30$ & 0,3805736 \\
\hline 18. Ourives/ Jaboticabal & $-0,375905$ & $-0,151$ & $-0,20$ & 0,321063 \\
\hline 19. Jaboticabal/ Moinho Velho & 0,1057402 & $-0,086^{\prime}$ & $-0,19$ & $-0,001093$ \\
\hline 20. Oratório/ Mooca & $-0,400453$ & $-0,119$ & $-0,16$ & 0,3561978 \\
\hline 22. Ipiranga/ Aclimação & $-0,771741$ & $-0,0$ & $-0,115$ & 0,7539332 \\
\hline 24. Moringuinho/ Anhangabaú & $-0,143325$ & -0 & $-0,21$ & 0,0004828 \\
\hline 25. Mooca/ Cassandoca & $-0,720126$ & $-0,112$ & $-0,09$ & 0,7377371 \\
\hline 26. Cassandoca & $-0,226606$ & $-0,060$ & $-0,2$ & 0,0809786 \\
\hline 27. Billings/Varginha & 0,8254251 & $-0,14$ & $-0,2$ & 0,7184043 \\
\hline 30. Cintra/ Vermelho & $-0,457095$ & $-0,142$ & $-0,19$ & 0,402174 \\
\hline 31. Fiat Lux/ Cintra & $-0,506241$ & $-0,174$ & $-0,122$ & 0,5582828 \\
\hline 33. Verde/ Pirituba & $-0,181259$ & $-0,119$ & $-0,152$ & 0,1483112 \\
\hline 34. Água da Pedra/ Verde & $-0,681291$ & $-0,124$ & $-0,18$ & 0,616964 \\
\hline 35. Cabuçu de Baixo/ Água da Pedra & 0,0719636 & $-0,1450$ & $-0,197002$ & 0,0199894 \\
\hline 36. Mandaqui/ Cabuçu de Baixo & $-0,328153$ & $-0,1007$ & $-0,199621$ & 0,2293001 \\
\hline
\end{tabular}



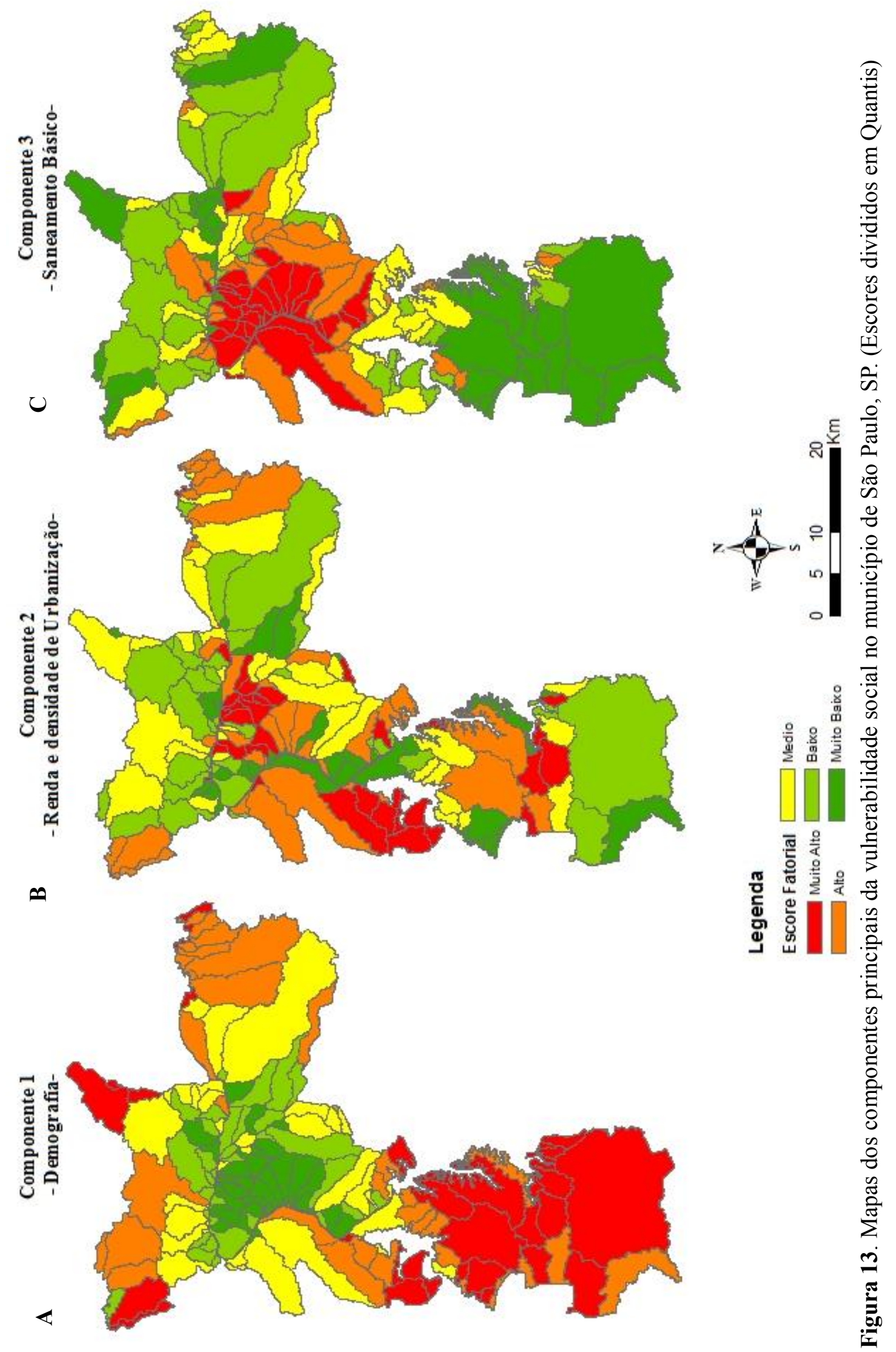
bacia São Miguel/Santa Fé, no distrito Anhanguera na zona noroeste sobre o limite do município (número 17 no mapa do apêndice III). Os valores do componente 1 vão em aumento no sentido centro-periferia, por isso os valores altos e muito altos, representados de cor laranja e vermelha no mapa da Figura $13 A$, estão sobre a zona sul e os limites do município com o resto da área metropolitana de São Paulo, com muito poucas exceções. O oposto acontece no mapa do componente 3, onde os valores dos scores aumentam no sentido periferia centro.

Assim, o componente 3 (Figura 13C), mostra que as regiões mais centrais estão mais densamente conectadas às redes de água e eletricidade do que as regiões mais afastadas do centro. Existem poucas exceções como a bacia Jacu/Mongaguá, localizada na zona nordeste do município dentro do território dos distritos Vila Jacuí e Ermelino Matarazzo (número 58 no mapa do apêndice III), a bacia do córrego do Itaim na zona noroeste no distrito Anhanguera (número 155 no mapa do apêndice III) e as bacias Jusante córrego Golfe Clube (número 160 no mapa do apêndice III) e contr. Montante Ribeirão Parelheiros (número 177 no mapa do apêndice III) ambas na zona sul no distrito de Parelheiros.

O componente 2, densidade de Urbanização e renda (Figura 13B) não possui um padrão diferenciado tão evidente quanto os outros componentes. Observam-se grupos de bacias de valores muito altos e altos no centro, sudoeste, leste e sul do município separados de grupos de valores muito baixos e baixos por conjuntos de bacias de valores médios ou valores baixos. Não existe uma distribuição geográfica apreciável que mostre uma tendência única para o componente 2. Assim, para este componente cuja maior carga está na densidade de domicílios por quilômetro quadrado e na renda média mensal, existem escores muito altos na região do M' Boi Mirim e parte do distrito de Capão redondo. Já no centro os distritos com escores muito altos estão localizados nos distritos Perdizes, República, Sé, Liberdade, Bela Vista e parte de Consolação, Santa Cecilia, Belém e Vila Mariana.

No mapa da Figura $13 B$, que representa as unidades de estudo classificadas pelo seu índice de vulnerabilidade social hierarquizado em quantis, pode-se observar como as bacias hidrográficas com índices maiores (Índice de vulnerabilidade Alto e Muito Alto), apresentam uma tendência a se localizar sobre os limites do município. O índice 
calculado, diminui da periferia do município ao centro, sendo que no centro da cidade está localizado o maior número de bacias com índices de vulnerabilidade muito baixos ($12,34--0,80)$.

\section{c. Autocorrelação espacial}

Para testar a existência de aglomerados espaciais do Índice de Vulnerabilidade Social das bacias hidrográficas do município de São Paulo, foi calculado o estatístico de Moran global $(\mathrm{I}=0,219644)$ para as bacias do município.

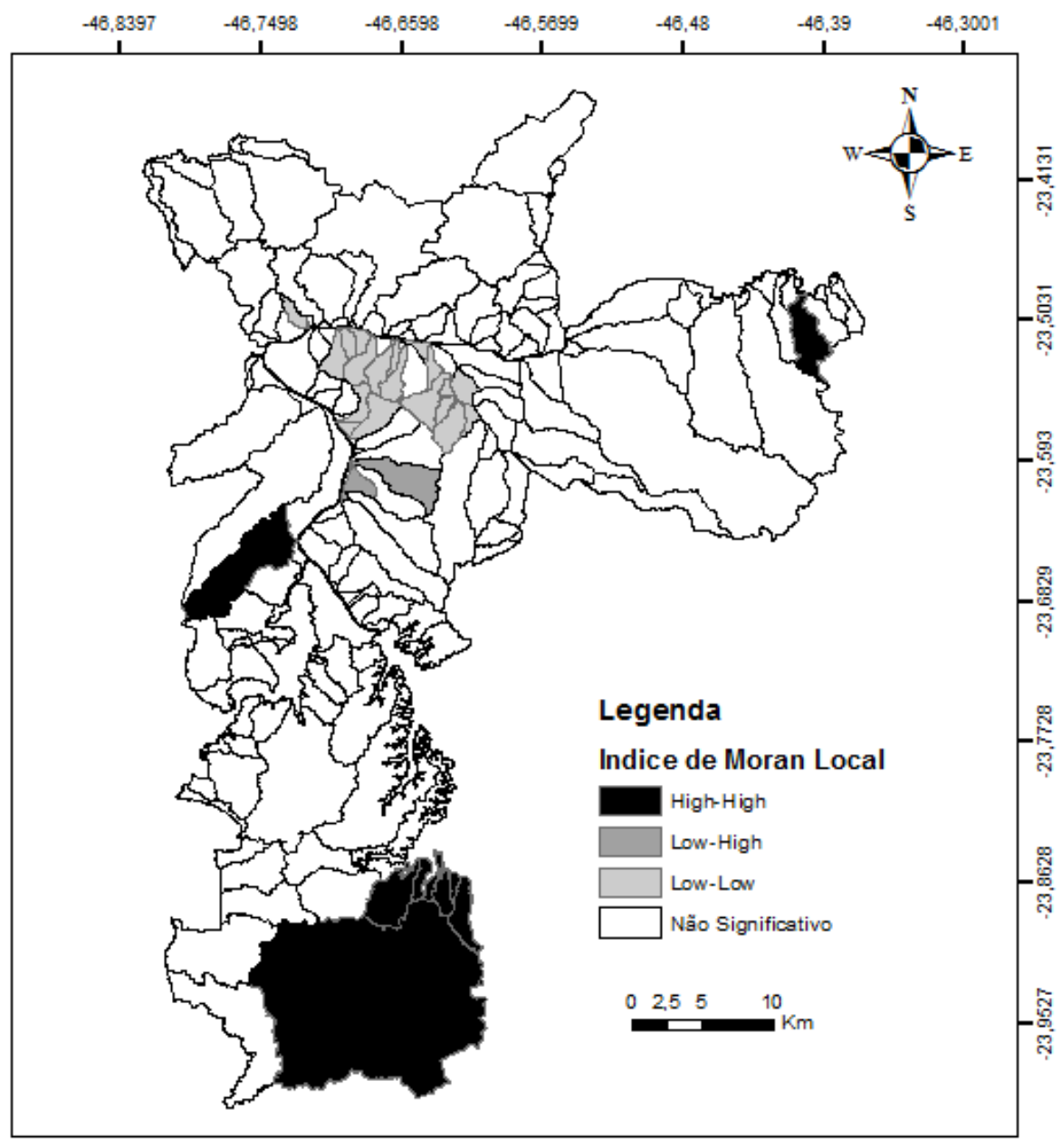

Figura 14. Mapa do índice de Moran Local para o Índice de Vulnerabilidade Social ao nível de bacias Hidrográficas. Município de São Paulo, SP.

O estatístico resultou positivo e o Z-Score foi maior do que o limite de 2,58 $(\mathrm{p}<0,001)$, isto denota que a distribuição do Índice de Vulnerabilidade Social para as bacias tem uma correlação espacial positiva significativa. 
As bacias com um Índice de Vulnerabilidade Social significativamente alto que fazem vizinhança com bacias com valores igualmente altos do Índice de Vulnerabilidade (High-High) estão aglomeradas na zona sul, sudoeste e nordeste, nos limites do município com outros municípios da área metropolitana. Do mesmo modo, as bacias hidrográficas com SoVI ${ }^{\circledR}$ significativamente baixo (Low-Low, $\left.\mathrm{p}<0,05\right)$, isto é bacias com Índices de Vulnerabilidade significativamente baixos que fazem vizinhança com bacias com valores do Índice igualmente baixos, estão aglomeradas no centro da cidade em Distritos como Lapa, Perdizes, Barra Funda, Santa Cecilia, Bom Retiro, Consolação, Bela Vista, República, Sé, Brás, Liberdade, Cambuci, Vila mariana, Jardim Paulista e Pinheiros.

No mapa da Figura 14 são identificadas também bacias que nos términos do Índice de Vulnerabilidade Social se desviam do padrão global de aglomeração de valores similares. Duas (2) bacias exibem uma associação de valores pouco similares (2 LowHigh e 0 High-Low). Cento e cinquenta e três (153) bacias hidrográficas, $84 \%$ do total de bacias avaliadas, não apresentam uma autocorrelação espacial significativa.

\subsubsection{Proporção de Autorizações de Internação Hospitalar}

A Tabela 8 apresenta o número e proporção de casos de Autorização de Internação Hospitalar dos anos 2009 e 2010 para o diagnóstico A09 do CID 10 (Diarreia e gastroenterite de origem infecciosa), segundo características demográficas. Das dois mil trezentas e trinta e sete (2337) internações registradas para 2009, sessenta e dois virgula dois por cento $(62,2 \%)$ pertence à população de crianças entre 0 e 5 anos de idade, vinte oito por cento (28\%) à população entre 6 e 64 anos e perto de dez por cento $(9,8 \%)$ referirse a população idosa com mais de 64 anos.

Para o ano 2010 as proporções de internações registradas apresentam uma distribuição similar à apresentada nos dados de 2009: Sessenta e um virgula cinco por cento $(61,5 \%)$ pertence à população de crianças entre 0 e 5 anos, vinte sete virgula nove $(27,9 \%)$ à população entre 6 e 64 anos e dez virgula seis (10,6\%) às internações registradas para idosos com mais de 64 anos. No total dois mil e novecentas e trinta e uma (2931) internações foram registradas para esse ano, isto é quinhentos e noventa e quatro (594) casos a mais do que no ano imediatamente anterior cuja maior proporção (59\%) 
foram casos somados à faixa etária de crianças.

Tabela 8. Número e proporção de Autorizações de Internação Hospitalar segundo as características demográficas. São Paulo 2009-2010.

\begin{tabular}{ccccc}
\hline & $\mathbf{2 0 0 9}$ & $\mathbf{\%}$ & $\mathbf{2 0 1 0}$ & $\mathbf{\%}$ \\
\hline $\begin{array}{c}\text { Crianças } \\
0-5\end{array}$ & 1455 & 62,2 & 1803 & 61,5 \\
$\begin{array}{c}\text { Pop. De } \\
6-64\end{array}$ & 653 & 28,0 & 817 & 27,9 \\
$\begin{array}{c}\text { Idosos } \\
>64\end{array}$ & 229 & 9,8 & 311 & 10,6 \\
\hline Total & 2337 & 100 & 2931 & 100 \\
\hline
\end{tabular}

A Tabela 9 apresenta os resultados do cálculo do Índice de Moran Global. Nela se observa que nas temporadas de chuvas dos anos 2009 e 2010 tanto para crianças quanto para idosos, os dados de proporção de Autorizações de Internação Hospitalar (AIH) apresentam padrões de agrupamento (Aglomerados). Para as temporadas secas pelo contrário, os dados para as crianças no ano 2010 e para os idosos no 2009 apresentam correlação espacial positiva mas não significativa (aleatória). Isto indica que os dados de proporções de AIH para o diagnóstico avaliado nas estações chuvosas, têm uma alta correlação espacial para os dois anos avaliados.

Tabela 9. Cálculo do Índice de Moran Global das proporções de AIH de crianças de entre 0 e 5 anos e Idosos com mais de 64 anos para os anos 2009 e 2010.

\begin{tabular}{|c|c|c|c|c|c|}
\hline $\begin{array}{l}\text { Grupo } \\
\text { etário }\end{array}$ & Ano & Estação & $\begin{array}{c}\text { Índice de } \\
\text { Moran Global } \\
\text { (I) }\end{array}$ & Z-score & $\begin{array}{l}\text { Padrão de } \\
\text { distribuição } \\
\text { espacial }\end{array}$ \\
\hline \multirow{4}{*}{ Crianças } & 2009 & Úmido & 0,2374 & $4,8249 * *$ & Aglomerado \\
\hline & & Seco & 0,1366 & $2,7552 * *$ & Aglomerado \\
\hline & 2010 & Úmido & 0,0824 & $1,7252 *$ & Aglomerado \\
\hline & & Seco & 0,0278 & 0,715 & Aleatório \\
\hline \multirow{4}{*}{ Idosos } & 2009 & Úmido & 0,4341 & $9,300 * *$ & Aglomerado \\
\hline & \multirow{3}{*}{2010} & Seco & 0,0151 & 0,414 & Aleatório \\
\hline & & Úmido & 0,0869 & $1,955^{*}$ & Aglomerado \\
\hline & & Seco & 0,1454 & $3,216^{* *}$ & Aglomerado \\
\hline
\end{tabular}

Embora a distribuição destas proporções mostra uma autocorrelação espacial positiva na maior parte dos períodos avaliados, ela varia para cada um deles. Os maiores 
índices (aqueles mais próximos a 1) se calcularam para a faixa etária acima dos 64 anos (idosos) na estação úmida do ano 2009 ( $\mathrm{I}=0,4341)$. O segundo maior índice calculado é o da estação úmida de 2009 para a faixa de crianças ( $\mathrm{I}=0,2374)$, em seguida os o índice calculado para os dados da estação seca de 2010 dos idosos $(I=0,1454)$ e por último a estação seca de 2009 para as crianças $(\mathrm{I}=0,1366)$. Outros índices significativos ficaram abaixo de 0,1 .

A Tabela 10. Mostra os resultados da análise para a detecção dos aglomerados (Moran local) para a faixa etária de crianças com menos de cinco (5) anos nas estações chuvosa e seca dos anos em estudo. Observa-se que o maior número de aglomerados detectados foi de 14 na estação úmida de 2009, seguido de 11 na estação seca do mesmo ano e 5 para a estação Úmida de 2010, valores todos encontrados para aglomerados com proporções médias de AIH significativamente altas. Isto significa que dentro do território do município de São Paulo o teste encontrou mais valores similarmente altos próximos uns de outros do que valores baixos, e que eles estão geograficamente juntos de maneira mais pronunciada do que seria esperado numa distribuição aleatória.

Tabela 10. Estadísticas de aglomerados espaciais locais, estações chuvosas e secas de 2009-2010 para a faixa etária de crianças.

\begin{tabular}{|c|c|c|c|c|}
\hline & \multicolumn{2}{|c|}{2009} & \multicolumn{2}{|c|}{2010} \\
\hline & Úmido & Seco & Úmido & Seco \\
\hline \multicolumn{5}{|c|}{ Aglomerados espaciais locais significativos $(\mathrm{p}<0,05)$} \\
\hline High-High & 14 & 11 & 5 & \multirow{5}{*}{ N/A* } \\
\hline Low-Low & 0 & 4 & 3 & \\
\hline \multicolumn{4}{|c|}{ Bacias com valores atípicos $(\mathrm{p}<0,05)$} & \\
\hline Low-High & 2 & 4 & 3 & \\
\hline High-Low & 2 & 2 & 1 & \\
\hline \multicolumn{5}{|c|}{ Bacias com aglomerados espaciais estatisticamente não significativos } \\
\hline $\begin{array}{l}\text { Número de } \\
\text { bacias }\end{array}$ & 165 & 162 & 171 & \multirow[t]{2}{*}{ N/A* } \\
\hline Total & 183 & 183 & 183 & \\
\hline
\end{tabular}

A Figura 15 expõe a localização dos aglomerados detectados para a faixa de crianças na estação úmida de 2009 e 2010. Das bacias avaliadas na estação úmida de 2009 
aquelas com valores médios do Índice de Vulnerabilidade Social significativamente alto ou High-High $(\mathrm{HH})$ estão localizadas numa faixa que atravessa o município desde o sudoeste até o sudeste descendendo continuamente na direção Sul, nos distritos de Jardim Ângela, Jardim São Luís, Socorro, Cidade Dutra e Grajaú. Em adição, foi detectado outro aglomerado na região Leste no distrito Jardim Helena. Para este conjunto particular de dados de proporção de Autorizações de Internação Hospitalar não foram detectados aglomerados de bacias com valores significativamente baixos.
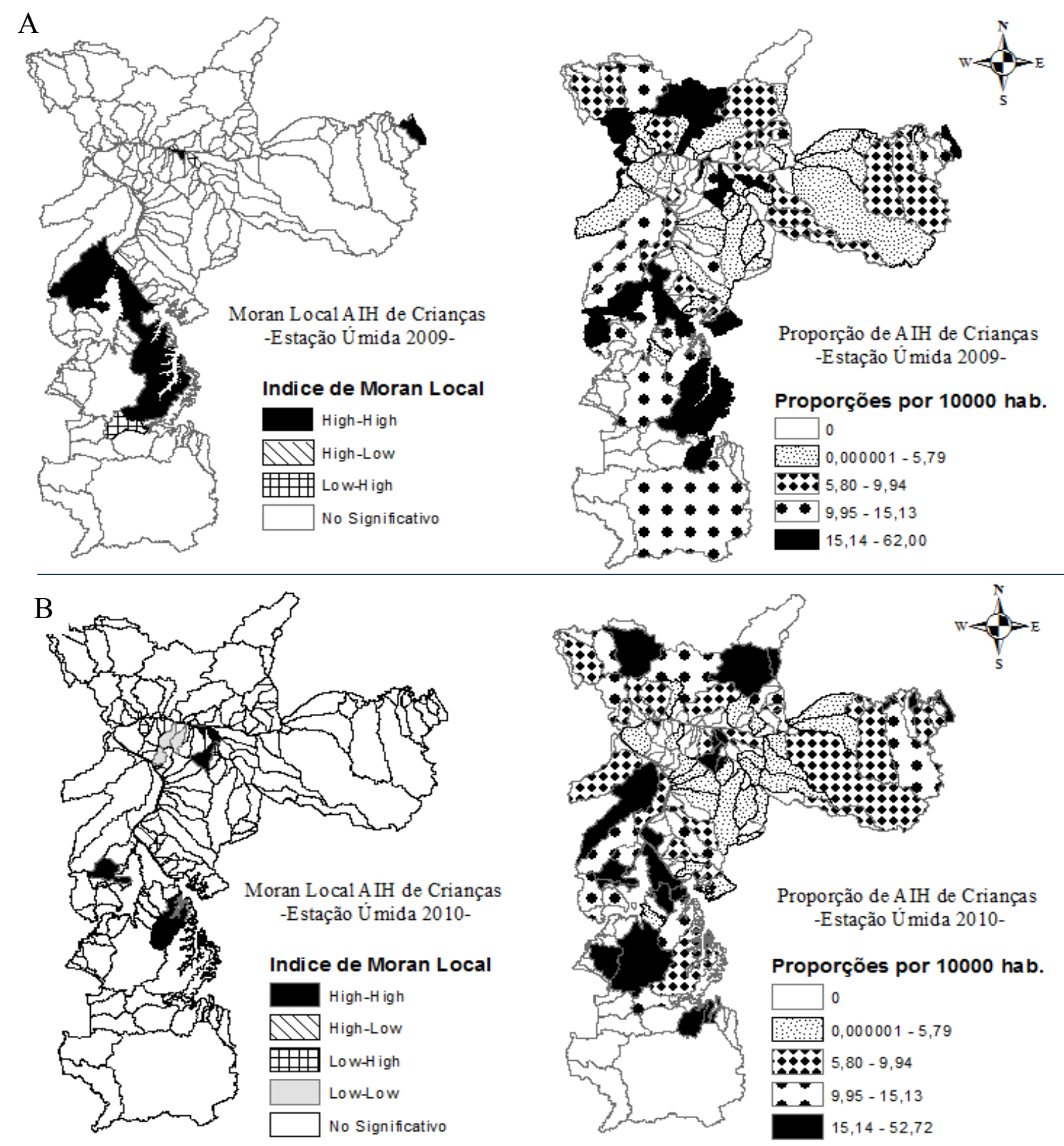

Figura 15. Mapas de proporções e aglomerados de AIH de Crianças para a estação Úmida de 2009 (A) e 2010 (B).

Continuando com a mesma faixa etária, na estação chuvosa de 2010 (Figura 
15B), os aglomerados de valores altos $(\mathrm{HH})$ continuam sendo detectados nas mesmas direções geográficas que em 2009 mas não como uma faixa continua. Além disso, foram detectados outros aglomerados no centro do município. Assim, aglomerações pequenas aparecem nas zonas sudeste e sudoeste, próximas da periferia, nos distritos Grajaú, Jardim Ângela e Jardim São Luiz. Já as bacias mais centrais estão localizadas nos distritos Bela Vista, República e Bom Retiro. Do mesmo modo, os aglomerados com proporções de AIH médias significativamente menores ou Low-Low (LL) aparecem em bacias localizadas no centro em distritos como Perdizes, Barra Funda, e Pinheiros.

A Tabela 11 mostra os resultados da análise para a detecção dos aglomerados para a faixa etária de idosos com mais de sessenta e quatro (64) anos para os dados das estações chuvosa e seca dos anos em estudo. Observa-se que o maior número de aglomerados detectados foi de cinco (5) na estação Úmida de 2009, seguido de quatro (4) na estação úmida de 2010 e três (3) para a estação Seca de 2010, valores todos encontrados para aglomerados com proporções médias de AIH significativamente altas. Isto significa que dentro do território do município de São Paulo o teste detectou, para a faixa de idosos, mais valores similarmente altos próximos uns de outros do que valores baixos.

Tabela 11. Estatísticas de aglomerados espaciais locais, estações chuvosas e secas de 2009-2010 para a faixa etária de idosos.

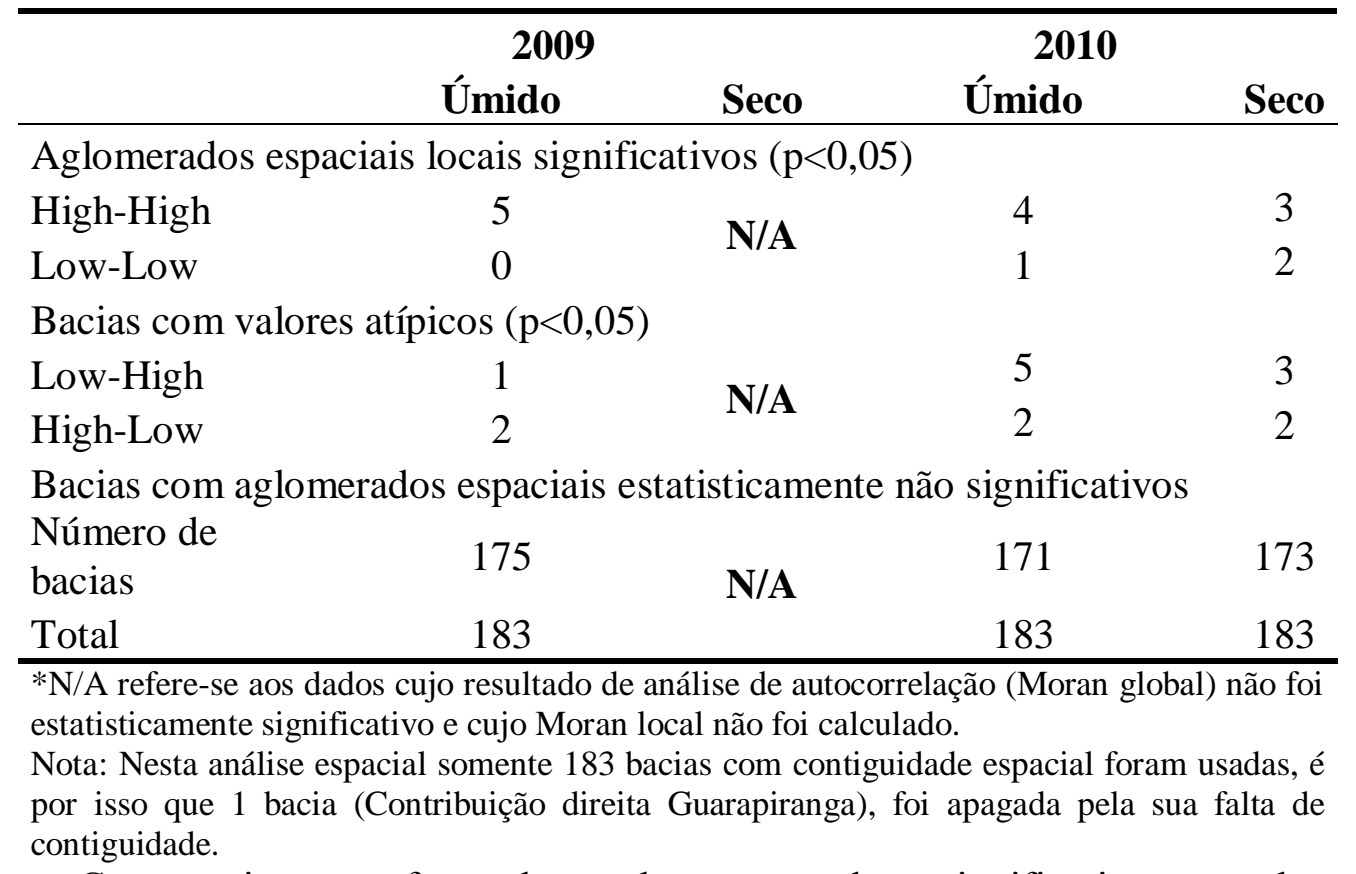

Comparativamente foram detectados menos valores significativamente altos para a faixa de crianças do que para a faixa de idosos. No entanto, em ambas as faixas o maior 
número de aglomerados pertence à categoria High-High e não existe uma diferença muito grande entre as quantidades de aglomerados encontradas para as estações Úmida e Seca.

No caso da análise de aglomeração das proporções de AIH de Idosos para a estação Úmida, existe uma intensa e significativa $(\mathrm{p}<0,05)$ aglomeração das bacias no ano 2009 ( $\mathrm{I}=0,4341)$, e menos intensa para o ano 2010 ( $\mathrm{I}=0,0869)$. Na Figura 16 se observa que o número de aglomerados encontrados para os idosos na estação úmida de 2009 e 2010 é baixo, no total apenas oito (8) aglomerados foram encontrados para o ano 2009 e doze (12) para 2010.

A

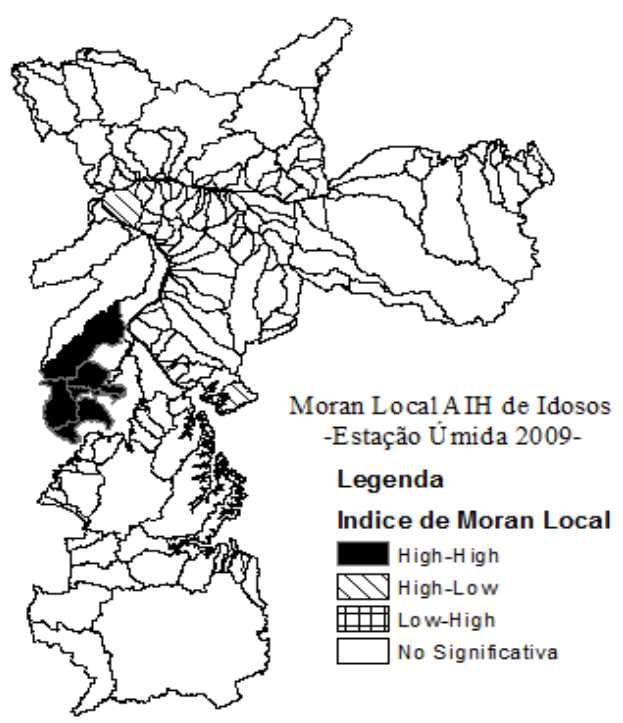

B

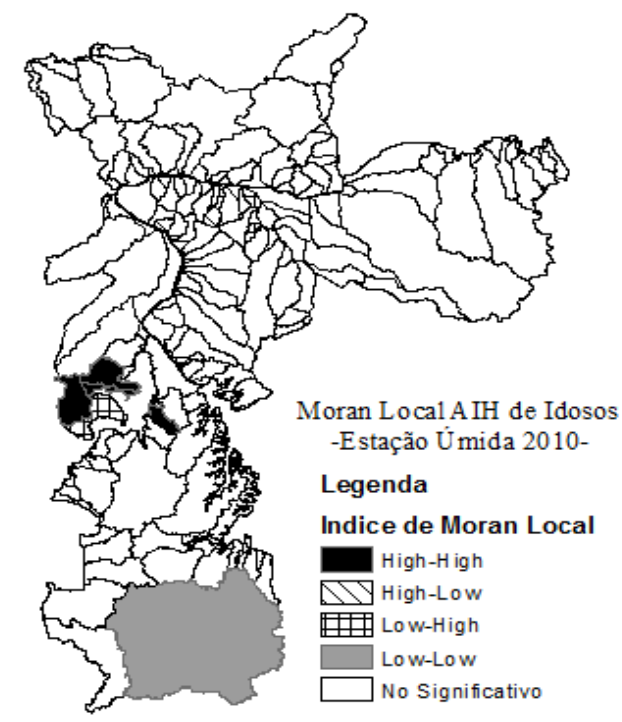

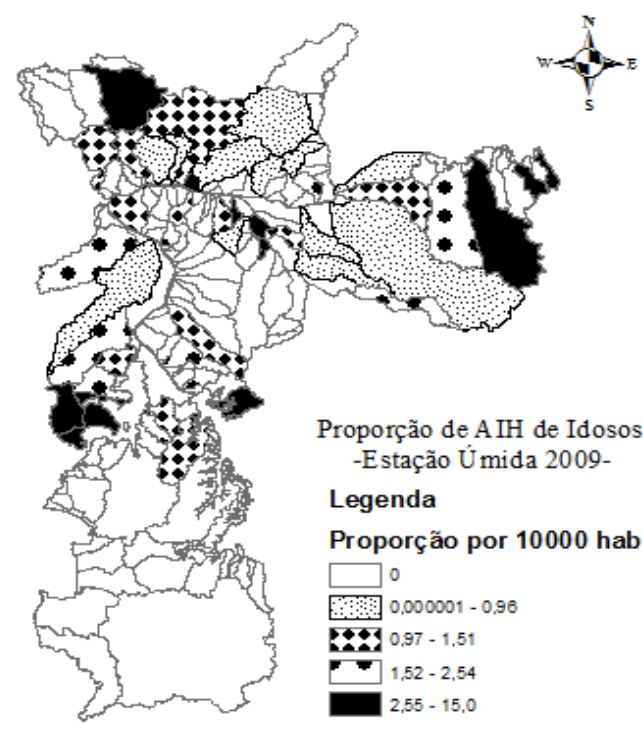

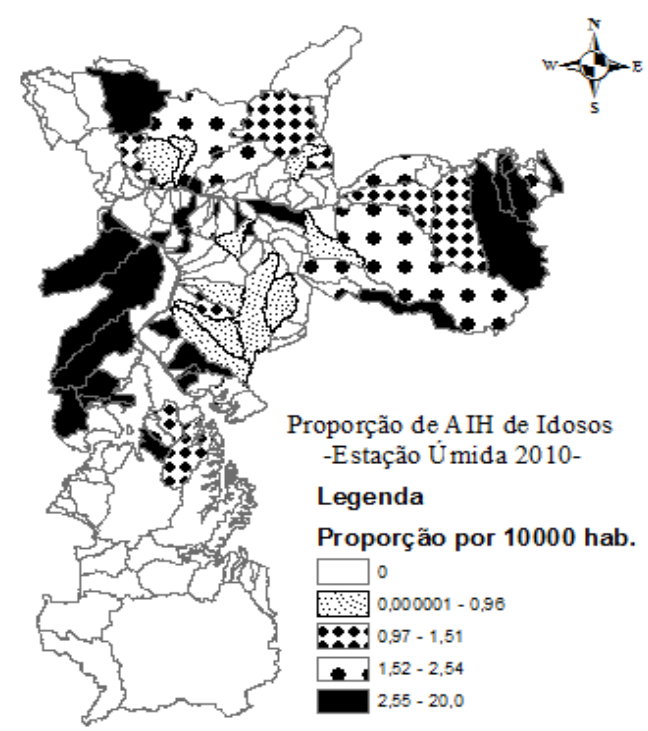

Figura 16. Mapas de proporções e aglomerados de AIH de Idosos para a estação Úmida de 2009 (A) e 2010 (B). 
Referenciando as categorias homogêneas encontradas, o maior número de aglomerados encontrados foi cinco (5) para aglomerados significativamente altos $(\mathrm{HH})$ em 2009 e quatro (4) em 2010 para a mesma categoria. Não existem aglomerados significativamente baixos ou Low-Low (LL) para o ano 2009 e só um (1) foi encontrado para a estação úmida de 2010. Comparativamente, a localização dos aglomerados $\mathrm{HH}$ muda pouco entre os anos em estudo para a faixa etária de idosos. No ano 2009, estes aglomerados aparecem nos distritos Capão Redondo, Campo limpo, Jardim São Luís e Jardim Ângela. Entretanto, para o ano 2010 eles aparecem em parte do distrito Jardim Ângela, Jardim São Luís e em Cidade Dutra unicamente.

Nas Figura 17 e 18 respectivamente, são mostrados os resultados do índice de Moran local pertencente ao ano 2010 para os idosos e ano 2009 para as crianças, devido a que os cálculos do índice de Moran global para as proporções de AIH nas estações secas de 2009 para os $I d o s o s ~(I=0,0151)$ e 2010 para as crianças $(I=0,0278)$ não mostraram distribuição geográfica em aglomerados que seja significativa.
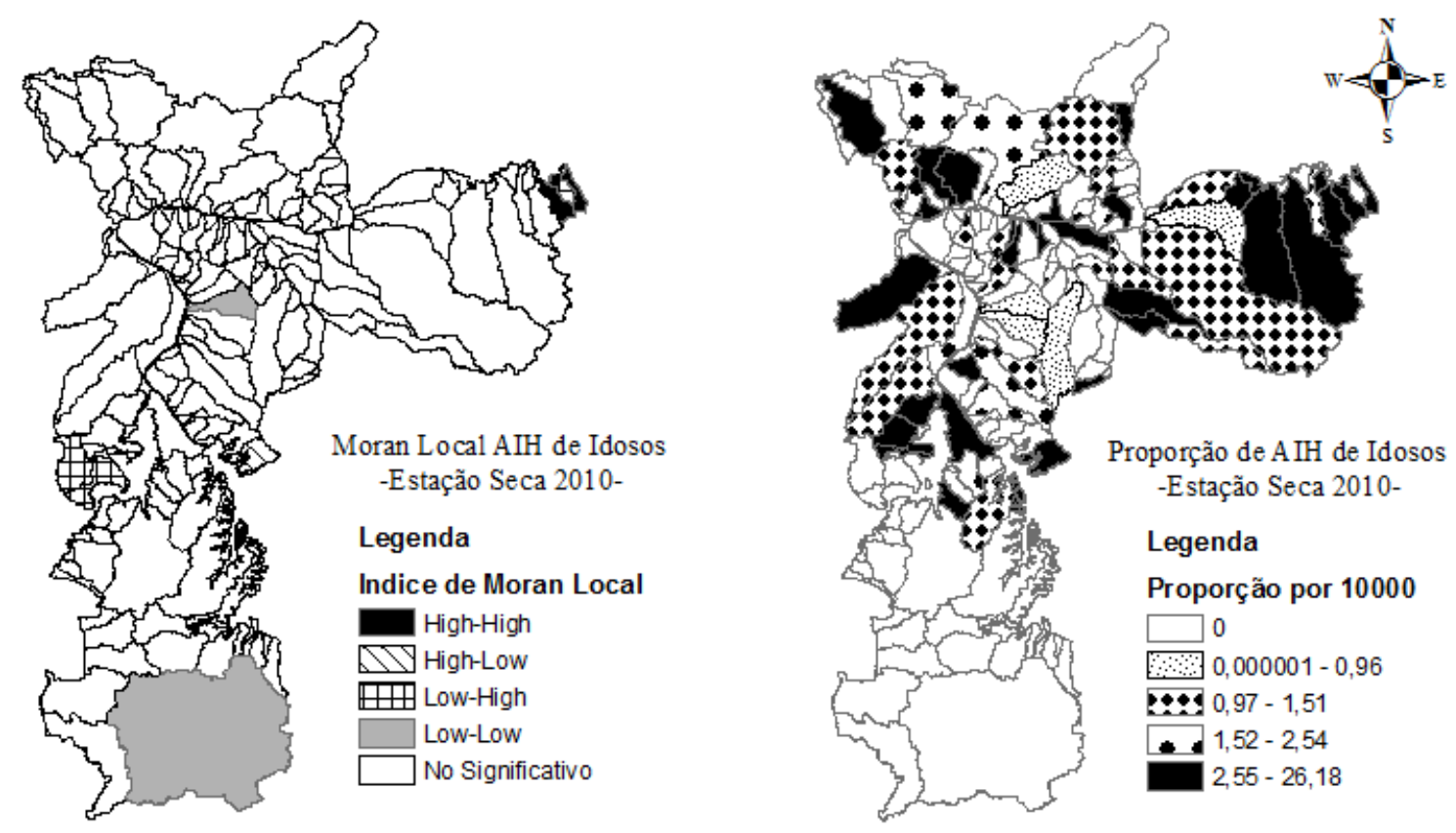

Figura 17. Mapas de proporções e aglomerados de AIH de Idosos para a estação Seca de 2010 .

Na estação seca de 2010 para a faixa de idosos foram encontrados no total dez (10) aglomerados, três (3) dos quais são de valores significativamente altos que representam $30 \%$ do total de aglomerados encontrados e dois (2) de bacias com proporções significativamente baixas que representam $20 \%$ do total. Da localização 
destes aglomerados pode-se ver na Figura 17 que os aglomerados $\mathrm{HH}$ estão todos na região Leste sobre o limite do município, nos distritos Jardim Helena e Itaim Paulista. Dos aglomerados Low-Low a pode-se dizer que a sua localização não varia muito da de aqueles aglomerados Low-Low encontrados para a estação úmida do mesmo ano (Figura 17). Aparece um aglomerado novo no centro do município (distritos Moema, Itaim bibi e Vila Mariana) e continua a ser detectado o aglomerado do distrito de Marsilac.

A Figura 18 mostra o mapa de Moran Local e proporções de AIH para crianças na estação seca de 2009. Foram encontrados doze (12) aglomerados, cinco (5) dos quais são aglomerados da categoria High-High que representam o $42 \%$ do total de aglomerados encontrados, e três (3) aglomerados na categoria Low-Low o que significa $25 \%$ do total de aglomerados detectados para a estação e faixa etária.
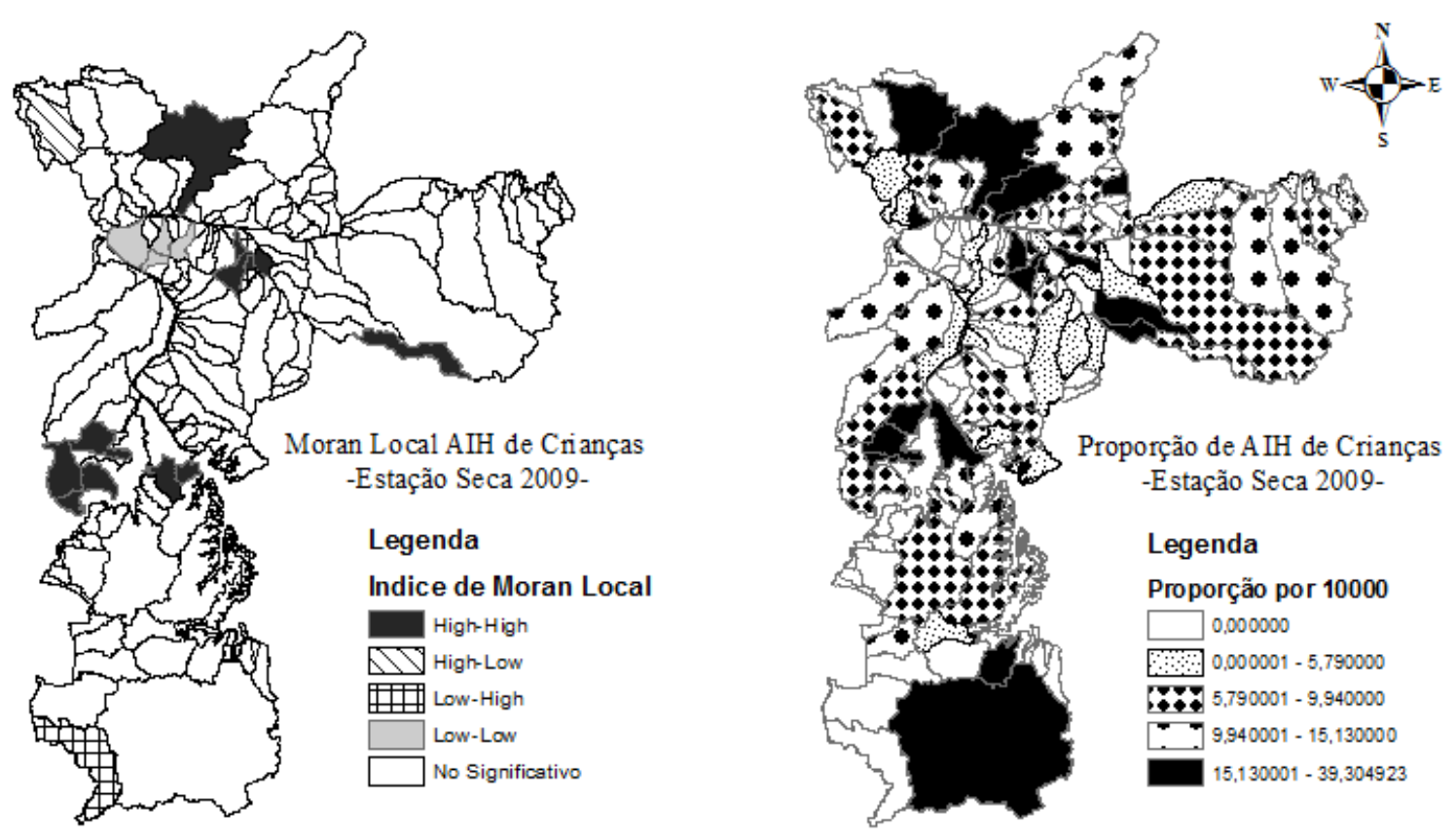

Figura 18. Mapas de proporções e aglomerados de AIH de Crianças para a estação Seca de 2009.

Observando o mapa, ressalta que a distribuição geográfica dos aglomerados $\mathrm{HH}$ encontrados não estão localizados em lugares afastados aos detectados para a estação úmida da mesma faixa etária e ano. Aparecem aglomerados pequenos na região sudeste e sudoeste do município como também na região leste. Os distritos onde estão localizados esses aglomerados continuam a ser Jardim Ângela, Jardim São Luís e Cidade Dutra na direção sudoeste-sudeste. Já no leste o único aglomerado encontrado está localizado nos 
distritos de São Rafael, São Mateus, Sapopemba e São Lucas.

Como é anotado na Tabela 10 as bacias com valores atípicos na estação úmida de 2009 para as crianças apresentaram quatro (4) aglomerados de bacias com associações dissímeis, este número aumenta para a estação seca do mesmo ano, sendo de seis (6) no total. No ano 2010 os aglomerados de valores atípicos para a faixa de crianças diminuíram a três (3), no havendo dados para a estação seca do mesmo ano.

Por outra parte, a Tabela 11 apresenta os valores de aglomerados atípicos encontrados para a faixa etária de idosos. No ano 2009 apenas três (3) aglomerados de bacias de valores dissimiles foram encontradas, já para o ano 2010 este número aumentou para sete (7). Para estação seca do ano 2009 não foram analisados os dados por não apresentar um índice de Moran global significativo, já para a estação seca do ano 2010 foram encontrados cinco (5) aglomerados de valores atípicos.

De maneira geral, observa-se que embora foram detectados quatro tipos diferentes de aglomerados espaciais para as proporções de AIH no período de tempo e faixas etárias estudadas, a proporção da distribuição das bacias homogêneas (High-High e Low-Low) e heterogêneas (High-Low e Low-High) permanece relativamente estável para cada um dos regimes de chuvas entre um ano e o seguinte. Mesma coisa acontece para a comparação estação Úmida e Seca, embora a quantidade de aglomerados de valores similares diminua para as estações secas tanto para aglomerados de valores altos, a localização dos aglomerados continua a ser similar.

\subsubsection{Médias de precipitação}

Com o objetivo de observar o comportamento espacial do diagnóstico A09 não só na frente dos regimes de precipitação de maneira geral como também dentro da distribuição espacial dessa precipitação no território do município, calcularam-se as médias de precipitação para as estações úmida e seca dos anos 2009 e 2010 . A Figura 19 mostra a distribuição espacial das médias de precipitação calculadas de acordo com o método apresentado no item 5.4.3.

Evidentemente existe uma diferencia entre os máximos e mínimos da precipitação média nas duas estações apresentadas tanto para 2009 quanto para 2010. Para 
a estação seca de 2009 (abril a setembro) a precipitação máxima está no nível entre 28 e $30 \mathrm{~mm}$, enquanto para a estação úmida do mesmo ano (outubro a Março) o máximo está entre os 48 e $54 \mathrm{~mm}$. Para a estação seca do ano imediatamente seguinte (2010) o máximo de precipitação chega só até o intervalo de entre 20 e $25 \mathrm{~mm}$ enquanto o máximo de precipitação da estação úmida atinge o nível de entre 48 e 54 mm de chuva.

A distribuição espacial das chuvas é bastante homogênea quando comparados os mesmos regimes de chuvas para anos diferentes. Durante a estação úmida de 2010 as médias de precipitação altas têm tendência a se localizar nos extremos sul e leste do município.

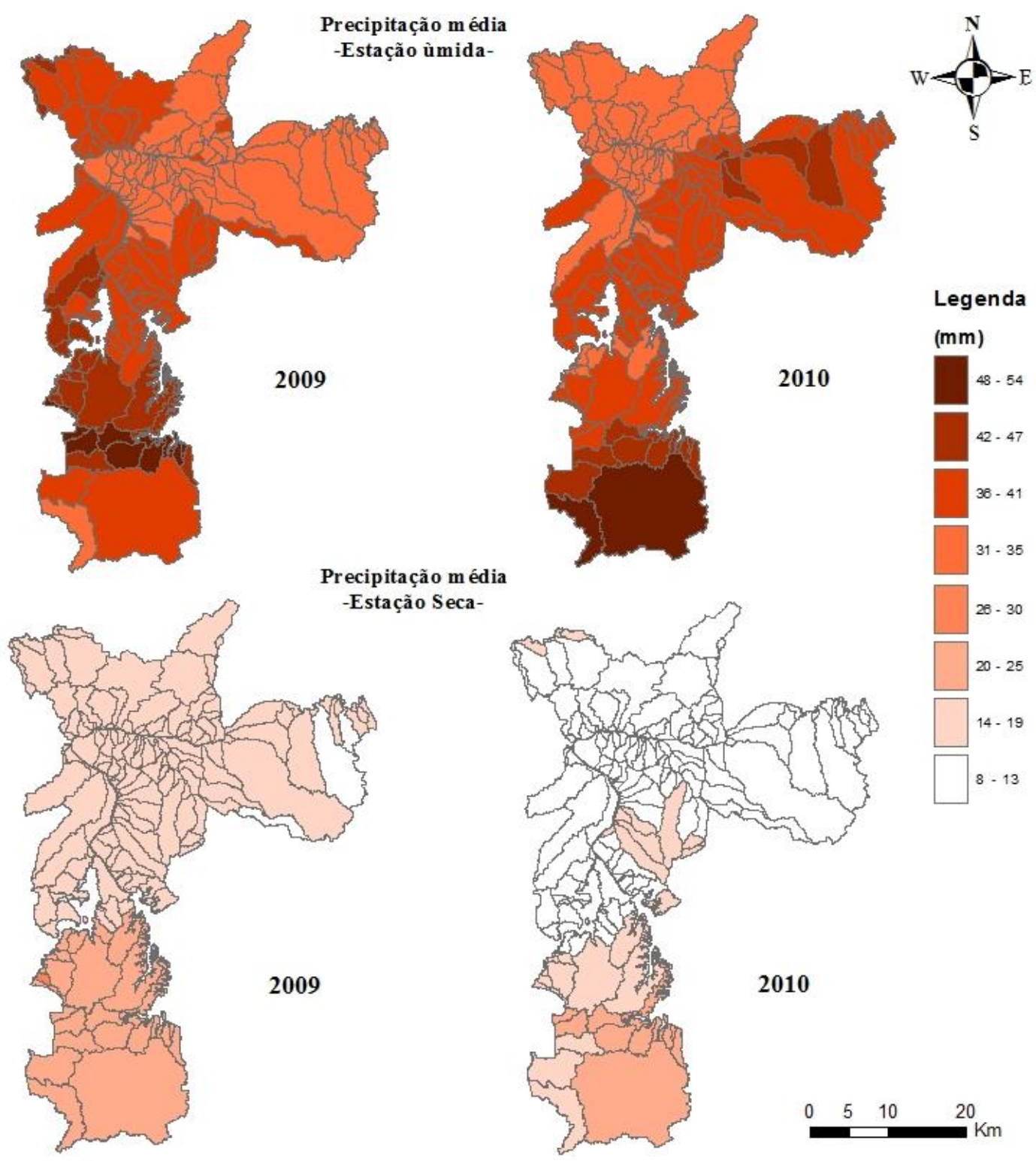

Figura 19. Mapas de precipitação media para as Estação úmida e Seca de 2009 e 2010. 
Entretanto para o ano 2009, embora as maiores médias continuem a se localizar na região sul, outras precipitações médias de valores altos estão localizadas para a região oeste. Em ambos os anos a precipitações médias baixas estão localizadas na região norte do município. Acontece uma distribuição similar na estação seca para os anos em estudo. As maiores precipitações acontecem na região sul nos distritos Parelheiros, Grajaú e Marsilac enquanto as precipitações baixas estão concentradas na região norte do município. No caso da estação seca não existe uma diferença notável entre os níveis de precipitação das regiões este e oeste como pode ser observado nos mapas da segunda metade da Figura 19.

\subsubsection{Relações espaciais entre duas variáveis}

As relações espaciais apresentadas neste inciso constituem a última fase do processo de exploração da possível associação das variáveis escolhidas como indicadores da vulnerabilidade da população do município de São Paulo ás doenças infecciosas associadas com inundações.

Sobrepondo o mapa dos aglomerados de proporções de AIH similares sobre o mapa do índice de vulnerabilidade social calculado para as estações úmidas de 2009 e 2010 da faixa etária de crianças (Figura 20), encontramos que para o ano 2009 a maior parte dos aglomerados $\mathrm{HH}$ estão localizados em bacias classificadas com vulnerabilidade social Muito Alta e Alta sendo a exceção as bacias Guarapiranga/Pinheiros, localizada no distrito Socorro e Cidade Dutra (Número 79 no mapa do apêndice III), do Rio das pedras localizada no distrito Cidade Dutra (Número 144 no mapa do apêndice III), Bacia Itupu/Ponte baixa dentro do distrito de São Luís (Número 80 no mapa do apêndice III) e a bacia de contribuição direta Guarapiranga no distrito Parelheiros (Número 7 no mapa do apêndice III) classificadas com vulnerabilidade Média e a bacia Luz/Anhanguera dentro dos distritos Bom Retiro e Barra Funda (Número 52 no mapa apêndice III) classificada com vulnerabilidade Baixa (Figura 20B).

No ano 2010 as aglomerações de bacias com valores HH aparecem nas zonas sudeste e sudoeste, todas em bacias classificadas com vulnerabilidades altas e muito altas próximas da periferia, nos distritos Grajaú, Jardim Ângela e Jardim São Luiz. São a 
exceção as bacias Córrego Anhangabaú (Número 137 no apêndice III), bacia Anhangabaú/Luz (Número 53 no apêndice III) e a bacia Luz/Anhanguera (Número 52 no apêndice III) localizadas nos limites comuns dos distritos Bom Retiro, Bala Vista e República (Figura 20D). Os aglomerados significativamente baixos para esta faixa etária não foram detectados para o ano 2009, no ano 2010 eles estão presentes em bacias da zona centro do município classificadas com vulnerabilidades baixas nos distritos de Pinheiros, Alto de Pinheiros, Barra Funda e Perdizes (Figura 20D).

Para a faixa etária de Idosos na estação úmida de 2009 e 2010, os aglomerados HH estão presentes em muito menor número. Ao adicionar o mapa de Vulnerabilidade Social para analisar a localização dos aglomerados de AIH (Figura 21), observa-se que todos os aglomerados High-High estão localizados em bacias classificadas com Vulnerabilidade Social Muito Alta e Alta sem exceções, nas mesmas regiões para os dois anos. De outro lado, o aglomerado LL nesta faixa etária para o ano 2010, encontra-se localizado na bacia hidrográfica do Rio Capivari (Número 184 no mapa do apêndice III) no distrito Marsilac, classificada com vulnerabilidade muito alta, próxima de bacias com vulnerabilidades altas. Observa-se que as proporções de AIH dos idosos moradores nesta região do município são significativamente baixas (ver Figura 16B. Proporção de AIH de idosos. Estação Úmida de 2010) ou próximas a zero, o que explica a detecção do aglomerado LL para esta região.

No caso das aglomerações que resultaram significativas para as estações secas (Estação seca de 2009 para as crianças e estação seca de 2010 para os idosos, Figura 22) observa-se que para o caso das crianças persistem os aglomerados High-High encontrados no sudeste do município nos distritos de Jardim Ângela, Jardim São Luís e Cidade Dutra e acrescentam-se bacias na Zona Norte e Centro do município nos distritos Brasilândia, Cachoeirinha, Limão, Mandaqui, Bela Vista, Brás, República e Sé.

Quando sobrepostos ao mapa de Vulnerabilidade Social, os aglomerados $\mathrm{HH}$ estão distribuídos tanto em bacias classificadas com vulnerabilidades muito alta e alta, quanto em bacias classificadas com vulnerabilidades média, baixa e muito baixa. Observando os componentes principais da Vulnerabilidade Social destas bacias, nota-se que embora as bacias classificadas com vulnerabilidades muito baixas e baixas tenham valores do componente 1 baixos, todas as bacias com proporções de AIH altas apresentam 
valores do componente dois abaixo de zero (que para o cálculo realizado representa um aumento da vulnerabilidade) e valores do componente 3 também abaixo de zero que representa bacias com proporções médias de domicílios conectados às redes de água potável baixas, aliás, número baixo do componente 2 e 3 podem significar baixos níveis do índice de desenvolvimento humano.

Os aglomerados Low-Low encontrados para a faixa etária de crianças estão localizados na zona Oeste do município nos distritos de Vila Leopoldina, Alto de pinheiros, Lapa, perdizes e Barra Funda. Quando comparados com o mapa de Vulnerabilidade Social aparecem em bacias hidrográficas classificadas com vulnerabilidades médias, baixas e muito baixas. Para os aglomerados do mesmo tipo encontrados para a faixa de Idosos (Figura 22), observa-se que estão localizados no centro e sul do município nos distritos de Itaim Bibi, Moema e Vila Mariana no centro, que são classificados como de vulnerabilidade social muito baixa e em duas bacias específicas dos distritos de Marsilac e Parelheiros no sul classificadas com vulnerabilidade muito alta. Estas últimas bacias localizadas no Sul do município aparecem também como exceção ao resultado esperado de encontrar bacias altamente vulneráveis com aglomerado de proporções de AIH altas, no mapa feito para a estação de chuvas do ano 2010. 


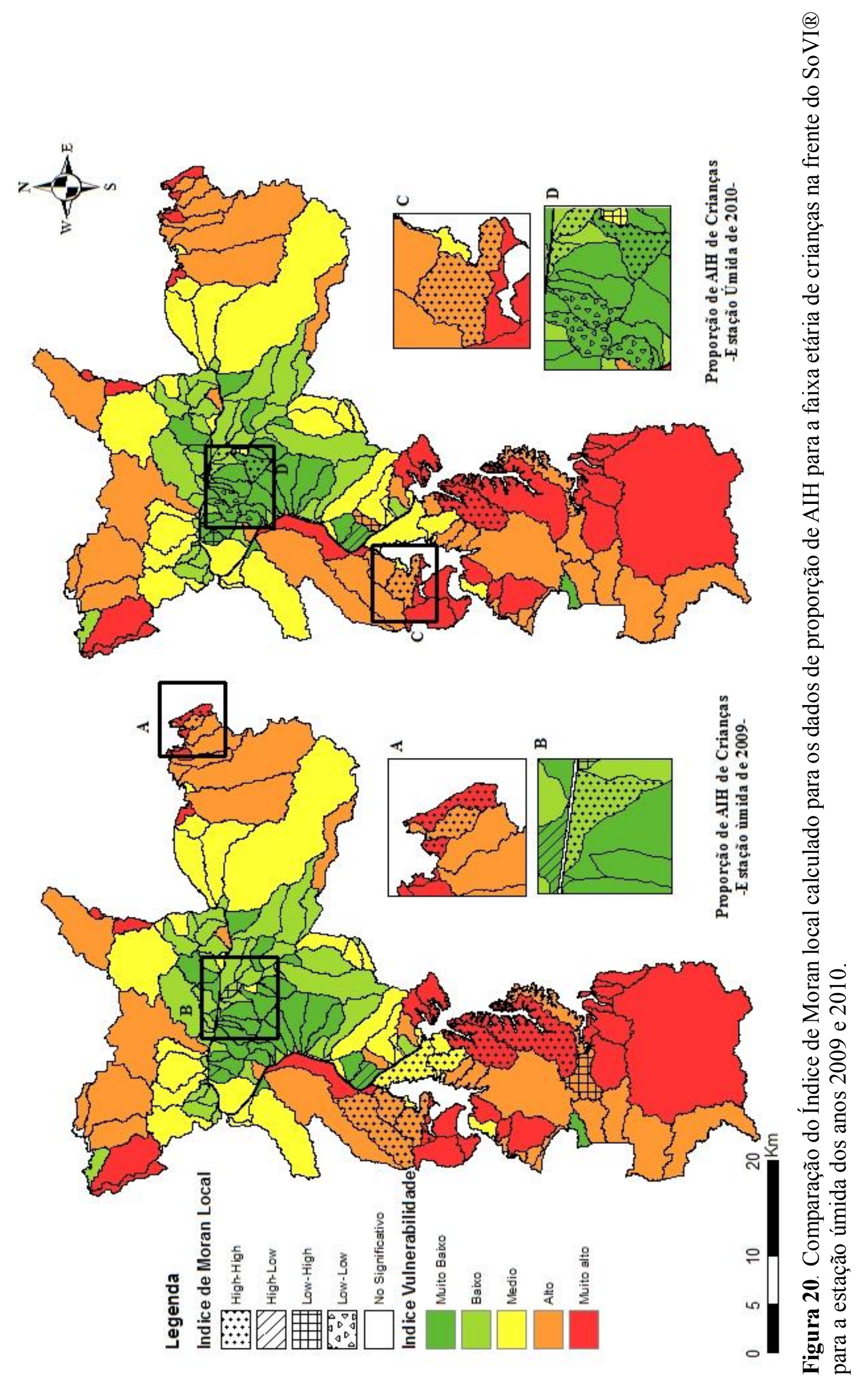




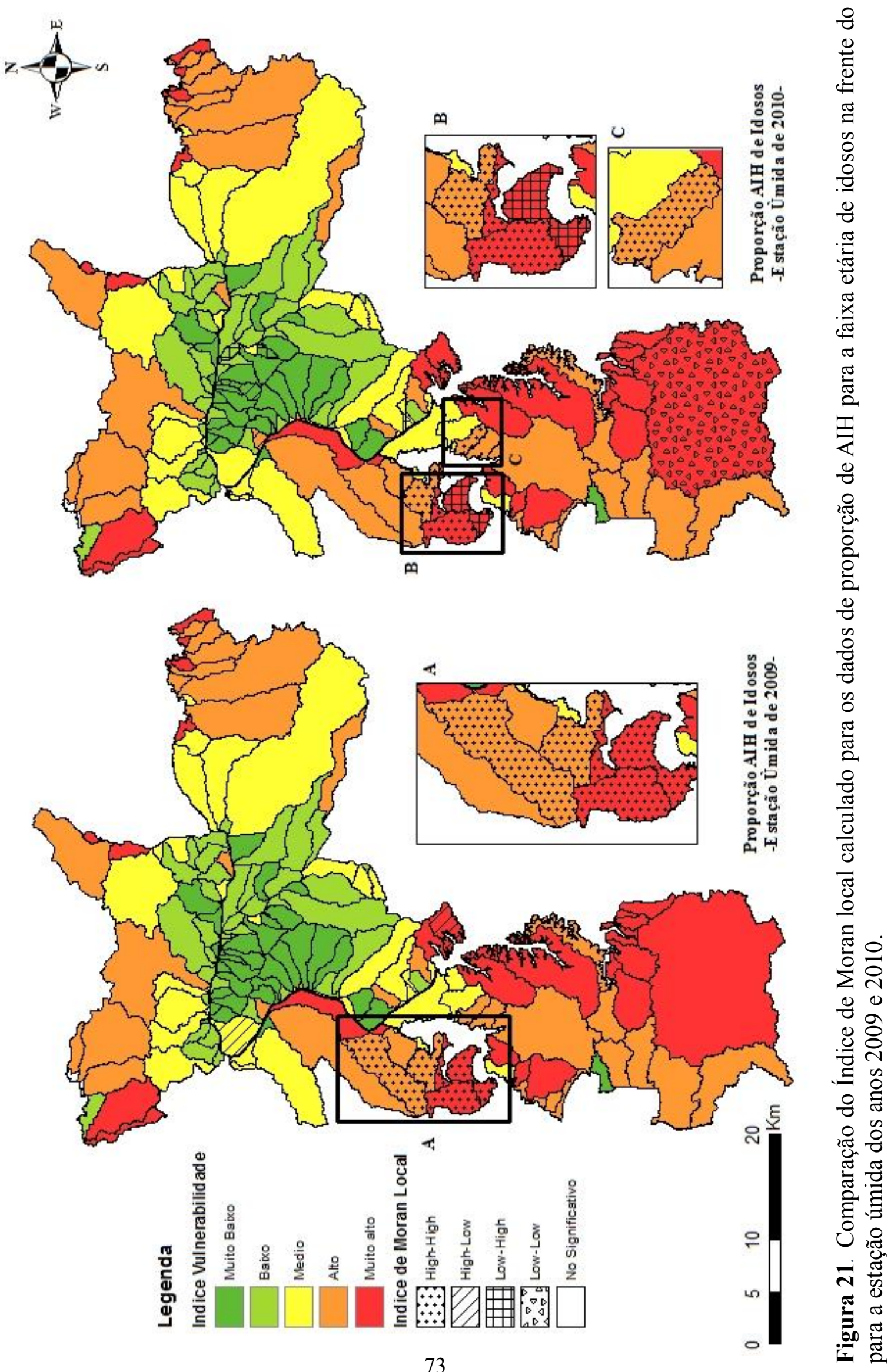




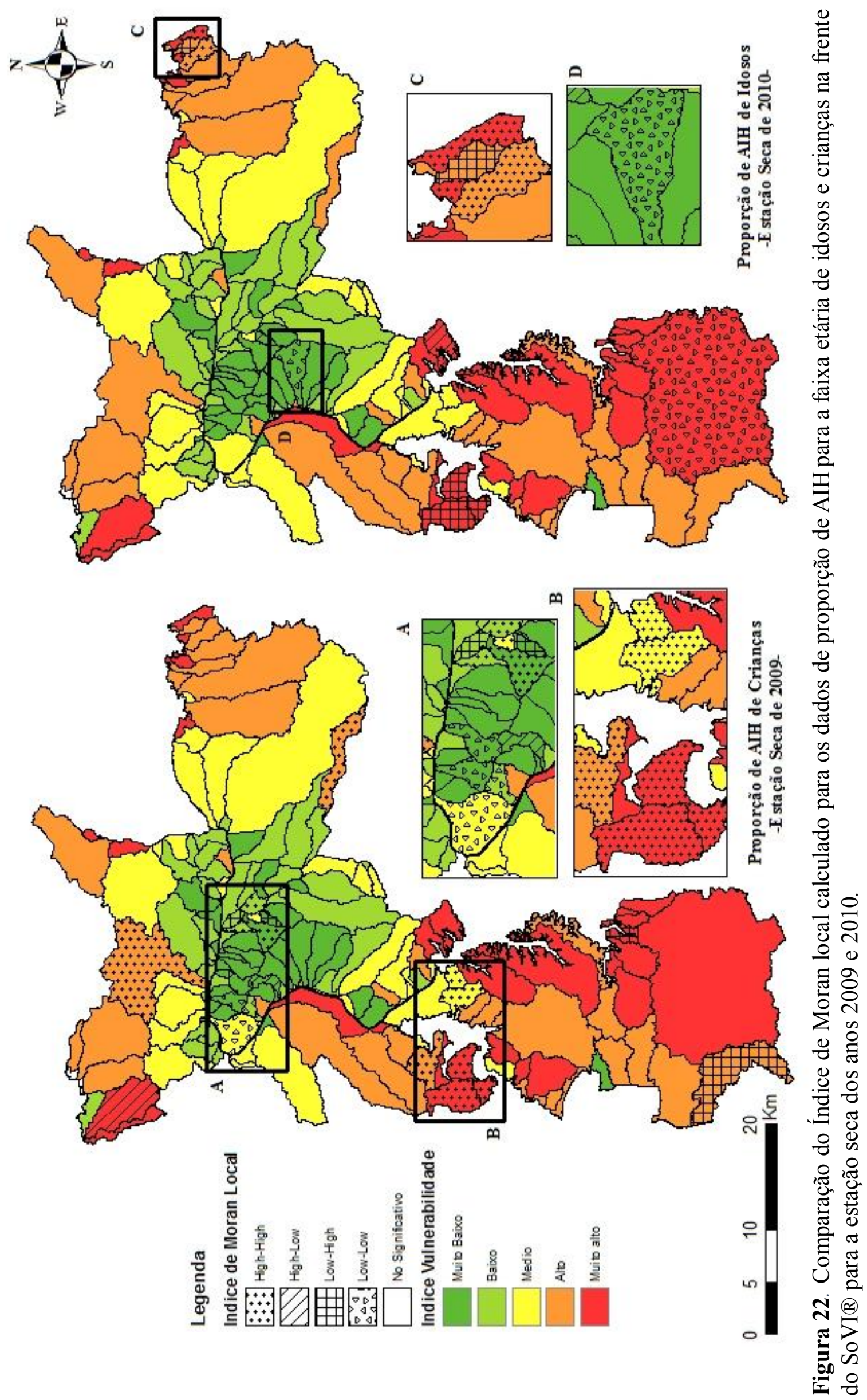




\section{DISCUSSÃO DE RESULTADOS}

\section{1. Índice de Vulnerabilidade}

As unidades de análise mais vulneráveis desde o ponto de vista do Índice de Vulnerabilidade Social calculado para o município de São Paulo, estão localizadas em maior quantidade nos limites geográficos do município com outros municípios da área metropolitana, especialmente nas regiões sul, sudeste e leste. Em outras palavras, a tendência observada nos mapas da Figura 12 e Figura 14 é a diminuição do índice calculado, no sentido periferia-centro. Não existe uma variância grande no intervalo do Índice de Vulnerabilidade Social calculado. O que quer dizer que os dados não estão muito afastados da média $(-0,22)$ e o intervalo continuo dos valores resultantes é curto [12.3:14,2]. No entanto, os valores extremos estão evidentemente afastados dos valores imediatamente seguinte e anterior respectivamente. Estes valores extremos representam a maior vulnerabilidade achada (bacia intermedia do Dreno de Brooklin/Uberaba com um valor de 14,2) e a menor vulnerabilidade achada (bacia Aclimação/Moringuinho, com um índice de vulnerabilidade de -12,3).

A tendência da distribuição geográfica da vulnerabilidade social observada na Figura 12, onde a maior parte das unidades de estudo são classificadas como valores médios, pode ser explicada como um reflexo da história do crescimento urbano e populacional da região metropolitana de São Paulo como unidade geográfica. Como é anotado por NOBRE et al. (2011), em anos recentes a metrópole compacta, densa e dicotômica (centro-periferia) passa a apresentar sinais de um padrão disperso, fragmentado, heterogêneo e multifuncional. Desde os anos 1980, anotam, o estado de São Paulo passa por um processo de desconcentração da indústria que começa a se expandir aos municípios do interior do estado. Além dessa expansão, a região metropolitana começa a ter um ritmo de crescimento populacional moderado e a população inicia uma redistribuição no espaço. Segundo DURAND ALVES et al. (2008), a metrópole tem sofrido uns processos de crescimento demográfico e expansão horizontal localizados nas áreas periféricas mais distantes que contribuem "para o aumento da heterogeneidade das periferias e para o aumento da pobreza e vulnerabilidade social e ambiental". 
Observou-se que existem diferenças consideráveis na variância da vulnerabilidade explicada pelos componentes principais encontrados e na distribuição espacial desses componentes. Analisando os indicadores específicos do componente 1 por exemplo, observa-se que ele descreve condições de estruturação da família e a população que são muito importantes na hora de fazer uma análise integral dos resultados.

O componente 1 associou a presença de mulheres jovens (entre cinco (5) e quinze (15) anos), com proporções altas de moradores por domicilio e proporções altas de crianças. Esta associação é visivelmente mais significativa para os distritos da periferia nas regiões noroeste, norte, leste e sul do município (Figura 13A), nos distritos Parelheiros, Marsilac, Grajaú, Jardim Ângela, Jardim São Luís, Capão Redondo, Pedreira, Cidade Ademar, Cidade Tiradentes, Jardim Paulista e Jardim Helena entre outros. Acontece o contrário para os distritos do centro onde as características são opostas. Isto é, altas proporções de idosos associadas a altas proporções de mulheres responsáveis pelos domicílios. Isto indica que a distribuição espacial do componente 1 mostra como a estrutura etária varia consideravelmente ao longo do território embora existam concentrações regionais específicas (Figura 13A).

Porém, estes lugares exibem também outras dimensões da vulnerabilidade. Por exemplo o Distrito de Parelheiros (zona sul) tem um escore baixo no componente de renda e densidade de urbanização que expõe a sua condição de distrito rural do município. Mesma coisa acontece para o distrito Cidade Tiradentes que possui um score fatorial muito baixo para o componente 3 (saneamento básico) e alto para o componente 2 devido à grande densidade de domicílios por quilômetro quadrado do distrito (Ver Apêndice II).

Não foi observado um padrão diferenciado no mapa feito para o componente 2 (Figura 13B), fato que dificultou a análise da sobreposição de mapas e comparação posterior do índice de vulnerabilidade social e a distribuição das proporções de AIH. Observou-se que a diferenciação do indicador que leva a maior carga dentro deste componente nas bacias avaliadas é difícil. Existem bacias com características de renda e densidade de urbanização conhecidas desde a experiência real que são altamente contrastantes e cujos scores fatoriais aparecem classificados dentro da mesma faixa no mapa realizado. Isto significa que há diferenças importantes na vulnerabilidade das bacias 
que não são obvias no mapeamento de vulnerabilidade realizado.

Por exemplo, dentro do Mapa de Vulnerabilidade Social da população de São Paulo (CEBRAP; SESC; SAS-PMSP, 2004) os setores censitários dos distritos de Vila Mariana, são classificados dentro do grupo social "Nenhuma privação", que descreve uma população que apresenta as melhores condições de escolaridade e renda do município. O mesmo mapa apresenta a região do M'Boi Mirim (Jardim Ângela e Jardim São Luís) com setores censitários classificados nos grupos sociais com privações sociais que vão desde "alta" até "altíssima", onde a população possui rendas baixas, baixas escolaridade, grandes concentrações de crianças e grande presencia de adolescentes. Estas mesmas bacias são classificadas com scores fatoriais altos para o componente 2 no mapa resultante da PCA realizada.

Por tanto pode-se concluir que a expansão urbana da cidade de São Paulo e a quantidade de população que alberga faz com que desde a escala geográfica escolhida (Bacias Hidrográficas) seja difícil avaliar a partir das variáveis escolhidas, as diferencias entre uma área densamente povoada que signifique uma boa ou uma má qualidade de vida. Este fato tem decorrência na análise desde a perspectiva das diferenças socioeconômicas da população. O componente 3 é, neste caso, um complemento eficiente à análise na hora de fazer diferenças entre bacias com bairros densamente povoados $\mathrm{e}$ rendas altas ou bairros densamente povoados e rendas baixas porque indica uma aparentemente forte diferencia nos níveis de cobertura dos serviços públicos dentro do município.

Visivelmente, as regiões mais centrais estão mais densamente conectadas às redes de água e eletricidade do que as regiões mais afastadas do centro. O componente 3 é de grande importância para a análise realizada porque ele envolve os indicadores de vulnerabilidade às doenças diarreicas que podem ser mais obviamente associados com níveis de saneamento relacionados com a ocorrência destas doenças e oferece um diferencial fundamental nas bacias hidrográficas densamente urbanizadas onde os componentes principais de maior dominância não conseguem explicar a variância na vulnerabilidade social. Sugere-se que a adição de uma base de dados com informações da população dependente dos programas sociais desenvolvidos em qualquer nível político, poderia contribuir na análise da vulnerabilidade social desde a perspectiva da escala de 
bacias hidrográficas para o Município de São Paulo.

7.2. Proporções de Internação Hospitalar e relações espaciais entre duas variáveis

Entende-se que desde a visão sistémica de avaliação da vulnerabilidade proposta por TURNER II et al. (2003), interpretada e usada como veículo para a pesquisa aqui apresentada, deve-se definir o subsistema biofísico e os seus componentes. Assim, define-se aqui o sistema biofísico do município de São Paulo como o filtro geográfico que inclui o lugar e situação do espaço e a proximidade às fontes de ameaças ou eventos perigosos e interage com o potencial do perigo para resultar na vulnerabilidade biofísica (CUTTER et al. 2000). Na prática a identificação dos perigos na pesquisa desenvolvida, está traduzida na avaliação, no nível de bacias hidrográficas ${ }^{16}$, da precipitação média para as estações chuvosa e seca. Esta característica representa quanto as médias de precipitação aproximam ou removem as probabilidades de eventos de inundação. Assim, deve-se levar em conta que a avaliação do perigo que está sendo analisando nesta pesquisa, não está constituído por eventos pontuais de inundação porque não foram encontrados nem utilizados dados de lugares de inundação específicos e áreas inundadas. Entretanto, está constituído pelas médias de precipitação que representam uma situação potencial à qual o subsistema humano responderá segundo as suas características e possibilidades.

Desta maneira, os resultados de médias de precipitação indicam que existe um aumento visível nos níveis de precipitações para a estação úmida comparada com a estação seca, que validam a diferenciação realizada para o cálculo das proporções de AIH. As proporções de Internação Hospitalar analisadas por períodos de chuva ou seca, mostram que existe uma probabilidade maior à vizinhança de bacias com valores similares de proporções de Autorização de Internação Hospitalar, durante as estações úmidas dos anos em estudo do que nas estações secas.

Os resultados mostram também que as aglomerações de valores altos (HH) são evidentemente mais abundantes do que as aglomerações de valores baixos (LL), o que significa que as proporções altas de AIH estão menos dispersas do que as proporções

\footnotetext{
${ }^{16}$ Que são, per se, unidades biogeográficas com características particulares que dependendo das suas características naturais serão objeto de mudanças mais ou menos pronunciadas pelos efeitos da intervenção humana.
} 
baixas. Porém, é importante apontar que a tendência à vizinhança das bacias com valores similares HH nas estações úmidas, não pode ser diretamente associada com eventos de inundação devido a que o aumento deste diagnóstico pode estar associado com doenças virais de ocorrência comum nas estações úmidas, a falta de cuidado na manipulação e conservação de alimentos durante o verão quando as temperaturas e as precipitações aumentam, entre outras causas. Existe a possibilidade da ocorrência estar relacionada com a contaminação da água potável diretamente conexa com a exposição direta a água de inundação mas as observações de dados realizadas não mostram evidencias suficientes que permitam fazer esta afirmação.

Os números de aglomerados de bacias com proporções de Autorizações de Internação Hospitalar significativamente altas não variam em quantidades importantes entre estações, porém variam entre as faixas etárias estudadas sendo maiores para a faixa de crianças com menos de cinco (5) anos do que para os idosos com mais de sessenta e quatro (64) anos. Este achado pode ser explicado pela priorização no atendimento hospitalar que têm as crianças sobre os idosos, como indicam as diferenças de porcentagens de ocorrências de AIH encontradas entre faixas etárias e anotadas na Tabela 3, e pela limitação que introduze o uso da base de dados de atendimentos hospitalares exclusivos da rede pública de saúde. Além disso, os aglomerados de proporções similarmente altas tendem a se localizar nas bacias classificadas com vulnerabilidades sociais altas e muito altas. Isto acontece tanto nas estações úmidas quanto nas estações secas ${ }^{17}$ dos anos avaliados e não é diferenciado entre faixas etárias, descartando possíveis vieses atribuíveis à distribuição da população dentro do território.

A pequena variação na quantidade de aglomerados de valores significativamente altos nas estações úmida e seca junto com a localização da maior parte destes aglomerados nas bacias classificadas com vulnerabilidades muito altas e altas, sugere que mesmo fora dos períodos de altas precipitações, quando as inundações são menos frequentes, as populações convivem com os fatores de risco para o aparecimento da doença.

Por isso, nota-se que a avaliação da susceptibilidade da população à Diarreia e gastroenterite de origem infecciosa presumível no contexto de inundações poderia ser

\footnotetext{
${ }^{17}$ Estações secas com valores de aglomeração global significativa.
} 
melhorada avaliando quais a rotas de exposição e qual o contato da população com os agentes patogênicos de uma maneira mais especifica, processo que, embora seja do interesse da análise da vulnerabilidade avaliada nesta pesquisa, foi limitado pelo tempo e recursos disponíveis para a sua realização. EISENBERG et al. (2007), aludem à deficiência de modelos de avaliação dos determinantes ambientais de doenças infecciosas que contribuam com a avaliação da vulnerabilidade das populações ás mudanças ambientais desde o marco de conhecimento da saúde pública. Afirmam que é preciso articular diferentes modelos conceituais para organizar o conhecimento sobre sistemas de componentes que interatuam e ligam forças acionantes fundamentais para o surgimento e ressurgimento de doenças através do interagir desses subsistemas. Desta maneira, os resultados encontrados seriam enriquecidos se ampliássemos o alcance da pesquisa e afundássemos nos processos infecciosos que surgem na interfase população/meio ambiente durante as inundações no município de São Paulo.

Por outro lado, foram encontradas no mapa de Índice de Vulnerabilidade Social relacionado com a distribuição espacial de diarreia e gastroenterite de origem infecciosa presumível, bacias que não seguem a disposição aglomerado HH-Bacia altamente vulnerável, e que sendo classificadas com vulnerabilidades baixas e muito baixas fazem parte de aglomerações de proporções de AIH significativamente altas, ou bacias com índices de vulnerabilidade altos que formam parte de aglomerados de proporções significativamente baixas. Duas questões se levantam dessa observação: Primeiro, desde a visão da metodologia utilizada para o cálculo do índice de vulnerabilidade, essa vulnerabilidade social pode ser expressada como a junção de diferentes forças interagindo de maneira diferenciada para as distintas unidades de estudo avaliadas, o que cria dinâmicas sociais e ambientais que poderiam explicar as sobreposições contrastantes encontradas quando observadas dentro da escala de bacia hidrográfica. Segundo, a disponibilidade de dados limitou a observação da dinâmica de ocorrência do diagnostico avaliado e não é possível rejeitar a possibilidade de que as bacias hidrográficas onde não foram registrados $\mathrm{AIH}$, representem áreas cujos registros poderiam mudar a análise de distribuição espacial dos aglomerados de proporções de AIH.

O uso da bacia hidrográfica como unidade de análise numa área urbana de dinâmicas variadas como o município de São Paulo, pode limitar os resultados da análise nas unidades de estudo onde extremos diferentes do espectro de vulnerabilidade podem 
acontecer em áreas geograficamente muito próximas. Contudo, a sobreposição díspar encontrada reforça o argumento de que é necessário um olhar mais específico e detalhado das rotas de infecção e os ciclos de transmissão ${ }^{18}$ das doenças infecciosas de interesse. Considerando que as doenças de veiculação hídrica possuem uma forte relação com a qualidade de vida e as condições de habitação, altas proporções de AIH desses agravos em áreas específicas do município podem ser indicativas de condições de vida precárias e/ou deficiência na atenção primaria em saúde, porque de ser eficiente a atenção no chegaria a necessidade de Autorizações de internação Hospitalar.

Apesar disso, é necessário anotar que as proporções de AIH de Diarreia e gastroenterite de origem infecciosa presumível utilizadas para a pesquisa, não refletem a incidência real da doença no município, questão que limita as inferências que podem ser realizadas.

Os dados de internação hospitalar registrados pela rede de atenção pública, restringem a avaliação da ocorrência real de casos do diagnóstico analisado devido a que não fornecem informação completa sobre a incidência da doença, porque só representam os casos que precisaram de um atendimento de nível hospitalar com os decorrentes vieses que isso possa significar por causa da priorização do atendimento (priorizar a internação de crianças mais do que a internação de idosos), além da falta de informação que de fato representa a falta de dados de atendimentos e internações realizadas pelos planos e seguros de saúde particulares. Isto significa que as aglomerações de bacias com valores HH e LL encontradas poderiam não ser um reflexo real da distribuição espacial da doença avaliada. Na análise realizada, muitas das bacias com proporções de Internação Hospitalar iguais a zero, podem ser bacias com incidências de diarreia e gastroenterite de origem infecciosa presumível altas que não são levadas em conta devido à falta de dados. Porém, este tipo de dado já tem sido reportado e usado com o fim de estabelecer associações entre doenças e eventos climáticos extremos (SALASAR-LINDO et al. 1997) ou doenças e vulnerabilidade social (CEBRAP; SESC; SAS-PMSP, 2004).

Os resultados de estudo similares apresentam conclusões heterogêneas para a relação entre doenças infecciosas e eventos extremos de precipitação. Segundo GUZMAN HERRADOR et al. (2015), esta heterogeneidade nos resultados é reflexo da

\footnotetext{
${ }^{18}$ Uma proposta de classificação das doenças infecciosas realizada por (WILSON, 2001)
} 
complexidade da relação entre eventos de precipitação extremos e doenças infecciosas de veiculação hídrica. No caso avaliado neste documento, não foi possível avaliar a relação doença infecciosa e eventos de inundação por não possuir dados pontuais de eventos de inundação nem informações suficientemente confiáveis de níveis de precipitação que ajudem na inferência de uma relação com a ocorrência de doenças infecciosas para a escala de bacia hidrográfica. Mas podemos concluir que a ocorrência de diarreia e gastroenterite de origem infecciosa presumível pode sim estar associada com baixos níveis socioeconômicos da população do município de São Paulo. No entanto, uma tendência mais sequencial e continua à aglomeração de bacias com proporções altas de AIH durante as estações úmidas (Resultados de Moran global significativos para todas as estações úmida e não para todas as estações secas) abre a porta para afundar na relação inundação/Diarreia e gastroenterite de origem infecciosa presumível. 


\section{CONCLUSÕES E RECOMENDAÇÕES}

Os resultados do Índice de vulnerabilidade social (SoVI $\left.{ }^{\circledR}\right)$, mostram que as unidades de análise mais vulneráveis encontradas estão localizadas em maior quantidade nos limites geográficos do município com outros municípios da área metropolitana, o que significa que existe uma tendência a diminuição do índice de Vulnerabilidade Social calculado, na direção periferia-centro. Por outro lado, não existe uma variância grande no intervalo dos valores resultantes calculados. Assim, os valores médios descrevem a vulnerabilidade do $96 \%$ das bacias avaliadas, isto mostra a grande fragmentação social que acontece dentro do território do município e aumenta a dificuldade do delineamento, gestão e ações preventivas.

Dos três componentes principais da vulnerabilidade social calculada para o município de São Paulo, o componente 1, de características demográficas, mostrou ser uma força acionadora da vulnerabilidade muito importante, cujas características mudam dentro do índice calculado, em decorrência da sua interação com os outros componentes principais achados. Isso significou que uma das maiores dificuldades na hora de realizar a análise dos resultados encontrados foi a limitação que representou a escala geográfica escolhida para avaliar a vulnerabilidade de uma área urbana de dinâmicas variadas como o município de São Paulo, onde dois extremos diferentes do espectro de vulnerabilidade podem acontecer em áreas geograficamente muito próximas.

Devido à importância da bacia hidrográfica como sistema ambiental e social definido e como unidade territorial de planejamento sobre a qual seria mais eficiente trabalhar nos termos de vulnerabilidade aos eventos extremos de precipitação e sua relação com a ocorrência de doenças infecciosas, sugere-se que a melhora do marco conceitual do índice de vulnerabilidade para o contexto brasileiro seria a maneira mais eficaz de enriquecer o conhecimento sobre vulnerabilidade da sociedade na região e encontrar os caminhos apropriados e únicos para reduzir os risco da ocorrência de doenças relacionadas com eventos climáticos extremos. Sendo que o modelo de avaliação da vulnerabilidade social utilizado foi criado para os Estados Unidos de América, mais trabalhos precisam ser realizados para desenvolver as bases teóricas de avaliação de doenças infecciosas e eventos climáticos extremos adaptados à realidade dos países da América latina. 
Para as proporções de Internação Hospitalar devida a diarreia e gastroenterite de origem infecciosa presumível, os resultados mostram que existe uma probabilidade maior à aglomeração de bacias com valores similares de proporções de AIH, durante as estações úmidas dos anos em estudo do que nas estações secas. Mostram também que as aglomerações de valores altos $(\mathrm{HH})$ são evidentemente mais abundantes do que as aglomerações de valores baixos (LL), o que significa que as proporções altas de AIH estão menos dispersas do que as proporções baixas. No entanto, os números de aglomerados de bacias com proporções de AIH significativamente altas não variam em quantidades importantes entre as estações secas e úmidas avaliadas, porém variam entre as faixas etárias estudadas sendo maiores para a faixa de crianças com menos de 5 anos do que para os idosos com mais de 64 anos, fato que pode ser consequência das múltiplas limitações que o uso de dados de internação hospitalar exclusivos da rede de atendimento pública inseriu na análise realizada.

Uma das maiores limitações no momento de realizar a análise dos resultados encontrados foi precisamente o uso da base de dados de Autorizações de Internação Hospitalar como possível reflexo da incidência da doença avaliada. Embora os resultados sejam altamente úteis na avaliação da associação da vulnerabilidade social com doenças gastrointestinais, existe a possibilidade de melhora se fosse disponibilizada uma base de dados de atendimentos, onde não exista a limitação do nível de complexidade do atendimento e as consequentes limitantes que representa na visão geral da população que procura atenção. Isto melhoraria a análise da distribuição da ocorrência as AIH e, em decorrência, a sua associação com a vulnerabilidade social.

Realizando a sobreposição dos mapas base (AIH e Índice de vulnerabilidade), encontra-se que os aglomerados de proporções similarmente altas tendem a se localizar nas bacias classificadas com vulnerabilidades sociais altas e muito altas, o que acontece tanto nas estações úmidas quanto nas estações secas dos anos avaliados e não é diferenciado entre faixas etárias. Este último achado é muito importante porque estabelece uma relação entre as bacias socialmente vulneráveis encontradas e a ocorrência das internações hospitalares que vá além do possível viés que a priorização do atendimento hospitalar inclui na pesquisa, devido a que diz que embora a população idosa esteja muito mais presente no centro, os aglomerados $\mathrm{HH}$ dessa faixa etária estão nas 
bacias da periferia. Assim, a pequena variação na quantidade de aglomerados de valores significativamente altos nas estações úmida e seca junto com a localização da maior parte destes aglomerados nas bacias classificadas com vulnerabilidades muito altas e altas, sugere que mesmo fora dos períodos de altas precipitações, as populações convivem com os fatores de risco para o aparecimento da doença. Desta maneira, a pesquisa revela que os modos de vida das pessoas e o desenvolvimento da sociedade afetam as dinâmicas epidemiológicas do diagnóstico avaliado de maneira direta.

Não foi possível reconhecer a relação doença infecciosa e eventos de inundação devido à falta de informações pontuais e suficientemente confiáveis que ajudem na inferência de uma relação com a ocorrência de doenças infecciosas na escala de bacia hidrográfica. No entanto, podemos concluir, que a ocorrência de diarreia e gastroenterite de origem infecciosa presumível pode sim estar associada com baixos níveis socioeconômicos da população do município de São Paulo.

Foram encontradas também bacias que não seguem a disposição aglomerado HHBacia altamente vulnerável e vice-versa. Isto é devido a que os resultados estão influenciados pelos indicadores escolhidos e os componentes principais resultantes da análise junto com a limitação que tem o uso da bacia hidrográfica como unidade de análise. Sugere-se que a avaliação da susceptibilidade da população à Diarreia e gastroenterite de origem infecciosa presumível no contexto de inundações pode ser melhorada avaliando quais a rotas de exposição e qual o contato da população com os agentes patogênicos de uma maneira mais especifica, além da melhora das informações disponibilizadas já discutida anteriormente. 


\section{BIBLIOGRAFIA CITADA}

ADGER, W. Neil. Social Vulnerability to Climate Change and Extremes in Coastal Vietnam. World Development, v. 27, n. 2, p. 249-269, 1999.

ADGER, W. N. et al. Chapter 17: Assessment of Adaptation Practices, Options, Constraints and Capacity. In: INTERGOVERNMENTAL PANEL OF CLIMATE CHANGE. Contribution of Working Group II to the Fourth Assessment Report of the Intergovernmental Panel on Climate Change. Cambridge: Cambridge University Press, 2007. p. 717-743.

AHERN, M; KOVATS, R.S; WILKINSON, P.; FEW, R.; MATTHIES, F. Global Health Impacts of floods: Epidemiologic Evidence. Epidemiologic Reviews, v. 27, p. 36-46, 2005 .

ALDERMAN, K.; TURNER, L. R.; TONG, S. Floods and human health: A sistematic Review. Environmental International, v. 47, p. 37-47, 2012. Acesso em: Janeiro 2014.

BICH, T. H.; LA NGOC QUANG, L.T.T.; HA, T.T.D.H; GUHA-SAPIR, D. Impacts of flood on health: epidemiologic evidence from Hanoi, Vietnam. Global Health Action, p. 6356, 2011.

BINDOFF, N.; STOTT, P.A; ACHUTARAO, M.; ALLEN, M.R; GILLET, N.; GUTSLER, D et al. Detection and Attribution of Climate Change: from Global to Regional. In: IPCC, INTERGOVERNMENTAL PANEL OF CLIMATE CHANGE. Climate Change 2013: The Physical Science Basis. Contributions from the Working Group I to the e Fifth Assessment Report of the Intergovernmental Panel on Climate Change. Cambridge, United Kingdom and New York, NY, USA: Cambridge University, 2013. p. 867-928.

BIRKMANN, J. Measuring Vulnerability to Natural Hazards: Towards Disaster Resilient Societies. Tokyo, Japão: United Nations University Press, 2006.

BROOKS, N. Vulnerability, risk and adaptation: a conceptual framework. Tyndall Center for Climate Change Research and Center for Social and Economic Research on the Global Environment (CSERGE). [S.1.]. 2003. (Working Paper No. 38).

BUARQUE DE HOLANDA FERREIRA, A. Novo Dicionário Aurelio -Século XXI. [S.1.]: Editora Nova Fronteira, 1999.

CANN, K. F. et al. Extreme water-related weather events and waterborne disease. Epidemiology and Infection, n. 141, p. 671-686, 2013.

CEBRAP, CENTRO BRASILEIRO DE ANÁLISE E PLANEJAMENTO; SESC, SERVIÇO SOCIAL DO COMERCIO; SAS-PMSP, SECRETARIA MUNICIAPL DE ASSISTENCIA SOCIAL DE SÃO PAULO. Mapa de Vulnerabilidade Social da Cidade de São Paulo. Centro de Estudos da Metrópole. São Paulo. 2004.

CHEN, W.; CUTTER, S.; EMRICH, C.; SHI, P. Measuring Social Vulnerability to Natural Hazards in the Yangtze River Delta Region, China. International Journal of 
Disasters Risk Science., p. 169-181, 2013.

CONFALONIERI, U. Variabilidade climática, vulnerabilidade social e saúde no Brasil. Terra Livre, v. 1, n. 20, Janeiro/Julho 2003.

CONFALONIERI, U.; MENNE, B.; AKHTAR, R.; EBI, K.L.; HAUENGUE, M.; KOVATS, R.S.; REVICH, B.; WOODWARD, A. Human health. In: INTERGOVERNMENTAL PANEL OF CLIMATE CHANGE. Climate Change 2007: Impacts, Adaptation and Vulnerability. Contribution of Working Group II to the Fourth Assessment Report of the Intergovernmental Panel on Climate Change. , Cambridge, UK: Cambridge University Press, 2007. p. 391-431.

CURRIERO, FRANK C.; PATZ, JONATHAN A.; ROSE, JOAN B.; LELE, SUBHASH. The Association between extreme precipitation and waterbeorn disease outbreakes in the United States, 1948-1994. American Journal of Public Health, v. 91, n. 8, p. 1194 1199, Agosto 2001.

CUTTER, S. L.; MITCHELL, J. T.; SCOTT, M. S. Revealing the Vulnerability of People and places: A case estudy of Geargetown County, South Carolina. Anals of the Association of American Geographers. Oxford, Oxford. United Kingdom: Blackwell Publichers. 2000. p. 713 - 737

CUTTER, S.; BORUFF, B.; SHIRLEY, W. Social Vulnerability to Environmental Hazards. Social science quarterley, p. 242-261, 2003.

DEMIRKESES, A. C.; EVRENDILEK, F.; BERBEROGLU, S. Quantifying coastal inundation vulnerability of Turkey to sea-level rise. Environmental Monitoring and Assessment, v. 101 - 106, n. 138, 2008.

DONOVAN, E.; UNICE, K.; ROBERTS, J. D.; HARRIS, M.; FINLEY, B. Risk of Gastrointestinal Disease Associated with Exposure to Pathogens in the Lower Passaic River. Applied and Environmental Microbiology, v. 74, n. 4, p. 994 - 1003, Fevereiro 2008.

DU, W.; FITZGERALD, G. J.; CLARK, M.; HOU, X. Health Impacts of Floods. Prehospital and Disaster Medicine, v. 25, n. 3, p. 265-272, Junho 2010.

DURAND ALVES, C.; ALVES, H.; NIERO PEREIRA, M.; VIEIRA MONTEIRO, A.M. Análise dos processos de Expanção Urbana e das situações de Vulnerabilidade Socioambiental em escala Intra-Urbana. IV Encontro Nacional de ANPPAS. Brasilia DF- Brasil: [s.n.]. 2008.

EISENBERG, J.N.S; DESAI, M.A.; LEVY, K.; BATES, K.J; LIANG, S.; NAUMOFF, K.; SCOTT, J.C. Environmental Determinants of Infectious Disease: A Framework for Tracking Casual Links and Guilding Health Research. Environmental Health Perspectives, n. 115, p. 1216-1223, Maio 2007.

ENCONTRA SÃO PAULO. Sobre Parelheiros. Encontra Parelheiros, [s.d]. Disponivel em: <http://www.encontraparelheiros.com.br/parelheiros/>. Acesso em: 14 Abril 2015.

ESRI. ArcGIS help 10.1. ArcGis resourses for spacial statistics toolbox, 2013. Disponivel

em: 
$<$ http://resources.arcgis.com/en/help/main/10.1/index.html\#/Spatial_Autocorrelation_Gl obal_Moran_s_I/005p0000000n000000/>. Acesso em: 20 Março 2015.

FANG, C.; CHHETRI, N. What have we Learned about Climate Variability and Human Health? In: PIELKE, R. Climate Vulnerability: Understanding and Addressing Threats to Essential Ressources. [S.1.]: Academic Press is an imprint of Elsevier, 2013. p. 79-86.

FBHAT - FUNDAÇÃO AGÊNCIA DA BACIA HIDROGRÁFICA DO ALTO TIETÊ. Plano da Bacia Hidrográfica do Alto Tietê. Fundação Agência da Bacia Hidrográfica do Alto Tietê, Biblioteca, 2009. Disponivel em: $<$ http://www.fabhat.org.br/site/index.php?option=com_content\&task=category\&sectioni $\mathrm{d}=4 \& \mathrm{id}=22 \&$ Itemid=24>. Acesso em: 12 Maio 2015.

FEWTRELL, L.; KAY, D.; WATKINS, J.; DAVIES, C.; FRANCIS, C. The microbiollogy of Urban UK floodwaters and quantitative microbial risk assessment of flooding and gastrointestinal illness. Journal of flood risk management, v. 4, n. 2, p. 77 - 87, Março 2011.

FIELD, A. Discovering statistics using SPSS for Windows. New Delhi: LondresThousand Oaks, 2000.

FIGUEREIDO, C.M. DE; MOURÃO, A.; OLIVEIRA, M. DE; ALVES, R.W.; COSTA, M.; BUFFE, C.; KOURY, M. Leptospirose humana no município de Belo Horizonte, Minas Gerais, Brasil: uma abordagem geográfica. Revista da Sociedade brasileira de medicina Tropical, v. 34, n. 4, Julho/Agosto 2001.

FREITAS, C.; XIMENES, E. Floods and Public Health - a review of the recent scientific literature on the causes, consequences and responses to prevention and mitigation. Ciência e saúde coletiva, v. 17, n. 6, 2012.

FÜSSEL, H. Vulnerability: A general applicable conceptual framework for climate change research. Global environmental change, p. 155-167, 2007.

FÜSSEL, H.-M.; KLEIN, R. J. T. Climate Change Vulnerability Assessment: An Evolution of Conceptual Thinking. Climate Change, n. 75, p. 301-329, 2006.

GARCIA CHARRIA, W. Sistema Cuenca Hidrográfica. Universidad Nacional de Colombia sede Medellín, [s.d]. Disponivel em: $<$ www.unalmed.edu.co $>$. Acesso em: 16 Abril 2015.

GRAVELLE, G.; MIMURA, N. Vulnerability assessment of sea-level rise in Viti Levu, Fiji Islands. Sustainability Science, v. 3, p. 171 - 180, 2008.

GREENOUGH, G. et al. The Potential Impacts of Climate Variability and Change on Health Impacts of Extreme Weather Events in the United States. Environmental Health Perspectives, v. 109, n. 2, Maio 2001.

GUHA-SAPIR, D.; BELOW, R.; HOYOLIS, P. EM-DAT: International Disaster Database. Université Catholique de Louvain - Bruxelas - Bélgica, 2014. Disponivel em: <www.emdat.be>. Acesso em: 15 Fevereiro 2014.

GUZMAN HERRADOR, B.R.; FRIESLEBEN DE BLASIO, B.; MACDONALD, E.; 
NICHOLS, G.; SUDRE, B.; VOLD, L.; SEMEZA, J.C.; NYGARD, K. Analytical studies assessing the association between extreme precipitation or temperature and drinking water-related waterborn infections: a review. Environmental health, p. 14-29, 2015.

HAMMAR-CLOSE, E. S. et al. Coastal Vulnerability Assessment of Cape Cod National Seashore to sea-level rise. US Geological Survey. Woods Hole. 2003. (Report 02-233).

HASIZUME, M. Precipitation and Flood Hazards: Health Effects, Risks, and Impacts. In: PIELKE, R. Climate Vulnerability. Understandig and Addressing Threats to Essencial Resources. Volume 1: Reference Module in Earth Systems and Environmental Sciences. Tokyo: Academic Press is an imprint of Elsevier, 2013. p. 115-124.

HEBB, A. M. L. Floods: mapping vulnerability in the Upper Thames watershed under changing climate. Report XICanadian Foundation for Climate and Atmospheric Science. Ontario. 2007.

HVRI - HAZARDS AND VULNERABILITY RESEARCH INSTITUTE. Social Vulnerability Index | Selected Applications of the Usage. Departamento de Geografia. Universidade da Carolina do Sul, 30 Outubro 2013. Disponivel em: $<$ http://webra.cas.sc.edu/hvri/products/SoVIapplications.aspx $>$. Acesso em: 29 Janeiro 2015.

IBGE - INSTITUTO BRASILEIRO DE GEOGRAFIA E ESTATISTICA. Características da População e dos Domicilios. Instituto Brasileiro de Geografia e Estatistica. Rios de janeiro. 2000.

ILLGEN, M. Hydrology of Urban Environments. In: NIEMELÄ, J. Urban Ecology: Patterns, processess and aplications. New York: Oxford University Press, 2014. Cap. 1.4, p. $59-70$.

INSTITUTO BRASILEIRO DE GEOGRAFÍA E ESTATISTICA -IBGE-. São Paulo. Cidades, $2014 . \quad$ Disponivel em: $<$ http://cidades.ibge.gov.br/xtras/perfil.php?lang=\&codmun=355030\&search=saopaulo|sao-paulo|infograficos:-informacoes-completas $>$.

IPCC - INTERGOVERNMENTAL PANEL ON CLIMATE CHANGE. Climate change 2001: Impacts, Adaptation and Vulnerability, Summary for Policymakers. Climate change 2007: Impacts, Adaptation and Vulnerability., 2007. Disponivel em: $<$ http://www.ipcc.ch/publications_and_data/ar4/wg2/en/ch19s19-es.html $>$. Acesso em: 25 Fevereiro 2014.

IVERS, L.; RYAN, E. Infectious diseases of severe weather-related and flood-related natural disasters. Current Opinion in Infectious Diseases, p. 408-414, 2006.

KARIM, M.; MIMURA, N. Impacts of climate chnge and sea-level rise on cyclonic storm surge floods in Bangladesh. Global Environmental Change, v. 18, p. 490 - 500, 2008.

KATSUMA, T., HOSEA; D., WASITO, B.; KOHNO, S.; HARA, K.; SOEPARTO, P.; RANUH, L.. Cryptosporidiosis in Indonesia: a hospital-based study and a communitybased survey. American Journal of Tropical Medicine and Hygine, v. 59, n. 4, 1998. 
KELLY, P.; ADGER, W. Theory and Practice in Assessing Vulnerability to Climate Change and Facilitating Adaptation. Climate Change, v. 27, 2000.

LUERS, A.L.; LOBELL, D.B.; SKLAR, L.S.; ADDAMS, C. L.; MARSON, PAMELA A. A method for quantifying vulnerability, applied to the agricultural system of the Yaqui Vally, Mexico. Global Environmental Change, n. 13, p. 255 - 267, 2003.

MARCHEGGIANI, S.; PUCCINELLI, C.; CIADAMIDARO, S.; DELLA, B.V.; CARERE, M.; BLASI, F.; PACINI, N.; FUNARI, E.; MANCINI, L.Risk of water-born disease outbreaks after extreme events. Toxicological and environmental chemestry, $p$. 593-599, 2010.

MCMICHAEL, A.; GITHEKO, A.; AKHTAR, R.; CARVALLO, R.; GUBLER, D.; HAINES, A.; KOVATS, R.S.; MARTENS, P.; PATZ, J.; SASAKI, A.. Chapter 9: Human Health. In: CHANGE, I. P. O. C. Third Assessment Report. Contributions of Working Group II: Impacts, Adaptation and Vulnerability. Cambridge, U.K: Cambridge University Press, 2001. p. 453-478.

MILOCA, S. Instituto de Matemática e Estatística Universidade de São Paulo. Métodos Estatísticos, S.D. Disponivel em: <https:/www.ime.usp.br/ yambar/MI404Metodos\%20Estatisticos/Aula\%208-

9\%20Regress $\%$ E3o\%20mult $\% 20 \mathrm{dim} /$ inete $\% 20$ adicional $\% 20-\% 20$ multicolinearidade $\%$ 20em\%20modelos\%20de\%20regressao.pdf $>$.

NIR, D. Man, a geomorphological agent: An introduction to antrophic geomorphology. Jerusalem, Israel: Keter publishing house, 1983.

NOBRE, C.A.; YOUNG, A. F.; SALDIVA DE NASCIMENTO, P. H.; MARENGO, J. A.; NOBRE, A. D.; OGURA, A.; OSÓRIO, T.; OBREGÓN PÁRRAGA, G.O.; COSTA MOREIRA DA SILVA, G.; OJIMA, R.; VALVERDE, M.; CARVALHO S., ANDRÉ; DE OLIVEIRA RODRIGUES, G.Megacidades Brasileiras: Cenários de risco e vulnerabilidade associadas a enchentes e inundações na região Metropolitana de São Paulo, 2011. Disponivel em: $<$ http://megacidades.ccst.inpe.br/sao_paulo/VRMSP/capitulo6.php>. Acesso em: 13 Março 2014.

NYCHKA, D.; WIKLE, C.; ROYLE, J. A. Large spatial prediction problems and nonstationary random fields. Journal of the Royal Statistical Society B, 1999.

O'BRIEN, K.; LEICHENKO, R.; ULKA, K.; VENEMA, H.; AANDAHL, G.; TOMPKINS, H.; JAVED, A.; et al. Mapping Vulnerability to Multiple stressors: Climate Change and Globalization in India. Global Environmental Change, n. 14, p. 303 - 313, 2004.

OMS - ORGANIZAÇÃO MUNDIAL DE SAÚDE. Classificação Internacioanl de Doenças e Problemas Relacionados à Saude. 10a rev. Sâo Paulo: Universidade de Sâo Paulo, 1997.

PAULO, P. D. $\quad$ S. Infocid@de, 2010. Disponivel em: $<$ http://infocidade.prefeitura.sp.gov.br/>. Acesso em: 13 Março 2014.

PEREIRA, R. Leptospirose: alguns aspectos do seu comportamento epidemiológico 
no estado de São Paulo. [S.1.]. 1998. Tese de Mestrado, Faculdade de Saúde Pública da Universidade de São Paulo.

PREFEITURA DE SÃO PAULO. Secretarias. Protocolo de assitência MédicoHospitalar, Hospital Municipal Infantil Menino de Jesús, [s.d]. Disponivel em: $<$ http://www.prefeitura.sp.gov.br/cidade/secretarias/upload/HIMJ_protocolo_diarreia_ag uda_1254773643.pdf>. Acesso em: 16 Maio 2015.

PREFEITURA DE SÃO PAULO. Territorio. Infocid@de, 2014. Disponivel em: $<$ http://infocidade.prefeitura.sp.gov.br/index.php?cat $=3 \&$ titulo=Territ\%F3rio $>$.

PREFEITURA DE SÃO PAULO, SECRETARIA MUNICIPAL DO VERDE E MEIO AMBIENTE. GEO cidade de São Paulo: Panorama do meio ambiente urbano. Brasilia: PNUMA, 2004.

PRESTON, L.; YUEN, E.; WESTWAY, R. Putting vulnerability to climate change on the map: a review of approaches, benefits and risks. Sustainability Science, v. 6, n. 2, July 2011.

R FOUNDATION FOR STATISTICAL COMPUTING. R: A language and environment for statistical computing, Viena, 2013. Disponivel em: $<$ http://www.R-project.org/ $>$.

RAKOTOMALALA, R. Tanagra project: a free software for research and academic purposes tutorials. PCA using R-KMO index and Bartlett's test, 2013. Disponivel em: $<$ http://data-mining-tutorials.blogspot.com.br/2013/01/pca-using-r-kmo-index-andbartletts-test.html>. Acesso em: 18 Novembro 2014.

ROMÉRO, M.; J.A., P.; GILDA, C. B. Panorama Ambiental da Metrópole de São Paulo. São Paulo: Universidade de São Paulo. Faculdade de Saúde Pública, Faculdade de Arquitetura e Urbanismo, Núcleo de Informações em Saúde Ambiental: Signus Editora, 2004.

SALASAR-LINDO, E.; PINEL-SALLES, M. A.; CHEA-WOO, E. El niño and Diarrhoea and dehydration in Lima, Peru. Lancet, n. 350, p. 1597-1598, 1997.

SCHETS, F.M.; VAN WIJNER, J.H.; SCHIJVEN, J.F.; SCHOON, H.; DE RODA HUSMAN, A.M. Monitoring of water Pathogens in surface water in Amsterdam, the Netherlans and the Potencial Health Risk associated with Exposure to Cryptosporidium and Giardia in These Waters. Applied and Environmenatl Microbiology, v. 74, n. 7, p. 2069 - 2078, Abril 2008.

SHARMA, U. . P. A. Methodology for identifying vulnerability hotspots to tropical cyclone hazards in India. Mitigation and Adaptation strategies for Global Change, v. 13, p. 703-717, 2008.

SHARPLES, C.; MOUNT, R.; PEDERSEN, T.; LACEY, M.; NEWTON, J.; JASKIERNIAK, D.; WALLACE, L.. The Australian coastal smartline geomorphic and stability map version 1. Prepared for Geoscience Australia and the Department of Climate Change by School of Geography and Environmental Studies, University of Tasmania. Hobart. 2009.

SIDDIQUE, A.; BAQUI, A.; EUSOF, A.; ZAMAN, K.. Floods in Bangladesh: pattern of 
illness and causes of death. Journal of Diarrhoeal Diceases Research, v. 9, n. 4, 1991.

SILVA, G. C. M. D. Opções de adaptação às mudanças do clima para a bacia do rio Aricanduva. Universidade de São Paulo. São paulo. 2010.

SUR, D.; DUTTA, G.; NAIR, B.; BHATTACHAYA, S. Severe cholera outbreak following floods in a northern district of West Bengal. Indian Journal of Medicine, $\mathrm{v}$. $112,2000$.

THI VIET NGA, T.; FUKUSHI, K.; PARSONS, M. Climate change and the urban Poor: Quantifying the health risks of floods in Manila, Philippines. The Environments of the Poor. New Delhi, India: [s.n.]. 2010.

THROW, A. . B. D. M. Climate change and human vulnerability: mapping emerging trends and risk hotspots for humanitarian actors. Report to the UN Office Corrdination of Humanitarian Affairs by Maplecroft, Bath. [S.1.]. 2008.

TURNER II, B.; KASPERSON, R.; MATSON, P.; MCCARTHY, J.; CORELL, R.; CHRISTENSEN, L.; ECKEY, N.; KASPERSON, J.; LUERS, A.; MARTELLO, M.; POLSKY, C.; PULSIPHER, A.; SCHILLER, A.. A framework for Vulnerability analysis in sustainability science. Proceedings of the National Academy of Sciences, v. 100, n. 14, Julho 2003.

VELDHUIS, J.A.; CLEMENS, F.H.; STERK, G.; BERENDS, B.R. Microbial Risk associated with exposure to pathogens in contaminated urban flood water. Water Research, v. 44, n. 9, p. 2910-8, 2010.

VICAIRE- VIRTUAL CAMPUS IN HYDROLOGY AND WATER RESOURSES MANAGEMENT. Chapter 2: Watershed Characteristics. Module 1a, [s.d]. Disponivel em: <http://echo2.epfl.ch/VICAIRE/mod_1a/chapt_2/main.htm>. Acesso em: 12 Maio 2015 .

WHO - WORLD HEALTH ORGANIZATION. Climate change and human health, 6 Agosto $2000 . \quad$ Disponivel em: $<$ http://whqlibdoc.who.int/hq/2000/WHO_SDE_OEH_00.4.pdf $>$. Acesso em: 13 Marco 2012.

WHO - WORLD HEALTH ORGANIZATION. Floodign and communicable diseases fact sheet. Technical guidelines, 2014. Disponivel em: $<$ www.who.int/hac/techguidance/ems/flood_csd/en/\#>.

WILSON, M. L. Ecology and infectious Disease. In: ARON, J. L.; PATZ, J. A. Ecosystem Change and Public Health: A global perspective. Baltimore: Jhons Hopkins University Press, 2001. p. 283-324.

WOODRUFF, B.; TOOLE, M.; RODRIGUE, C.; BRINK, E.; MAAHGOUB, L.; AHMED, M.; BABIKAR, A. Disease Surveillance and control after flood: Khartoum, Sudan. Disasters, v. 14, n. 2, 1988.

ZHOU, Y. et al. Local spatial and Temporal Factors Influencing Population and Societal Vulnerability to Natural Disasters. Risk Analysis, v. 34, n. 4, p. 614-638, Abril 2014. ISSN doi: 10.1111/risa.12193. 


\section{APÊNDICE I}

Tabela 12. Variáveis extraídas da base de dados do censo 2010 ao nível de bacia hidrográfica no município de São Paulo.

\begin{tabular}{|c|c|c|}
\hline $\begin{array}{l}\text { Nome da } \\
\text { Variável }\end{array}$ & Descrição da variável & Incluído \\
\hline P_Set_Censit & Proporção de setores censitários urbanos & Não \\
\hline Den_Dom & Densidade de domicílios particulares permanentes (\# domicílios $/ \mathrm{Km}^{2}$ ) & Sim \\
\hline P_Aglomera & Proporção de aglomerados subnormais & Não \\
\hline $\begin{array}{l}\text { Renda_Sal_M } \\
\text { in }\end{array}$ & $\begin{array}{l}\text { Média do número de salários mínimos mensais das pessoas responsáv } \\
\text { eis por domicílios particulares permanentes }\end{array}$ & Sim \\
\hline Mora_Dom & Média do número de moradores por domicílio & Sim \\
\hline Resp_Alfabe & $\begin{array}{l}\text { Média do número de responsáveis de domicílios particulares permane } \\
\text { ntes alfabetizados }\end{array}$ & Não \\
\hline P_Abastecim & $\begin{array}{l}\text { Proporção média de domicílios particulares permanentes com abasteci } \\
\text { mento de água da rede geral. }\end{array}$ & Sim \\
\hline 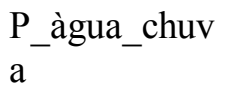 & $\begin{array}{l}\text { Proporção média de domicílios particulares permanentes com abasteci } \\
\text { mento de água da chuva armazenada em cisterna }\end{array}$ & Não \\
\hline$P \_a ́ g u a \_o u t r o$ & $\begin{array}{l}\text { Proporção média de domicílios particulares permanentes com outra fo } \\
\text { rma de abastecimento de água }\end{array}$ & Não \\
\hline P_esg_rede & $\begin{array}{l}\text { Proporção média de domicílios particulares permanentes com banheir } \\
\text { o ou sanitário e esgotamento sanitário via rede de esgoto ou pluvial }\end{array}$ & Não \\
\hline P_esg_fosep & $\begin{array}{l}\text { Proporção média de domicílios particulares permanentes com banheir } \\
\text { o ou sanitário e esgotamento sanitário via fossa séptica }\end{array}$ & Não \\
\hline P_esg_fosru & $\begin{array}{l}\text { Proporção média de domicílios particulares permanentes com banheir } \\
\text { o ou sanitário e esgotamento sanitário via fossa rudimentar }\end{array}$ & Não \\
\hline P_esg_viavala & $\begin{array}{l}\text { Proporção média de domicílios particulares permanentes com banheir } \\
\text { o ou sanitário e esgotamento sanitário via vala }\end{array}$ & Não \\
\hline $\begin{array}{l}\text { P_esg_riolag } \\
\text { ma }\end{array}$ & $\begin{array}{l}\text { Proporção média de domicílios particulares permanentes com banheir } \\
\text { o ou sanitário e esgotamento sanitário via rio, lago ou mar }\end{array}$ & Não \\
\hline P_esg_outro & $\begin{array}{l}\text { Proporção média de domicílios particulares permanentes com banheir } \\
\text { o ou sanitário e esgotamento sanitário via outro escoadouro }\end{array}$ & Não \\
\hline P_lixo_colet & $\begin{array}{l}\text { Proporção média de domicílios particulares permanentes com lixo col } \\
\text { etado }\end{array}$ & Não \\
\hline P_lixo_serlim & $\begin{array}{l}\text { Proporção média de domicílios particulares permanentes com lixo col } \\
\text { etado por serviço de limpeza }\end{array}$ & Não \\
\hline P_lixo_caçam & $\begin{array}{l}\text { Proporção média de domicílios particulares permanentes com lixo col } \\
\text { etado em caçamba de serviço de limpeza }\end{array}$ & Não \\
\hline P_lixo_queim & $\begin{array}{l}\text { Proporção média de domicílios particulares permanentes com lixo que } \\
\text { imado na propriedade }\end{array}$ & Não \\
\hline $\begin{array}{l}\text { P_lixo_enterr } \\
\text { a }\end{array}$ & $\begin{array}{l}\text { Proporção média de domicílios particulares permanentes com lixo ent } \\
\text { errado na propriedade }\end{array}$ & Não \\
\hline P_lixo_jogterr & $\begin{array}{l}\text { Proporção média de domicílios particulares permanentes com lixo jog } \\
\text { ado em terreno baldio ou logradouro }\end{array}$ & Não \\
\hline P_lixo_jogrio & $\begin{array}{l}\text { Proporção média de domicílios particulares permanentes com lixo jog } \\
\text { ado em rio, lago ou mar }\end{array}$ & Não \\
\hline P_lixo_outro & $\begin{array}{l}\text { Proporção média de domicílios particulares permanentes com outro de } \\
\text { stino de lixo }\end{array}$ & Não \\
\hline P_com_eletric & $\begin{array}{l}\text { Proporção média de domicílios particulares permanentes com energia } \\
\text { Elétrica }\end{array}$ & Sim \\
\hline
\end{tabular}


Tabela 13 (continuação). Variáveis extraídas da base de dados do censo 2010 ao nível de bacia hidrográfica no município de São Paulo.

\begin{tabular}{|c|c|c|}
\hline $\begin{array}{l}\text { Nome da } \\
\text { Variável }\end{array}$ & Descrição da variável & Incluído \\
\hline P_com_comp & $\begin{array}{l}\text { Proporção média de domicílios particulares permanentes com energia } \\
\text { Elétrica de companhia distribuidora }\end{array}$ & Não \\
\hline P_com_outras & $\begin{array}{l}\text { Proporção média de domicílios particulares permanentes com energia } \\
\text { Elétrica de outras fontes }\end{array}$ & Não \\
\hline P_sem_eletric & Proporção de domicílios particulares permanentes sem energia elétrica & Não \\
\hline $\begin{array}{l}\text { P_resp_Nalfa } \\
\text { b }\end{array}$ & $\begin{array}{l}\text { Média do número de responsáveis de domicílios particulares permane } \\
\text { ntes Não-alfabetizados }\end{array}$ & Não \\
\hline P_pess_alfab & Pessoas alfabetizadas com 5 ou mais anos de idade & \\
\hline P_Brancos & Proporção de residentes com cor ou raça branca & Sim \\
\hline $\begin{array}{l}\text { P_outro_bran } \\
\text { co }\end{array}$ & Proporção de residentes com cor ou raça diferente de branca & Não \\
\hline Crianças & Proporção de crianças & Sim \\
\hline Adultos & Proporção adultos & \\
\hline Idosos & Proporção Idosos & Sim \\
\hline Mulh_5_15 & Mulheres entre 5 y 15 anos & Sim \\
\hline P Mulh resp & Proporção de mulheres responsáveis & Sim \\
\hline
\end{tabular}




\section{APÊNDICE II}

Figura 23. Mapa de densidade de domicílios por quilômetro quadrado Segundo o censo de 2010, SP.

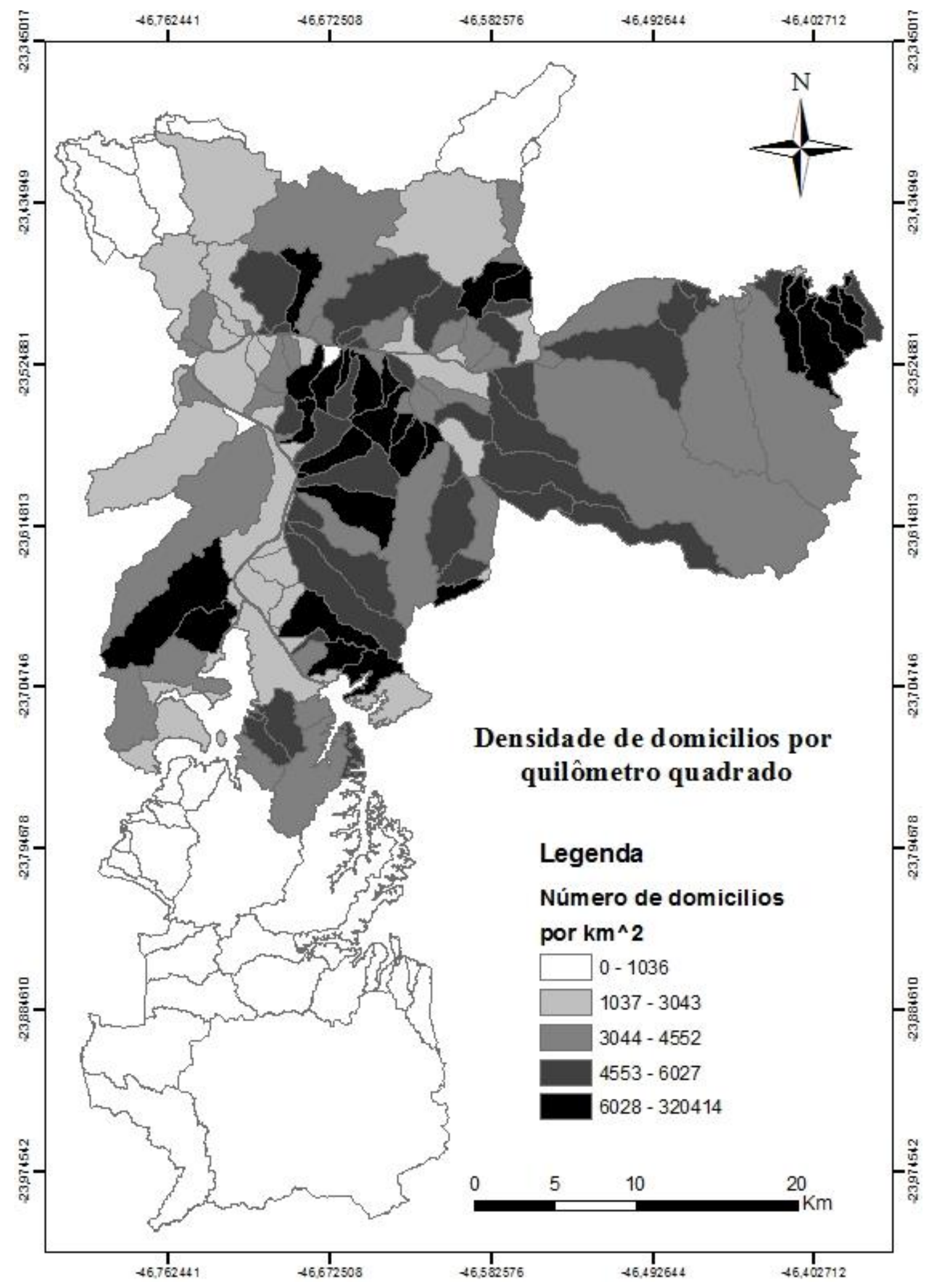



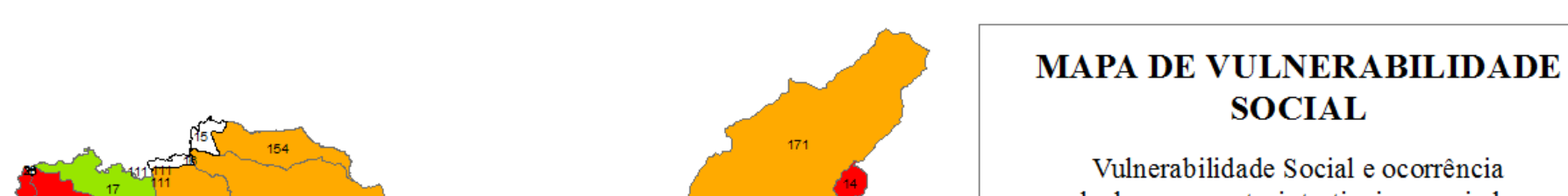

de doenças gastrointestinais associadas com inundações no

Município de São Paulo

Maio, 2015

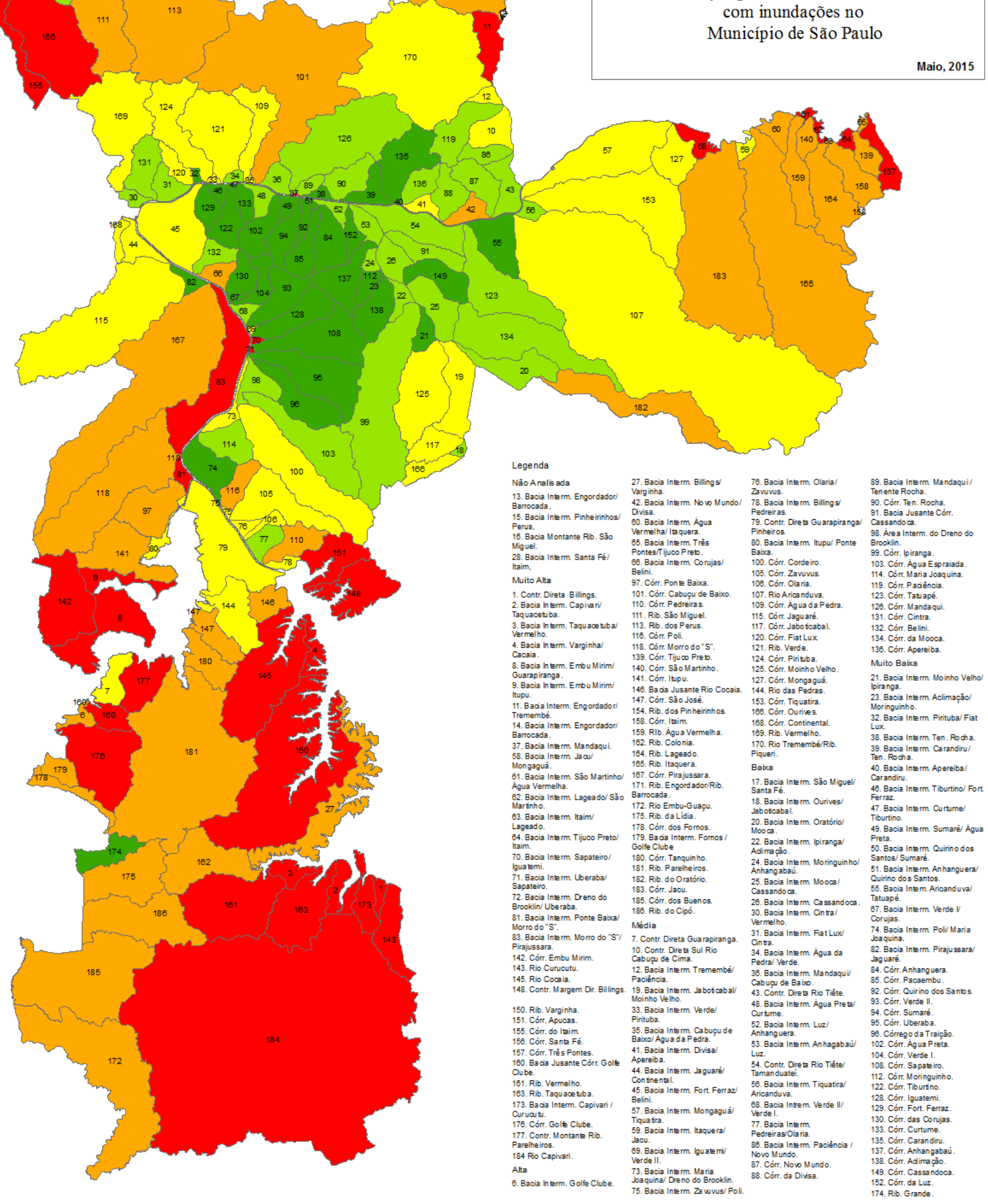

\section{Convenções}

Indice de vulnerabilidade

$\square$ Não Analisada

Legenda

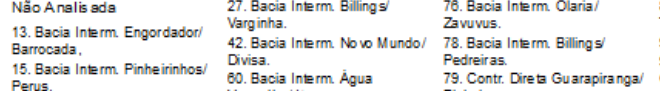

28. Bacia

1. Contr. Direta Bilings

2. Bacia Interm. Capisary

3. Bacia Interm. Taquace tib
Vermelho.

9. Bacia In term. Embu Mirim

11. Bada Interm. Engordado

14. Bacia Interm. Engordad
Barrocada.

37. Bacia Interm. Mand

Mongaguá.

A1. Bacia Interm. Sáo Marting
Agua Vermelha.

Martnho.
63. Bacia Interm. Itaim/

70. Bacia Interm. Sapat

71. Bacia Interm. Uberaba

72. Bacia Interm. Dr
Brooklin/ Uberaba.

81. Bacia Interm. Ponte Baida

142. Córr. Embu Mir

145. Rio Cunoult

48. Contr. Margem Dir. Billing

150. Rib. Varginhas
151. Córr. Apucas.

5. Córr. do Itaim

Clube

178. Córr. Golé Clube.
Interm. Corvjas

Rib. Săo Migu

Córr. dos Fornos.

33. Córr. Jacu.

18. Rib. do Cipó.

6. Bacia Interm Cabugu de

. Bacia Interm. Jaguar

7. Bacia Interm. Mongagu

. Bacia Interm. Itaquera

9. Bacia Interm, gauatem

3. Bacia Interm. Maria
Jaquina/ Dreno do Brooklin.
100. Córn. Corde iro.

120. Cór. Fiat Lis

124. Corr. Pirtuba
125. Corr. Moinho Vellho

127. Corr. Mongagua

153. Córr. Tiquatira

168. Corr. Continen
169. Rib. Vermelho.

acia Interm. Ourives

22. Bacia Interm. pirange

5. Bacia Interm. Mooca

28. Bacia Interm. Cassand

Bacia Interm. Cinta

31. Bacia Interm. FiatL

34. Bacia Interm. Água da

Interm. Anhag a

4. Contr Diret Rio Tiéte

58. Bacia Interm Tiquatt

68. Bacia Intem. Verde

sia interm. Pach

Nover Mundo

174. Rib Grande.

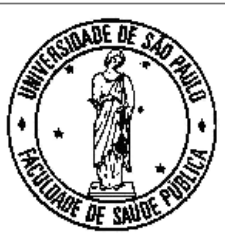

